\title{
The multi-scale aerosol-climate model PNNL-MMF: model description and evaluation
}

\author{
M. Wang ${ }^{1}$, S. Ghan ${ }^{1}$, R. Easter ${ }^{1}$, M. Ovchinnikov ${ }^{1}$, X. Liu ${ }^{1}$, E. Kassianov $^{1}$, Y. Qian ${ }^{1}$, W. I. Gustafson Jr. ${ }^{1}$, \\ V. E. Larson ${ }^{2}$, D. P. Schanen ${ }^{2}$, M. Khairoutdinov ${ }^{3}$, and H. Morrison ${ }^{4}$ \\ ${ }^{1}$ Atmospheric Science and Global Change Division, Pacific Northwest National Laboratory, Richland, Washington, USA \\ ${ }^{2}$ Department of Mathematical Sciences, University of Wisconsin - Milwaukee, Milwaukee, Wisconsin, USA \\ ${ }^{3}$ School of Marine and Atmospheric Sciences, Stony Brook University, Stony Brook, New York, USA \\ ${ }^{4}$ Mesoscale and Microscale Meteorology Division, National Center for Atmospheric Research, Boulder, Colorado, USA
}

Received: 18 September 2010 - Published in Geosci. Model Dev. Discuss.: 8 October 2010

Revised: 12 February 2011 - Accepted: 21 February 2011 - Published: 3 March 2011

\begin{abstract}
Anthropogenic aerosol effects on climate produce one of the largest uncertainties in estimates of radiative forcing of past and future climate change. Much of this uncertainty arises from the multi-scale nature of the interactions between aerosols, clouds and large-scale dynamics, which are difficult to represent in conventional general circulation models (GCMs). In this study, we develop a multi-scale aerosol-climate model that treats aerosols and clouds across different scales, and evaluate the model performance, with a focus on aerosol treatment. This new model is an extension of a multi-scale modeling framework (MMF) model that embeds a cloud-resolving model (CRM) within each grid column of a GCM. In this extension, the effects of clouds on aerosols are treated by using an explicit-cloud parameterized-pollutant (ECPP) approach that links aerosol and chemical processes on the large-scale grid with statistics of cloud properties and processes resolved by the CRM. A two-moment cloud microphysics scheme replaces the simple bulk microphysics scheme in the CRM, and a modal aerosol treatment is included in the GCM. With these extensions, this multi-scale aerosol-climate model allows the explicit simulation of aerosol and chemical processes in both stratiform and convective clouds on a global scale.

Simulated aerosol budgets in this new model are in the ranges of other model studies. Simulated gas and aerosol concentrations are in reasonable agreement with observations (within a factor of 2 in most cases), although the model underestimates black carbon concentrations at the surface by a factor of 2-4. Simulated aerosol size distributions are in reasonable agreement with observations in the ma-
\end{abstract}

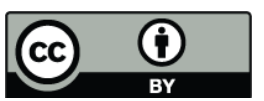

Correspondence to: M. Wang

(minghuai.wang@pnl.gov) rine boundary layer and in the free troposphere, while the model underestimates the accumulation mode number concentrations near the surface, and overestimates the accumulation mode number concentrations in the middle and upper free troposphere by a factor of about 2 . The overestimation of accumulation model number concentrations in the middle and upper free troposphere is consistent with large aerosol mass fraction above $5 \mathrm{~km}$ in the MMF model compared with other models. Simulated cloud condensation nuclei (CCN) concentrations are within the observational variations. Simulated aerosol optical depths (AOD) are in reasonable agreement with observations (within a factor of 2), and the spatial distribution of AOD is consistent with observations, while the model underestimates AOD over regions with strong fossil fuel and biomass burning emissions. Overall, this multiscale aerosol-climate model simulates aerosol fields as well as conventional aerosol models.

\section{Introduction}

Atmospheric aerosols are an important component of the global climate system. They can affect the climate system directly by scattering or absorbing solar radiation, and indirectly through their effects on clouds by acting as cloud condensation nuclei (CCN) or ice nuclei (IN). However, despite more than a decade of active research, anthropogenic aerosol effects on climate still produce one of the largest uncertainties in the estimates of radiative forcing of past and future climate change (IPCC, 2007).

Much of this uncertainty arises from the multi-scale nature of the interactions between aerosols, clouds and large-scale dynamics, which are difficult to represent in conventional

Published by Copernicus Publications on behalf of the European Geosciences Union. 
general circulation models (GCMs). These interactions span a wide range in spatial scales, from 0.01 to $1000 \mu \mathrm{m}$ for droplet and crystal nucleation, aqueous-phase chemistry, precipitation, and collection, to $100-1000 \mathrm{~m}$ for marine stratus, to $1-2 \mathrm{~km}$ for shallow cumulus, to $2-10 \mathrm{~km}$ for deep convection, and to $50-100 \mathrm{~km}$ for large-scale cloud systems. Given the typical GCM grid spacing of $100-400 \mathrm{~km}$, the treatment of most of those processes in conventional GCMs is highly parameterized and, therefore, also highly uncertain.

Representing aerosol/cloud processes in deep cumulus has been most problematic in GCMs. Cumulus parameterizations in current climate models rely on ad hoc closure assumptions designed to diagnose the latent heating and vertical transport of heat and moisture by deep convection, and provide little information about microphysics or updraft velocity (Emanuel and Zivkovic-Rothman, 1999; Del Genio et al., 2005; Zhang et al., 2005). As a result, aerosol effects on cumulus clouds are only represented, sometimes crudely, in a handful of GCMs using cumulus parameterizations (Nober et al., 2003; Menon and Rotstayn, 2006; Lohmann, 2008). Meanwhile, field and satellite measurements and simulations by cloud-resolving models (CRMs) provide increasing evidence that aerosols influence cumulus clouds (Andreae et al., 2004; Koren et al., 2004, 2005; Wang, 2005; Cui et al., 2006; Rosenfeld et al., 2008).

In addition, cumulus clouds play critical roles in determining the vertical distributions and lifetime of most aerosols. Convective clouds are responsible for much of the vertical transport of pollutants, the aqueous chemistry, and the removal of pollutants from the atmosphere (Chatfield and Crutzen, 1984; Wang and Prinn, 2000; Ekman et al., 2006). Easter et al. (2004) showed that convective clouds account for $80-95 \%$ of accumulation-mode aerosol number removal, $65-85 \%$ of carbonaceous aerosol wet removal, $50-85 \%$ of sulfate wet removal, and $10-70 \%$ of in-cloud $\mathrm{SO}_{2}$ oxidation in their global aerosol climate model. However, the treatment of convective cloud processes in global aerosol models is based on cumulus parameterizations, which are highly uncertain (Bechtold et al., 2000; Gregory and Guichard, 2002; Xie et al., 2002; Xu et al., 2002). In the global aerosol climate model used by Easter et al. (2004), the large range (10$70 \%$ ) for in-cloud $\mathrm{SO}_{2}$ oxidation reflects different assumptions made about the cloud volume of convective clouds, which is generally not predicted by cumulus parameterizations. Simulated vertical distributions of gas and aerosol species in global models have been shown to largely depend on the convective parameterization (Mahowald et al., 1995; Jacob et al., 1997; Rasch et al., 2000; Iversen and Seland, 2002).

To avoid the problems in cumulus parameterizations in GCMs, Suzuki et al. (2008) simulated aerosol-cloud interactions in convective clouds on the global scale by using an aerosol-coupled global CRM with a horizontal grid spacing of $7 \mathrm{~km}$. They showed that the model realistically simulated detailed spatial structure of cloud droplet effective radii and the relationship between liquid water path and aerosol optical properties, compared with satellite data. However, Suzuki's model is extremely expensive and hence was only run for 7 days. Given the high computational cost, it will not be feasible to use global CRMs with online aerosols for long-term climate-relevant simulations (decades) for at least five years and probably longer.

A new type of GCM called the multi-scale modeling framework (MMF) model, first introduced a decade ago (Grabowski, 2001; Khairoutdinov and Randall, 2001), uses a cloud resolving model (CRM) at each grid column of a host GCM to replace conventional parameterizations for moist convection and large-scale condensation. This approach permits explicit simulations of deep convective clouds for the whole global domain, while keeping the computational cost acceptable for multi-year climate simulations. The subgrid variability in cloud dynamics and cloud microphysics is explicitly resolved at spatial scales down to the resolution of the CRM. The MMF models have been shown to improve climate simulations in several important ways, including representation of convective clouds, the diurnal cycle of precipitation, and the subseasonal variability of tropical climate associated with the Madden-Julian oscillation (MJO) and equatorially trapped waves (Ovtchinnikov et al., 2006; Khairoutdinov et al., 2008; Pritchard and Somerville, 2009a, b; Tao et al., 2009).

The MMF model would be an ideal tool to study aerosol effects on climate on the global scale given its multi-scale nature and its moderate computational cost compared with global CRMs. However, several limitations in the original MMF (Khairoutdinov et al., 2008) have hindered its usage in studying aerosol effects on climate. First, the original MMF did not include any treatment of aerosol and chemical processes. Second, the original MMF has an oversimplified microphysics treatment consisting of only two predicted water variables. This simple scheme neglected the complex interactions between different hydrometeors and did not represent a variety of processes (e.g., the Bergeron-Findeisen process, droplet activation, and ice nucleation) that are important to the study of aerosol-cloud interactions.

In this study, we address these challenges and extended the original MMF in the following ways. First, the host GCM model is updated to use a modal aerosol approach to treat aerosol processes and represent aerosol size distributions; second, an explicit-cloud parameterized-pollutant (ECPP) approach (Gustafson et al., 2008) is added to link aerosol and chemical processes on the GCM grid with statistics of cloud properties resolved by the CRM, and third, a two-moment cloud microphysics scheme replaces the simple one moment scheme in the CRM. With these changes, the new MMF model (Pacific Northwest National Laboratory MMF, or PNNL-MMF) has the capability to study aerosolcloud interactions from cumulus to global scales. In this paper, we have documented these changes, with a focus on aerosol and chemical treatment, and evaluate the model 
results. Section 2 documents the improvements in detail, and the model results are shown in Sects. 3 and 4. Finally, Sect. 5 is the summary and discussion.

\section{Model description and set-up of simulations}

The PNNL-MMF is an extension of the Colorado State University (CSU) MMF model (Khairoutdinov et al., 2005, 2008), first developed by Khairoutdinov and Randall (2001). The CSU MMF was based on the Community Atmospheric Model (CAM) version 3.5, which is the atmospheric component of the NCAR Community Climate System Model (Collins et al., 2006). The embedded CRM in each GCM grid column is a two-dimensional version of the System for Atmospheric Modeling (SAM) (Khairoutdinov and Randall, 2003), which replaces the conventional moist physics, convective, turbulence, and boundary layer parameterizations, except for the gravity wave drag parameterization in CAM. During each GCM time step (every $10 \mathrm{~min}$ ), the CRM is forced by the large-scale temperature and moisture tendencies arising from GCM-scale dynamical processes and feeds the response back to the GCM-scale as heating and moistening terms in the large-scale budget equations for heat and moisture. The CRM runs continuously using a 20 -s time step. The CAM radiative transfer code is applied to each CRM column at every GCM time step (10 min), assuming 1 or 0 cloud fraction at each CRM grid point, which eliminates the cloud overlap assumptions used in conventional GCMs.

In this study, both the GCM and CRM components are updated from what is used in the CSU MMF. A third component, the ECPP approach, is added to link aerosol and chemical processes on the GCM grids with statistics of cloud properties resolved by the CRM. These extensions in the PNNLMMF are documented in detail below.

\subsection{The NCAR CAM5 atmospheric GCM}

The host GCM in the PNNL-MMF has been updated to version five of CAM (CAM5). Although CAM5 differs from CAM3.5 in many respects (e.g., cloud microphysics, cloud macrophysics, turbulence, shallow cumulus, aerosols, and radiative transfer), most of the changes are not relevant to the MMF model since the treatments of clouds and turbulence are replaced with the treatments in the CRM. The differences that are relevant to the MMF model are in the treatment of radiative transfer and of the aerosol lifecycle, which are briefly described below.

The radiative transfer scheme in CAM5 is the Rapid Radiative Transfer Model for GCMs (RRTMG), a broadband k-distribution radiation model developed for application to GCMs (Mlawer et al., 1997; Iacono et al., 2003, 2008).

A modal approach is used to treat aerosols in CAM5 (Liu et al., 2011). Aerosol size distributions are represented by using three or seven log-normal modes. The three-mode ver- sion adopted in this study has been shown to simulate aerosol fields in reasonable agreement with the 7-mode treatment and is computationally more efficient, which makes it more suitable for long-term climate simulations (Liu et al., 2011). The three-mode version has an Aitken mode, an accumulation mode, and a single coarse mode. Aitken mode species include sulfate, secondary organic aerosol (SOA), and sea salt; accumulation mode species include sulfate, SOA, black carbon (BC), primary organic matter (POM), sea salt, and dust; coarse mode species include sulfate, sea salt, and dust. Species mass and number mixing ratios are predicted for each mode, while mode widths are prescribed. Both aerosols outside the cloud droplets (interstitial) and aerosols in the cloud droplets (cloud-borne) are predicted. Aerosol nucleation from $\mathrm{H}_{2} \mathrm{SO}_{4}$ is treated and includes binary $\mathrm{H}_{2} \mathrm{SO}_{4}-\mathrm{H}_{2} \mathrm{O}$ homogeneous nucleation, based on the parameterization of Vehkamaki et al. (2002), and empirical boundary layer nucleation, based on the first order nucleation rate in $\mathrm{H}_{2} \mathrm{SO}_{4}$ from Sihto et al. (2006) with a first order rate coefficient of $1.0 \times 10^{-6} \mathrm{~s}^{-1}$ as in Wang et al. (2009). The new particles are added to the Aitken mode, and the parameterization of Kerminen and Kulmala (2002) is used to account for the loss of the new particles by coagulation as they grow from critical cluster size to Aitken mode size. Condensation of trace gases $\left(\mathrm{H}_{2} \mathrm{SO}_{4}\right.$ and semi-volatile organics) on existing aerosol particles, and coagulation (Aitken and accumulation modes) are treated. Water uptake and optical properties for each mode are expressed in terms of both relative humidity (accounting for hysteresis) and the hygroscopicities of the mode's component. The model simulates DMS, $\mathrm{SO}_{2}, \mathrm{H}_{2} \mathrm{SO}_{4}, \mathrm{H}_{2} \mathrm{O}_{2}$ gases, using monthly averaged oxidant fields $\left(\mathrm{OH}, \mathrm{O}_{3}\right.$, and $\mathrm{NO}_{3}$ ) produced by a version of CAM with detailed gas-phase chemistry.

In the standard CAM5, cloud fields from the conventional cloud parameterizations are used to drive the convective transport, aerosol activation in stratiform clouds, aqueous chemistry, and wet scavenging for aerosol and gas species. In the PNNL-MMF, the treatment of cloud-related aerosol and gas processes (i.e., aqueous chemistry, convective transport, and wet scavenging) in the standard CAM5 is replaced by the ECPP approach (Sect. 2.3), which uses cloud statistics simulated by the CRM to drive the aerosol processing by clouds.

\subsection{The SAM CRM}

The original SAM used in the CSU MMF had a simple bulk microphysics scheme in which only the liquid/ice-water moist static energy, the total nonprecipitating water, and the total precipitating water were predicted (Khairoutdinov and Randall, 2003). The mixing ratio of cloud water, cloud ice, rain, snow and graupel were diagnosed from the prognostic variables using temperature-dependent partitioning between liquid and ice. This simple scheme neglected the complex interactions between different hydrometeors and was not 
able to represent a variety of processes (e.g., the BergeronFindeisen process, droplet activation, and ice nucleation) that are important to the study of aerosol-cloud interactions.

In the PNNL-MMF, a double-moment microphysics scheme from Morrison et al. $(2005,2009)$ replaces the simple bulk microphysics in the CRM model. The new scheme predicts the number concentrations and mixing ratios of five hydrometeor types (cloud droplets, ice crystals, rain, snow, and graupel). The precipitation hydrometeor types (rain, snow, and graupel) are fully prognostic in the CRM model, rather than diagnostic as in CAM5. Droplet activation from hydrophilic aerosols, ice nucleation, ice crystal growth by vapor deposition, the dependence of ice crystal sedimentation on crystal number, and the dependence of autoconversion on droplet number are treated, in addition to several other microphysical processes.

Droplet formation by aerosol activation is calculated at each CRM grid point, based on the parameterization of Abdul-Razzak and Ghan (2000). The vertical velocity used in aerosol activation is the sum of the vertical velocity resolved at the CRM grid point and a sub-grid vertical velocity $\left(\sigma_{\mathrm{crmw}}\right)$ that accounts for the unresolved motion. The subgrid vertical velocity is diagnosed from the turbulent kinetic energy (TKE): $\sigma_{\text {crmw }}=\sqrt{(\mathrm{TKE} / 3)}$, where the TKE is predicted or diagnosed in the SAM CRM, depending on its sub-grid model. A simple Smagorinsky-type scheme is used to treat the subgrid-scale fluxes in the SAM model, and the TKE is diagnosed from the eddy viscosity. A minimum vertical velocity of $0.1 \mathrm{~m} \mathrm{~s}^{-1}$ is set for calculating aerosol activation, following Ghan et al. (1997) and Morrison et al. (2005). Sensitivity tests at a coarse GCM horizontal resolution $\left(4^{\circ} \times 5^{\circ}\right)$ show that using a minimum vertical velocity of $0.01 \mathrm{~m} \mathrm{~s}^{-1}$ instead of $0.1 \mathrm{~m} \mathrm{~s}^{-1}$ has little effect on simulated aerosol concentrations, since the aerosol activation in the CRM is only used for droplet formation and is not directly linked with the aerosol wet scavenging (which is treated in the ECPP, see details in Sect. 2.3.3). Aerosol fields used in the CRM are predicted on the GCM grid cells by CAM5, in which cloudrelated aerosol processes are treated by using the ECPP approach (Sect. 2.3).

The CAM radiative transfer scheme (RRTMG) is applied to each CRM column, assuming 1 or 0 cloud fraction at each CRM grid point. Aerosol water uptake is calculated at each CRM grid point, which accounts for the subgrid variation in relative humidity within each GCM grid cell. Aerosol water at the CRM grids together with dry aerosol on the GCM grids are used to calculate aerosol optical properties at each CRM grid.

\subsection{The Explicit-Cloud-Parameterized-Pollutant (ECPP) approach}

As we discussed in the introduction, one of the limitations in the CSU MMF is its lack of treatment of aerosol and chemical processes. An ideal way to account for these processes in the MMF model would be to add their treatment into the CRM component, thereby simulating aerosol and chemical processes directly on cloud scales. Given the large number of species and numerous processes involved, however, this approach is not computationally feasible for multi-year climate simulations in the near future. In this study, we take an alternative approach, the ExplicitCloud Parameterized-Pollutant method (ECPP) (Gustafson et al., 2008). The ECPP approach uses statistics of cloud properties resolved by the CRM (Explicit-Cloud) to drive aerosol and chemical processing by clouds on the GCM grids (Parameterized-Pollutant), which allows us to explicitly account for the effects of both stratiform clouds (i.e., clouds in quiescent classes as defined in Sect. 2.3.1) and convective clouds (i.e., clouds in updraft and downdraft classes as defined in Sect. 2.3.1) on aerosols while being computationally feasible. The treatment of vertical transport of tracers within ECPP is documented in detail in Gustafson et al. (2008) and is slightly modified in this study. The ECPP treatment is also extended to treat aerosol activation, resuspension (cloud-borne aerosol particles are resuspended and become interstitial aerosol particles due to the evaporation of cloud droplets), aqueous chemistry and wet scavenging.

In the ECPP approach, the aerosol species and aerosol precursor gases are carried on the GCM grid, while cloud variables are carried on the CRM grid. Large-scale transport of the aerosol and gas tracers and several "non-cloud" processes (emissions, vertical turbulent mixing, dry deposition, gas-phase chemistry, condensation/evaporation of gases on aerosols, aerosol nucleation, and aerosol coagulation) are calculated on the CAM grid. The resulting tracer distributions are passed to ECPP, in which information from the CRM is used to better simulate cloud processing of aerosols and trace species (i.e., vertical transport, aerosol activation/resuspension, aqueous chemistry, convective transport, and precipitation scavenging). The resulting aerosol fields from ECPP are then used in the CRM for cloud microphysics (droplet nucleation) and aerosol optical property calculations.

Besides using cloud statistics from the CRM instead of those from the conventional cloud parameterizations in CAM5 to drive aerosol and chemical processing by clouds, the ECPP approach differs from that in the conventional CAM5 in several other important aspects. First, the ECPP approach predicts cloud-borne aerosols (those inside cloud droplets) for all clouds, while the conventional CAM5 does not treat cloud-borne aerosols in convective clouds. So the conventional CAM5 needs to assume a convective-cloud activation fraction for each mode, which is used in computing in-cloud scavenging. In the ECPP approach, the cloud-borne aerosols in convective clouds are predicted through aerosol activation/resuspension associated with vertical transport, and entrainment/detrainment in convective up- and downdrafts (Sect. 2.3.3). Second, the ECPP approach treats convective transport, aqueous chemistry, and wet scavenging in 
an integrated, self-consistent way. The conventional CAM5 uses the process-split approach to treat convective transport, wet scavenging and aqueous chemistry in convective clouds. The grid-mean tracer concentrations are used to calculate tracer changes from each of these processes. In the real atmosphere, however, all these processes (convective transport, aqueous chemistry, and wet scavenging) occur concurrently in convective draft regions, and the resulting tracer concentrations can be significantly different from those in the ambient atmosphere. Using the grid-mean tracer concentrations in the convective draft regions may therefore bias results. In the ECPP approach, the continuity equation is integrated for convective draft regions, accounting for transport, aqueous chemistry, and wet scavenging in an integrated way (Sect. 2.3.3).

In the ECPP approach, the CRM cells on each GCM grid column are first classified into 12 different classes, according their vertical velocities, hydrometeor mixing ratios, and precipitating rates (Sect. 2.3.1). Once the class of each CRM cell is determined, fractional area, mass fluxes, entrainment and detrainment rates, and microphysical variables are diagnosed based on cloud fields from the CRM for each class (Sect. 2.3.2). These parameters are used to solve the continuity equation of tracer species for each class, which includes convective transport, activation/resuspension, aqueous chemistry, and wet scavenging (Sect. 2.3.3). The details of the ECPP approach are documented below.

\subsubsection{Classifications of CRM cells in each GCM grid}

The CRM grid cells within each GCM grid column are first categorized into updraft, downdraft and quiescent classes, based on their vertical velocities. The quiescent class contains cells with small vertical velocities. A single updraft and a single downdraft class are used in this study. Gustafson et al. (2008) also tested a multiple updraft and downdraft scheme and found no substantial improvement compared with the single updraft and downdraft scheme.

The updraft and downdraft classes are determined by comparing the vertical velocity at each CRM grid cell within a GCM grid with threshold values. The root-mean-square upwards (positive) and downwards (negative) vertical velocities ( $w_{\text {up,rms }}$ and $\left.w_{\text {down,rms }}\right)$ at each layer in a GCM column are calculated first. The local vertical velocity thresholds that determine updraft and downdraft classes are $w_{\text {up,rms }}$ and $-w_{\text {down,rms }}$, respectively. These thresholds are only applied to the layers below the updraft/downdraft centers. (The updraft center is defined as the $w_{\text {up,rms }}$-weighted average of the layer index, and similarly for downdraft). For the layers above the updraft/downdraft centers, column-wide thresholds are also used. These column-wide thresholds are calculated in a way similar to the local thresholds, based on the root-mean-square upwards and downwards vertical velocities in each column. For those layers above the updraft (or downdraft) center, the larger one of the local and column- wide updraft (or downdraft) thresholds is used. The columnwide threshold is used to in part filter out gravity wave activity at upper levels of the CRM. Following Xu (1995), the updraft and downdraft classes determined by using the vertical velocity are further adjusted based on the total condensate (cloud water + cloud ice) and precipitating hydrometeor mixing ratio. Updraft and downdraft are only allowed to exist at the CRM grids that have either cloud condensate larger than $10^{-5} \mathrm{~kg} \mathrm{~kg}^{-1}$ or precipitating hydrometeor mixing ratio larger than $10^{-4} \mathrm{~kg} \mathrm{~kg}^{-1}$. The CRM grids that do not meet these vertical velocity, condensate, and precipitation criteria are classified as the quiescent class.

Each transport class is further classified into liquid cloud and non-liquid subclasses based on a threshold liquid cloud water content of $10^{-6} \mathrm{~kg} \mathrm{~kg}^{-1}$. (We subsequently use cloudy and clear when referring to the liquid-cloud and non-liquidcloud subclasses.) Ice water is not included in the classification of the cloudy (liquid) and clear (non-liquid) subclasses since aqueous chemistry, activation, and in-cloud wet scavenging are limited to liquid clouds, as in the standard CAM5. Convective transport and aerosol activation/resuspension are calculated in each of these 6 subclasses. Each subclass is further classified into precipitating and non-precipitating (or very weakly precipitating) sub-subclasses based on a threshold precipitation rate of $10^{-6} \mathrm{~kg} \mathrm{~m}^{-2} \mathrm{~s}^{-1}$. Cloud chemistry is calculated in each of 6 cloudy (liquid) sub-subclasses, and wet scavenging is calculated in each of these 12 subsubclasses.

\subsubsection{Calculation of entrainment and detrainment rate}

Once the class of each CRM grid cell has been determined, the horizontal area fraction $\left(A_{j}\right)$ and the vertical mass flux $\left(M_{j}\right)$ for each of 6 subclasses (cloudy and clear subclasses for each of three transport classes, and $j$ is the subclass index) are calculated for each GCM grid cell. In computing these statistics, CRM variables are first time-averaged over the GCM time step (10 min), then grid-cell classification and class horizontal averaging are performed. The profiles of vertical mass fluxes are then used to diagnose up- and downdraft entrainment $\left(E_{j}\right)$ and detrainment $\left(D_{j}\right)$ rates, using the following mass balance equation:

$\frac{\partial M_{j}}{\partial z}=E_{j}-D_{j}$,

where $z$ denotes height. In order to yield a unique expression of $E_{j}$ and $D_{j}$, an assumption similar to Arakawa and Schubert (1974) is applied, such that $D_{j}$ is zero if $M_{j}$ increases with altitude, and $E_{j}$ is zero if $M_{j}$ decreases with altitude. Equation (1) does not include entrainment and detrainment associated with area changes in drafts $(\partial A / \partial t)$, which were treated in Gustafson et al. (2008). In the MMF implementation of ECPP, the subclass tracer concentrations are not saved from one GCM time step to the next, and effects of up/downdraft area changes between GCM time steps are not treated (see more details in Sect. 2.3.3). 
These entrainment and detrainment rates are further classified by the source or destination subclass, respectively: $E_{j, j^{\prime}}$ is the entrainment into subclass $j$ from subclass $j^{\prime}$, and $D_{j, j^{\prime}}$ is the detrainment from subclass $j$ to subclass $j^{\prime} . E_{j, j^{\prime}}$ and $D_{j, j^{\prime}}$ are derived from $E_{j}$ and $D_{j}$ with the following assumptions. First, entrainment in cloudy (or clear) updraft and detrainment in clear (or cloudy) updraft are assigned to (i.e., compensated by) each other, as much as possible. The same is done for downdrafts. Any remaining unassigned detrainment for up- and downdraft subclasses is assigned to the quiescent subclasses, with preference for clear (or cloudy) draft detrainment compensating clear (or cloudy) quiescent entrainment. Any remaining unassigned entrainment for upand downdraft subclasses is assigned to the quiescent subclasses, in proportion to the clear/cloudy quiescent fractional areas. After these steps, any remaining unassigned detrainment and entrainment will only exist for the quiescent subclasses, they will be equal in magnitude, and they are assigned to each other.

\subsubsection{Solving the continuity equation}

The continuity equation for the mixing ratio of trace species $l$ in the subclass $j\left(q_{j, l}\right)$ can then be used to solve for changes in tracer mixing ratios at each level from convective transport, aqueous chemistry, and wet scavenging:

$$
\begin{aligned}
\frac{\rho A_{j} \partial q_{j, l}}{\partial t}= & -\sum_{j^{\prime}} \frac{\partial\left(M_{j, j^{\prime}} q_{j^{\prime}, l}\right)}{\partial z} \\
& +\sum_{j^{\prime}} E_{j, j^{\prime}} q_{j^{\prime}, l}-D_{j} q_{j, l}+S_{\text {aqu_wet }, j, l},
\end{aligned}
$$

where $S_{\text {aqu_wet, } j, l}$ is the source/sink term from aqueous chemistry and wet scavenging, and $M_{j, j^{\prime}}$ is the vertical mass flux from subclass $j^{\prime}$ to $j$. For quiescent subareas, vertical transport between clear-clear, clear-cloudy, and cloudycloudy subarea pairs is treated, and the relative amounts are determined by the quiescent clear and cloudy areas for two adjacent layers. For up- and downdraft subareas, only transport within a subclass is treated (i.e., $j=j^{\prime}$ ). As a result, vertical transport from clear updraft at layer $k$ to cloudy updraft at layer $k+1$ is treated as transport to clear updraft at layer $k+1$, followed by detrainment from clear to cloudy updraft at layer $k+1$. This is an implementation decision that is not expected to have much impact on ECPP results.

For aerosol species, activation and resuspension associated with entrainment and detrainment must be included. Let $l i$ be an interstitial (i.e., outside cloud droplets) aerosol species (e.g., accumulation mode number or sulfate mass), and let la be the corresponding activated (i.e., cloud-borne) species. The continuity equations for the two species are:

$$
\frac{\rho A_{j} \partial\left(q_{j, l i}\right)}{\partial t}=
$$

$$
\begin{aligned}
& -\sum_{j^{\prime}} \frac{\partial\left[M_{j, j^{\prime}}\left(q_{j^{\prime}, l i}\left(1-f_{\text {act-vert }, j, j^{\prime}, l i}\right)+q_{j^{\prime}, l a} f_{\text {res-vert }, j, j^{\prime}, l a}\right)\right]}{\partial z} \\
& +\sum_{j^{\prime}} E_{j, j^{\prime}}\left[q_{j^{\prime}, l i}\left(1-f_{\text {act-ent }, j, j^{\prime}, l i}\right)+q_{j^{\prime}, l a} f_{\text {res-ent }, j, j^{\prime}, l a}\right] \\
& -D_{j} q_{j, l i}+S_{\text {aqu_wet }, j, l i} \\
& \frac{\rho A_{j} \partial\left(q_{j, l a}\right)}{\partial t}= \\
& -\sum_{j^{\prime}} \frac{\partial\left[M_{j, j^{\prime}}\left(q_{j^{\prime}, l i} f_{\text {act-vert }, j, j^{\prime}, l i}+q_{j^{\prime}, l a}\left(1-f_{\text {res-vert }, j, j^{\prime}, l a}\right)\right)\right]}{\partial z} \\
& +\sum_{j^{\prime}} E_{j, j^{\prime}}\left[q_{j^{\prime}, l i} f_{\text {act-ent }, j, j^{\prime}, l i}+q_{j^{\prime}, l a}\left(1-f_{\text {res-ent }, j, j^{\prime}, l a}\right)\right] \\
& -D_{j} q_{j, l a}+S_{\text {aqu_wet }, j, l a}
\end{aligned}
$$

Here $f_{\text {res-vert, } j, j^{\prime}, l i}$ is the fraction of the activated aerosol species that is resuspended during vertical transport from one layer to an adjacent layer, and $f_{\text {res-ent }, j, j^{\prime}, l i}$ is the fraction resuspended when air is entrained into subclass $j$ from $j^{\prime}$. The $f_{\text {res }}$ are 1 (or 0 ) whenever air is moving into a clear (or cloudy) subarea. The $f_{\text {act-vert, } j, j^{\prime}, l i}$ is the fraction of the interstitial aerosol species that is activated during vertical transport from one layer to an adjacent layer, and $f_{\text {act-ent }, j, j^{\prime}, l i}$ is the fraction activated when air is entrained into subarea $j$ from $j^{\prime}$. Aerosol activation occurs when (1) air moves upwards from a clear to a cloudy subarea and (2) air is entrained from a clear subarea into a cloudy subarea with upwards vertical velocity. The $f_{\text {act }}$ are calculated based on the AbdulRazzak and Ghan (2000) parameterization using the vertical velocity of the destination subarea.

Additional activation/resuspension associated with the turbulent vertical mixing into and out of the quiescent cloud is calculated in each GCM column, using the CAM5 routine for GCM vertical mixing with activation/resuspension (Liu et al., 2011). Activation is assumed to occur as turbulent mixing carries the air into the base of the cloud, and particles are resuspended as interstitial aerosols when turbulent mixing carries the air outside of clouds (Ovtchinnikov and Ghan, 2005). The subgrid vertical velocity $\left(\sigma_{\mathrm{w}}\right)$ from the turbulent mixing at each GCM grid is the root-mean-square vertical velocity of the quiescent class, which includes the contribution from both the resolved and subgrid vertical velocity in the CRM grids. A lower bound of $0.20 \mathrm{~m} \mathrm{~s}^{-1}$ is used for the subgrid vertical velocity, the same as that used in the standard CAM5. Since most aerosol mass is activated for a vertical velocity larger than $0.1 \mathrm{~m} \mathrm{~s}^{-1}$ (except where accumulation-mode number concentrations are quite high), decreasing the minimum vertical velocity from $0.2 \mathrm{~m} \mathrm{~s}^{-1}$ to $0.1 \mathrm{~m} \mathrm{~s}^{-1}$ would have limited effect on simulated aerosol mass, though its effect on aerosol number concentrations would be larger (Jensen and Charlson, 1984; Abdul-Razzak and Ghan, 2000). We note that the minimum vertical velocity 
used for droplet activation in GCMs is not well constrained yet. The eddy diffusivity is diagnosed from the subgrid vertical velocity $\left(\sigma_{\mathrm{w}}\right)$ and the mixing length (Wang and Penner, 2009). The mixing length is calculated based on Holtslag and Boville (1993). This vertical mixing and the associated activation/resuspension could have been incorporated into the ECPP governing equations and code. Treating it separately is another implementation decision: advective transport and turbulent mixing are often treated in separate steps in atmospheric models; doing so here and using the CAM mixing/activation routine save effort.

Aerosol activation calculated in ECPP, which affects the aerosols, is distinct from the activation calculated in the CRM microphysics scheme (Sect. 2.2), which affects droplet number. In the CRM microphysics scheme, the vertical velocity at each CRM grid point and the GCM grid-cell mean aerosol concentrations are used for activation, while in ECPP, the subclass vertical velocities and aerosol concentrations are used. Though the treatment of activations in ECPP is somewhat inconsistent with that in the CRM, they are in fact coupled since ECPP uses updraft statistics from the CRM, and the CRM uses aerosol statics from ECPP. Some inconsistency is inevitable due to the "parameterized" aspects of the Explicit-Cloud-Parameterized-Pollutant approach.

Aqueous chemistry is calculated in each of 6 cloudy sub-subclasses (precipitating and non-precipitating subsubclasses for each of 3 cloudy transport classes), using the CAM5 cloud-chemistry routine. Mean cloud water for the sub-subclasses is used to calculate the uptake and reaction of gas species in cloud water, which increases the mass of some cloud-borne aerosol species. A pH value of 4.5 is assumed in cloud droplet, following Liu et al. (2005). Aqueous chemistry can result in Aitken mode particles growing to a size that is nominally within the accumulation mode size range. We use the approach in Easter et al. (2004) to transfer part of the Aitken mode number and mass (those particles on the upper tail of the distribution) to the accumulation mode, the same approach as that in the standard CAM5.

In the ECPP, the wet removal of gas and aerosol species is treated by using cloud and precipitation fields in each of 12 sub-subclasses. The first-order loss rate for in-cloud scavenging in each sub-subclass is calculated from the loss rate of liquid cloud water to precipitation in the microphysics scheme of the SAM model, and is averaged to a GCM time step of $10 \mathrm{~min}$. Below cloud scavenging of aerosol is calculated as in CAM5 and Easter et al. (2004). In-cloud and below-cloud scavenging of trace gases (e.g., $\mathrm{SO}_{2}, \mathrm{H}_{2} \mathrm{O}_{2}$ ) are calculated assuming reversible uptake to cloud and rain drops. Aqueous oxidation of $\mathrm{SO}_{2}$ in rain is not yet treated. The soluble fractions of gas species in the ECPP are treated in the same way as in CAM5, except for $\mathrm{SO}_{2}$. In the standard CAM5, the $\mathrm{SO}_{2}$ soluble fraction used for wet removal follows that of $\mathrm{H}_{2} \mathrm{O}_{2}$, which is quite soluble, and this leads to efficient wet removal of $\mathrm{SO}_{2}$. In the ECPP, the $\mathrm{SO}_{2}$ soluble fraction is based on the effective Henry's law equilib- rium and is much smaller than that of $\mathrm{H}_{2} \mathrm{O}_{2}$, which leads to a larger $\mathrm{SO}_{2}$ burden in the MMF than in CAM5 (Wang et al., 2011).

The lifetime of updrafts and downdrafts are usually longer than the time step of the GCM model component in the MMF, which is 10 min in this study. Gustafson et al. (2008) found that using a 2-h lifetime for drafts gave best results when simulating transport of inert tracers with ECPP. Following the original Gustafson et al. (2008) approach would require (1) determining when (i.e., with GCM time step) the up- and downdrafts should begin their 2-h life cycle, (2) saving the ECPP subclass tracer concentrations from one GCM time step to the next and setting the updraft and downdraft fraction area to zero every two hours; and (3) applying gridcell average changes calculated in the GCM (for emissions, turbulent mixing, gas phase chemistry) to the ECPP subclass mixing ratios. Instead, we adopt a modified ECPP approach that avoids these complexities while mimicing the finite lifetimes of up- and downdrafts. At the beginning of each ECPP time step, draft areas are set to zero, and quiescent areas (cloudy and clear) are determined by the previous time step liquid cloud fraction. Tracer concentrations in the quiescent subclasses are initialized to the GCM grid-cell average values at each level, with some adjustment to deal with the distribution of interstitial aerosols in cloudy (liquid) versus clear (non-liquid) subclasses. The subclass areas are then changed to their current time step values (as diagnosed from the CRM results). Aerosol activation (associated with the cloudy subclass area increases) or resuspension (associated with the cloudy subclass area decreases) are calculated. (Up/downdraft areas increase from 0 , but individual quiescent areas may increase or decrease). Quiescent subclass tracer concentrations are saved at this point. Next, the tracer continuity equation (Eq. 2) is integrated for twelve 10-min steps. For each of these integrations, the quiescent subclass tracer concentrations are initialized to the earlier saved values, while the up- and downdraft tracer concentrations are carried over from the previous integration. The tracer tendencies at the end of each of twelve steps are averaged together and the averaged tendencies are used to produce the final ECPP tracer concentrations. In this hybrid approach to treating time-dependent up- and downdrafts, the drafts evolve over $2 \mathrm{~h}$, while the quiescent subclasses essentially evolve over $10 \mathrm{~min}$, but interact with drafts with a range of ages. This new approach was tested for transport of inert tracers and gave results very close to the original method of Gustafson et al. (2008).

\subsection{Emissions and set-up of simulations}

The host GCM CAM5 uses the finite-volume dynamical core, with 30 vertical levels at $1.9^{\circ} \times 2.5^{\circ}$ horizontal grid spacing. The GCM time step is $10 \mathrm{~min}$. Climatological sea surface temperature and sea ice are used. The embedded CRM includes 32 columns at 4-km horizontal grid spacing 
and 28 layers coinciding with the lowest 28 CAM levels. The time step for the embedded CRM is $20 \mathrm{~s}$. The model was integrated for 3 years, and results from the last 34 months are used in this study.

Anthropogenic $\mathrm{SO}_{2}, \mathrm{BC}$, and primary organic carbon (OC) emissions are from the Lamarque et al. (2010) IPCC AR5 emission data set. (The year 2000 emissions are used in this study.) An OM/OC ratio of 1.4 is used to convert OC emissions to OM emissions. This emission data set does not provide injection heights, so injection height profiles for forest and grass fire emissions are taken from the AeroCom unified emissions (Dentener et al., 2006), and $\mathrm{SO}_{2}$ from energy and industry sectors is emitted at $100-300 \mathrm{~m}$. Volcanic $\mathrm{SO}_{2}$ and DMS emissions are also taken from Dentener et al. (2006), and $2.5 \%$ of $\mathrm{SO}_{2}$ emissions are emitted as primary sulfate aerosol. Aerosol number emissions are derived from mass emissions using species densities and volume mean emissions diameters $\left(D_{\text {emit }}\right)$, which vary with species and emissions sector. The $D_{\text {emit }}$ follow recommendations in Dentener et al. (2006), with some changes that reflect values used in other studies and account for BC and OM emissions going into the model's accumulation mode. The $D_{\text {emit }}$ values are $0.134 \mu \mathrm{m}$ for BC, OM, and sulfate from forest fire, grass fire, waste, and volcano (50\%) sectors that go into the accumulation mode; $0.261 \mu \mathrm{m}$ for sulfate from energy, industry, and shipping sectors that go into the accumulation mode; and $0.0504 \mu \mathrm{m}$ for sulfate from domestic, transportation, and volcano (50\%) sectors that go into the Aitken mode. In the CAM5 simplified SOA mechanism (Liu et al., 2011), condensing gas-phase organic species, which condense (reversibly) to give SOA, are emitted directly in the model using prescribed yields for several primary VOC classes, rather than being formed by atmospheric oxidation. The VOC emissions are taken from the MOZART- 2 data set (Horowitz et al., 2003), and assumed yields are 5\% (by mass) for big alkane and big alkene, $15 \%$ to toluene, $4 \%$ for isoprene, and $25 \%$ for monoterpene classes.

Emissions of sea salt and mineral dust aerosols are calculated on line. The sea salt emissions parameterization follows Martensson et al. (2003). Particles with diameters between $0.02-0.08,0.08-1.0$, and $1.0-10.0 \mu \mathrm{m}$ are placed in the Aitken, accumulation, and coarse modes, respectively. Mineral dust emissions are calculated with the Dust Entrainment and Deposition Model. The implementation in CAM has been described in Mahowald et al. (2006a, b) and Yoshioka et al. (2007). Particles with diameters between 0.1-1.0 and 1.0$10.0 \mu \mathrm{m}$ are placed in the accumulation and coarse modes, respectively. Both sea salt and dust emissions are tuned by applying scaling factors to the calculated emission fluxes, so that their global burdens match those simulated in CAM5. These tunings minimize the differences in simulated natural aerosols between the MMF and CAM5, facilitating the comparison of aerosol indirect effects in both models, which we examine in a separate manuscript (Wang et al., 2011).
Table 1. Global annual budgets for DMS, $\mathrm{SO}_{2}$, and $\mathrm{H}_{2} \mathrm{SO}_{4}$. Values in the parenthesis show the range from other model studies, which include Liu et al. (2005) and those listed in Liu et al. (2005).

\begin{tabular}{|c|c|c|}
\hline \multirow{8}{*}{$\sum_{0}^{n}$} & Sources $\left(\mathrm{Tg} \mathrm{S} \mathrm{yr}^{-1}\right)$ & $18.21(10.7-23.7)$ \\
\hline & Emission $\left(\mathrm{Tg} \mathrm{S} \mathrm{yr}^{-1}\right)$ & 18.21 \\
\hline & Sinks $\left(\operatorname{Tg~S~yr}^{-1}\right)$ & 18.21 \\
\hline & Gas-phase Oxidation $\left(\mathrm{Tg} \mathrm{S} \mathrm{yr}^{-1}\right)$ & $18.21^{\mathrm{a}}$ \\
\hline & Burden $(\operatorname{Tg} S)$ & $0.06(0.02-0.15)$ \\
\hline & Above $5 \mathrm{~km}(\%)$ & 7.82 \\
\hline & In $\operatorname{polar}^{\mathrm{b}}(\%)$ & 1.73 \\
\hline & Lifetime (days) & $1.22(0.5-3.0)$ \\
\hline \multirow{15}{*}{ ঠ઼ } & Sources $\left(\mathrm{Tg} \mathrm{S} \mathrm{yr}^{-1}\right)$ & 79.61 \\
\hline & Emission $\left(\mathrm{Tg} \mathrm{S} \mathrm{yr}^{-1}\right)$ & $64.77(61.2-92.0)$ \\
\hline & DMS Oxidation $\left(\mathrm{Tg} \mathrm{S} \mathrm{yr}^{-1}\right)$ & $14.84^{\mathrm{a}}(10.0-24.7)$ \\
\hline & Sinks $\left(\operatorname{Tg~S~yr}^{-1}\right)$ & 79.61 \\
\hline & Dry deposition $\left(\mathrm{Tg} \mathrm{S} \mathrm{yr}^{-1}\right)$ & $15.78(16.0-55.0)$ \\
\hline & Wet deposition $\left(\mathrm{Tg} \mathrm{S} \mathrm{yr}^{-1}\right)$ & $5.74(0-19.9)$ \\
\hline & Gas-phase Oxidation $\left(\mathrm{Tg} \mathrm{S} \mathrm{yr}^{-1}\right)$ & $18.63(6.1-22.0)$ \\
\hline & Aqueous-phase Oxidation $\left(\mathrm{Tg} \mathrm{S} \mathrm{yr}^{-1}\right)$ & $39.46(24.5-57.8)$ \\
\hline & Burden $(\operatorname{Tg} S)$ & $0.59(0.20-0.69)$ \\
\hline & Above $5 \mathrm{~km}(\%)$ & 33.00 \\
\hline & In polar $(\%)$ & 1.15 \\
\hline & Lifetime (days) & $2.59(0.6-2.6)$ \\
\hline & Wet+dry removal rate $\left(\right.$ day $\left.^{-1}\right)$ & 0.10 \\
\hline & Wet/(Wet + Dry)(\%) & 26.69 \\
\hline & from Convective cloud ${ }^{\mathrm{c}}(\%)$ & 27.70 \\
\hline \multirow{13}{*}{$\begin{array}{l}\overbrace{}^{+} \\
\underset{\mathbb{I}}{ } \\
\mathbf{I}^{2}\end{array}$} & Sources $\left(\operatorname{Tg~S~yr}^{-1}\right)$ & 18.63 \\
\hline & Gas-phase Production $\left(\mathrm{Tg} \mathrm{S} \mathrm{yr}^{-1}\right)$ & $18.63(6.1-22.0)$ \\
\hline & Sinks $\left(\operatorname{Tg~S~yr}^{-1}\right)$ & 18.63 \\
\hline & Dry deposition $\left(\mathrm{Tg} \mathrm{S} \mathrm{yr}^{-1}\right)$ & 0.01 \\
\hline & Wet deposition $\left(\mathrm{Tg} \mathrm{S} \mathrm{yr}^{-1}\right)$ & 0.04 \\
\hline & Nucleation $\left(\mathrm{Tg} \mathrm{S} \mathrm{yr}^{-1}\right)$ & 0.17 \\
\hline & Condensation $\left(\mathrm{Tg} \mathrm{S} \mathrm{yr}^{-1}\right)$ & 18.32 \\
\hline & Aqueous-phase deposition $\left(\mathrm{Tg} \mathrm{S} \mathrm{yr}^{-1}\right)$ & 0.09 \\
\hline & Burden $(\operatorname{Tg} S)$ & 0.00052 \\
\hline & $(9.0$ & $\left.10^{-6}-1.0 \times 10^{-3}\right)$ \\
\hline & Above $5 \mathrm{~km}(\%)$ & 65.02 \\
\hline & In polar $(\%)$ & 0.52 \\
\hline & Lifetime (min) & $14.7(4.3-10.1)$ \\
\hline
\end{tabular}

a DMS oxidation products includes species other than $\mathrm{SO}_{2}$ (e.g., MSA), which explains why the source of $\mathrm{SO}_{2}$ from DMS oxidation is less than the sink of DMS from oxidation.

${ }^{b}$ South of $80^{\circ} \mathrm{S}$ and north of $80^{\circ} \mathrm{N}$.

${ }^{c}$ The percentage contribution of convective clouds to the total wet scavenging.

\section{Aerosol budgets and distributions}

\subsection{Annual global budgets of aerosols and gas species}

The global budgets of the simulated aerosols and their precursor species in the MMF model are shown in Tables 16 , which also lists ranges of results from other model studies. For gas species, a range of results from models listed in Liu et al. (2005), are given, and for aerosol species, the average, median, and standard deviation of all available models from the model intercomparison study in Aerosol Model 
Table 2. Global annual budget for sulfate. The values in the parenthesis are the mean value (left) and normalized standard deviation (right, as percentage) from available models in AeroCOM (see Textor et al., 2006, Table 10). The standard deviation is normalized by the all models average in the percentage in AeroCOM.

\begin{tabular}{|c|c|}
\hline Sources $\left(\mathrm{Tg} \mathrm{S} \mathrm{yr}^{-1}\right)$ & $59.75(59.67,22)$ \\
\hline Emission $\left(\mathrm{Tg} \mathrm{S} \mathrm{yr}^{-1}\right)$ & 1.66 \\
\hline Gas-phase $\mathrm{SO}_{2}$ oxidation $\left(\mathrm{Tg} \mathrm{S} \mathrm{yr}^{-1}\right)$ & 18.37 \\
\hline Aqueous-phase $\mathrm{SO}_{2}$ oxidation $\left(\mathrm{Tg} \mathrm{S} \mathrm{yr}^{-1}\right)$ & 39.54 \\
\hline from $\mathrm{H}_{2} \mathrm{O}_{2}$ chemistry $(\%)$ & 68.79 \\
\hline from convective clouds $(\%)$ & 23.19 \\
\hline Burden $(\operatorname{Tg} S)$ & $1.05(0.66,25)$ \\
\hline Aitken mode sulfate (\%) & 5.48 \\
\hline Accumulation mode sulfate $(\%)$ & 92.89 \\
\hline Coarse mode sulfate $(\%)$ & 1.63 \\
\hline Above $5 \mathrm{~km}(\%)$ & $44.01(32.33,36)$ \\
\hline In polar $(\%)$ & $0.88(5.91,55)$ \\
\hline Lifetime (days) & $6.42(4.12,18)$ \\
\hline Removal rate $\left(\right.$ day $\left.^{-1}\right)$ & $0.16(0.25,18)$ \\
\hline Wet $\left(\right.$ day $\left.^{-1}\right)$ & $0.13(0.22,22)$ \\
\hline Dry $\left(\right.$ day $\left.^{-1}\right)$ & $0.02(0.03,55)$ \\
\hline Wet/(Wet + Dry) $(\%)$ & $84.97(88.50,8)$ \\
\hline from convective clouds (\%) & 31 \\
\hline
\end{tabular}

Intercomparison Initiative (AeroCom) (Textor et al., 2006) are listed. More than a dozen models were included in the AeroCom intercomparison study.

The simulated DMS burden is $0.06 \mathrm{Tg} \mathrm{S}$ with a lifetime of 1.22 day, which are in the ranges of other model studies (DMS burden ranges from $0.02-0.15 \mathrm{Tg} \mathrm{S}$, and lifetime ranges from $0.5-3.0$ days) (Table 1, top). $7.8 \%$ of DMS is located above $5 \mathrm{~km}$, and $1.7 \%$ of DMS is located in the polar regions (south of $80^{\circ} \mathrm{S}$ and north of $80^{\circ} \mathrm{N}$, which comprises $1.5 \%$ of the earth's surface area). The simulated $\mathrm{SO}_{2}$ burden is $0.59 \mathrm{Tg} \mathrm{S}$ with a lifetime of 2.6 days, which are at the high end of those from other model studies $(0.2-0.6 \mathrm{Tg} \mathrm{S}$, and 0.6-2.6 days) (Table 1, middle). This is consistent with the low dry deposition rate, which removes $15.8 \mathrm{Tg} \mathrm{S} \mathrm{yr}^{-1}$ (compared with 16.0-55.0 $\mathrm{Tg} \mathrm{S} \mathrm{yr}^{-1}$ in other studies). Wet scavenging removes $5.7 \mathrm{Tg} \mathrm{S} \mathrm{yr}^{-1}, 28 \%$ of which is from convective clouds (i.e., clouds in up- and downdraft classes, see Sect. 2.3.1). $33 \%$ of $\mathrm{SO}_{2}$ is located above $5 \mathrm{~km}$ and $1.2 \%$ of $\mathrm{SO}_{2}$ is located in the polar regions. The simulated $\mathrm{H}_{2} \mathrm{SO}_{4}$ burden is $5.2 \times 10^{-4} \mathrm{Tg} \mathrm{S}$ with a lifetime of $14.7 \mathrm{~min}$, which are greater than other studies (Table 1, bottom). The longer $\mathrm{H}_{2} \mathrm{SO}_{4}$ lifetime can be explained by a large amount of $\mathrm{H}_{2} \mathrm{SO}_{4}$ located above $5 \mathrm{~km}(65 \%)$ where the condensation sink is low because of low preexisting aerosol surface area.

The sulfate burden is $1.05 \mathrm{Tg} \mathrm{S}$ with a lifetime of 6.4 days, which is larger than the AeroCom mean $(0.66 \mathrm{Tg} \mathrm{S}$ and 4.12 days). The larger sulfate burden in MMF is caused by a smaller wet removal rate coefficient (the inverse of the resident time) $\left(0.13 \mathrm{day}^{-1}\right.$ vs. $\left.0.22 \mathrm{day}^{-1}\right)$ (Table 2). The mass fraction of sulfate located above $5 \mathrm{~km}$ is $44 \%$ in the MMF
Table 3. Global annual budgets for BC and POM. The values in the parenthesis are the mean value (left) and standard deviation (right) from available models in AeroCOM (see Textor et al., 2006, Table 10). The standard deviation is normalized by the all models average in the percentage in AeroCOM.

\begin{tabular}{|c|c|c|}
\hline \multirow{10}{*}{$U_{\infty}$} & Sources $\left(\operatorname{Tg~yr}^{-1}\right)$ & $7.76(11.9,23)$ \\
\hline & Burden $(\mathrm{Tg})$ & $0.14(0.24,42)$ \\
\hline & Above $5 \mathrm{~km}(\%)$ & $32.28(21.20,52)$ \\
\hline & In polar $(\%)$ & $0.51(4.18,71)$ \\
\hline & Lifetime (days) & $6.59(7.12,33)$ \\
\hline & Removal rate $\left(\right.$ day $\left.^{-1}\right)$ & $0.15(0.15,21)$ \\
\hline & Wet $\left(\right.$ day $\left.^{-1}\right)$ & $0.11(0.12,31)$ \\
\hline & Dry $\left(\right.$ day $\left.^{-1}\right)$ & $0.03(0.03,55)$ \\
\hline & Wet $(\%)$ & $78.02(78.6,18)$ \\
\hline & from convective clouds (\%) & 32.88 \\
\hline \multirow{10}{*}{$\sum_{0}$} & Sources $\left(\mathrm{Tg} \mathrm{yr}^{-1}\right)$ & $50.29(96.60,26)$ \\
\hline & Burden $(\mathrm{Tg})$ & $1.04(1.70,27)$ \\
\hline & Above $5 \mathrm{~km}(\%)$ & $33.08(20.40,56)$ \\
\hline & In polar $(\%)$ & $0.50(3.27,76)$ \\
\hline & Lifetime (days) & $7.58(6.54,27)$ \\
\hline & Removal rate $\left(\right.$ day $\left.^{-1}\right)$ & $0.13(0.16,24)$ \\
\hline & Wet $\left(\right.$ day $\left.^{-1}\right)$ & $0.10(0.14,32)$ \\
\hline & Dry $\left(\right.$ day $\left.^{-1}\right)$ & $0.03(0.03,49)$ \\
\hline & Wet/(Wet+Dry) $(\%)$ & $79.54(79.90,16)$ \\
\hline & from convective clouds (\%) & 34.11 \\
\hline
\end{tabular}

Table 4. Global budget for SOA.

\begin{tabular}{|c|c|}
\hline Sources $\left(\mathrm{Tg} \mathrm{yr}^{-1}\right)$ & 103.44 \\
\hline Gas-phase Production $\left(\mathrm{Tg} \mathrm{yr}^{-1}\right)$ & 103.44 \\
\hline Burden $(\mathrm{Tg})$ & 1.83 \\
\hline Above 5 km (\%) & 39.44 \\
\hline In polar(\%) & 0.44 \\
\hline Lifetime (days) & 6.46 \\
\hline Removal rate $\left(\right.$ day $\left.^{-1}\right)$ & 0.15 \\
\hline Wet $\left(\right.$ day $\left.^{-1}\right)$ & 0.13 \\
\hline Wet/(Wet + Dry) $(\%)$ & 86.35 \\
\hline from convective clouds $(\%)$ & 35.38 \\
\hline
\end{tabular}

model while it is $32 \%$ in the AeroCom models. (See discussion of differences between the MMF and CAM5 in Sect. 5.) In contrast, the MMF model simulates a much smaller fraction of sulfate in the polar regions than that in AeroCom ( $0.88 \%$ vs. $5.91 \%)$. The larger mass fraction above $5 \mathrm{~km}$ and smaller mass fraction in the polar regions are also true for other aerosol species (see below). Difference in the partitioning of wet scavenging among stratiform and convective clouds and in the long range transports between the MMF model and AeroCom models may lead to these differences. Convective clouds account for $31 \%$ of sulfate wet scavenging in the MMF model. 
Table 5. Global annual budget for dust. The values in the parenthesis are the mean (left), median value (middle), and standard deviation (right) from available models in AeroCOM (see Textor et al., 2006, Table 10). The standard deviation is normalized by the all models average in the percentage in AeroCOM.

\begin{tabular}{|c|c|c|c|}
\hline Dust & Accumulation & Coarse & Total \\
\hline Sources $\left(\mathrm{Tg} \mathrm{yr}^{-1}\right)$ & 75.87 & 2295.20 & $2371.08(1840,1640,49)$ \\
\hline Burden (Tg) & 2.0 & 19.40 & $21.40(19.20,20.50,40)$ \\
\hline Above $5 \mathrm{~km}(\%)$ & 30.62 & 16.47 & $17.82(14.10,14.10,51)$ \\
\hline In polar $(\%)$ & 0.41 & 0.16 & $0.18(1.54,1.00,102)$ \\
\hline Fine mass $(\%)$ & - & - & $9.34(20.80,10.80,114)$ \\
\hline Lifetime (days) & 9.62 & 3.09 & $3.30(4.14,4.04,43)$ \\
\hline Removal rate $\left(\right.$ day $\left.^{-1}\right)$ & 0.10 & 0.32 & $0.30(0.31,0.25,62)$ \\
\hline Wet $\left(\right.$ day $\left.^{-1}\right)$ & 0.08 & 0.09 & $0.09(0.08,0.09,42)$ \\
\hline Wet/(Wet + Dry) $(\%)$ & 76.26 & 27.27 & $28.83(33,31.7,54)$ \\
\hline from convective clouds (\%) & 31.11 & 30.36 & 30.42 \\
\hline
\end{tabular}

Table 6. Global annual budget for sea salt. The values in the parenthesis are the mean (left), median value (middle), and standard deviation (right) from available models in AeroCOM (see Textor et al., 2006, Table 10). The standard deviation is normalized by the all models average in the percentage in AeroCOM.

\begin{tabular}{|c|c|c|c|c|}
\hline Sea Salt & Aikten & Accumulation & Coarse & Total \\
\hline Sources $\left(\operatorname{Tg~yr}^{-1}\right)$ & 0.73 & 122.09 & 3564.24 & $3687.06(16600,6280,199)$ \\
\hline Burden $(\mathrm{Tg})$ & 0 & 0.88 & 11.29 & $12.17(7.52,6.37,54)$ \\
\hline Above $5 \mathrm{~km}(\%)$ & 25.75 & 19.91 & 10.54 & $11.22(8.65,6.93,92)$ \\
\hline In polar $(\%)$ & 2.77 & 0.93 & 0.71 & $0.73(3.32,1.88,140)$ \\
\hline Fine mass $(\%)$ & - & - & - & $7.79(14.60,8.72,118)$ \\
\hline Lifetime (days) & 2.83 & 2.63 & 1.17 & $1.21(0.48,0.41,58)$ \\
\hline Removal rate $\left(\right.$ day $\left.^{-1}\right)$ & 0.35 & 0.38 & 0.86 & $0.83(5.07,2.50,188)$ \\
\hline Wet $\left(\right.$ day $\left.^{-1}\right)$ & 0.17 & 0.31 & 0.40 & $0.39(0.79,0.68,77)$ \\
\hline Wet/(Wet + Dry) $(\%)$ & 47.39 & 81.91 & 45.88 & $47.07(30.50,30.30,65)$ \\
\hline from convective clouds (\%) & 27.34 & 34.20 & 33.72 & 33.75 \\
\hline
\end{tabular}

The global annual burden of black carbon (BC) is $0.14 \mathrm{Tg}$, which is about half of the AeroCom mean $(0.24 \mathrm{Tg}$ ) (Table 3, top). This is largely explained by a smaller BC emission $\left(7.8 \mathrm{Tg} \mathrm{yr}^{-1}\right.$ vs. $\left.11.90 \mathrm{Tg} \mathrm{yr}^{-1}\right)$, but also partly due to a somewhat shorter lifetime (6.8 days vs. 7.1 days in AeroCom). Convective clouds account for about $33 \%$ of BC wet scavenging in the MMF model, which is slightly higher than that of sulfate aerosols and reflects the tropical biomass burning sources of $\mathrm{BC}$.

The primary organic carbon (POM) burden is $1.04 \mathrm{Tg}$, which is about half of the AeroCom mean (1.7 Tg) (Table 3, bottom). This is mainly caused by a smaller POM emission in the MMF model $\left(50.3 \mathrm{Tg} \mathrm{yr}^{-1}\right.$ vs. $96.6 \mathrm{Tg} \mathrm{yr}^{-1}$ in AeroCom). The POM lifetime is 7.6 days, larger than the AeroCom mean (6.5 days). Convective clouds contribute $34 \%$ to POM wet scavenging. The simulated SOA burden is $1.8 \mathrm{Tg}$.
The SOA lifetime is 6.5 days (Table 4), which is shorter than that of POM. This is caused by a large wet scavenging rate coefficient of SOA, which can be explained by a larger hygroscopicity parameter of SOA (Liu et al., 2011) and by the fact that SOA is produced mainly in the low latitudes (with more precipitation) from the condensation of semi-volatile organic gas species emitted near surface. The mass fraction of SOA located above $5 \mathrm{~km}$ is $39 \%$, which is larger than that of POM (33\%).

The simulated dust burden is $21.4 \mathrm{Tg}$, which is close to the AeroCom median $(20.50 \mathrm{Tg})$ (Table 5). The total dust emission is $2371.1 \mathrm{Tg} \mathrm{yr}^{-1}$ in CAM5, which is larger than the median of the AeroCom models $\left(1840 \mathrm{Tg} \mathrm{yr}^{-1}\right)$. The accumulation mode dust burden is $2.0 \mathrm{Tg}$ and accounts for $9.3 \%$ of the total dust burden, similar to the AeroCom median $(10.80 \%)$. The mass fraction of dust located above $5 \mathrm{~km}$ is 

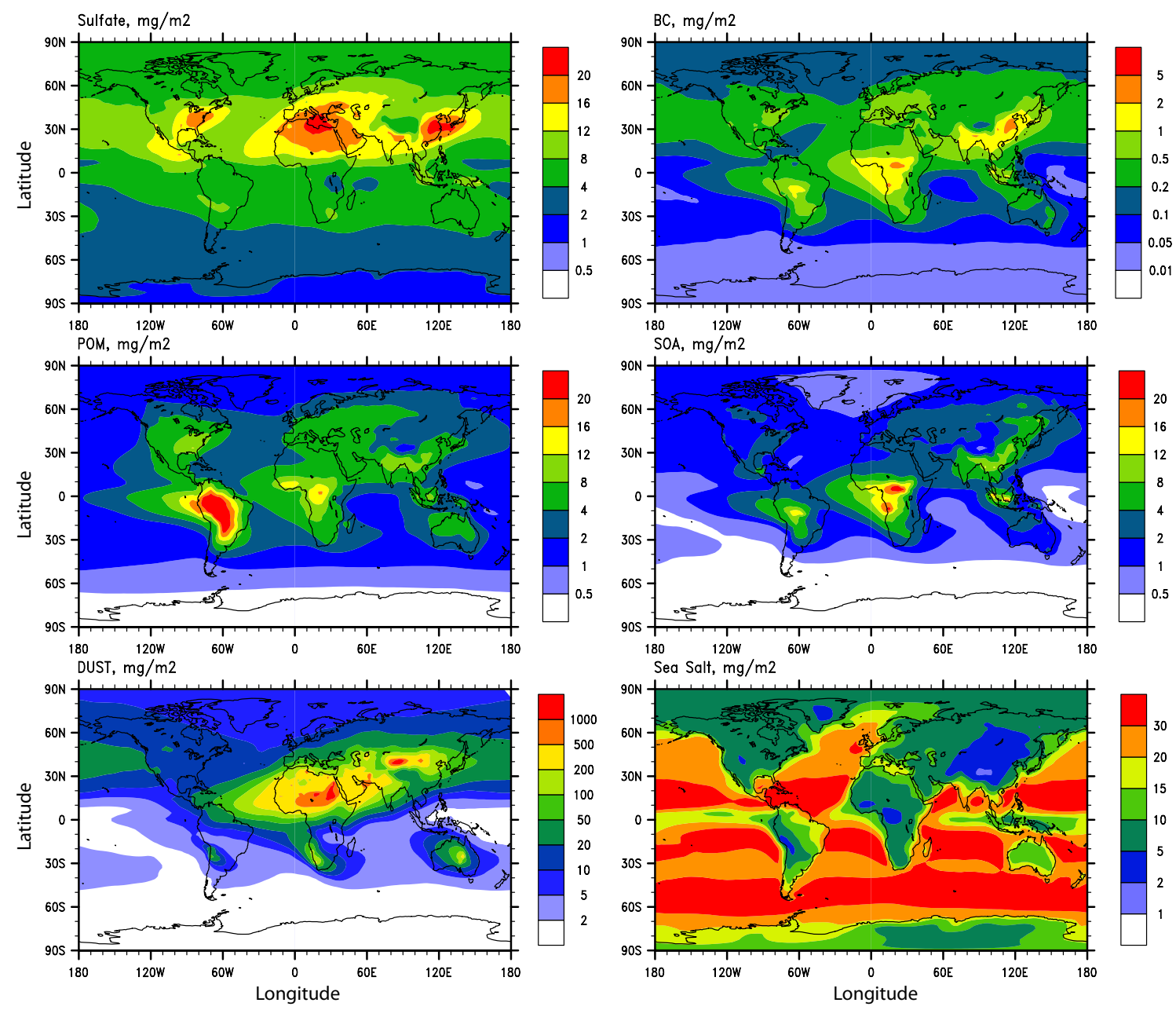

Fig. 1. Vertically integrated annual mean concentrations $\left(\mathrm{mg} \mathrm{m}^{-2}\right)$ of sulfate, BC, POM, SOA, dust, and sea salt predicted by the model.

$17.8 \%$, which is larger than the AeroCom median (14.10\%). Because of the larger particle size, the mass fraction of dust above $5 \mathrm{~km}$ is less than that of sulfate, BC, and POM.

The simulated sea salt burden is $11.29 \mathrm{Tg}$, which is larger than the AeroCom median (6.47 Tg) (Table 6). This is partly because sea salt in the MMF model has a longer lifetime (1.2 days) than that in the AeroCom models (the median lifetime of 0.42 days). The fine mode sea salt mass fraction is $7.8 \%$, which is similar to the median value of the AeroCom models $(8.72 \%)$. Convective clouds account for $34 \%$ of sea salt wet scavenging.

\subsection{Simulated global and vertical distributions of aerosols and gas species}

Figure 1 shows the vertically integrated annual mean column burdens for sulfate, BC, POM, SOA, dust and sea salt. Sulfate burden is high over the strong source regions (e.g., East Asia, and the eastern United States), and over the northernmost Africa. The peak over the northernmost Africa is caused by a combination of high oxidant concentrations and reduced precipitation scavenging in that region. We noticed that a similar peak over the northernmost Africa was also simulated in Mann et al. (2010). BC burden is high over regions with strong fossil fuel emissions (East Asia and South Asia) and biomass burning emissions (central Africa and South America). POM demonstrates a similar spatial pattern as $\mathrm{BC}$, but the maximum POM burden is located over regions with strong biomass burning emissions, while the $\mathrm{BC}$ burden is slightly larger over regions with strong fossil fuel emissions than over regions with strong biomass burning emissions. The maximum SOA burdens are located over southern Africa, South and East Asia, and South America. Dust burden is larger over strong dust source regions (northern Africa, northwest China, and Australia), and over the downwind of dust source regions $\left(40-60^{\circ} \mathrm{N}\right.$ in the western Pacific, and 10 $30^{\circ} \mathrm{N}$ in the Atlantic). Sea salt burden is high in the subtropics of both hemispheres and over the Southern Ocean. Less precipitation over the subtropics leads to the accumulation of sea salt over those regions. 

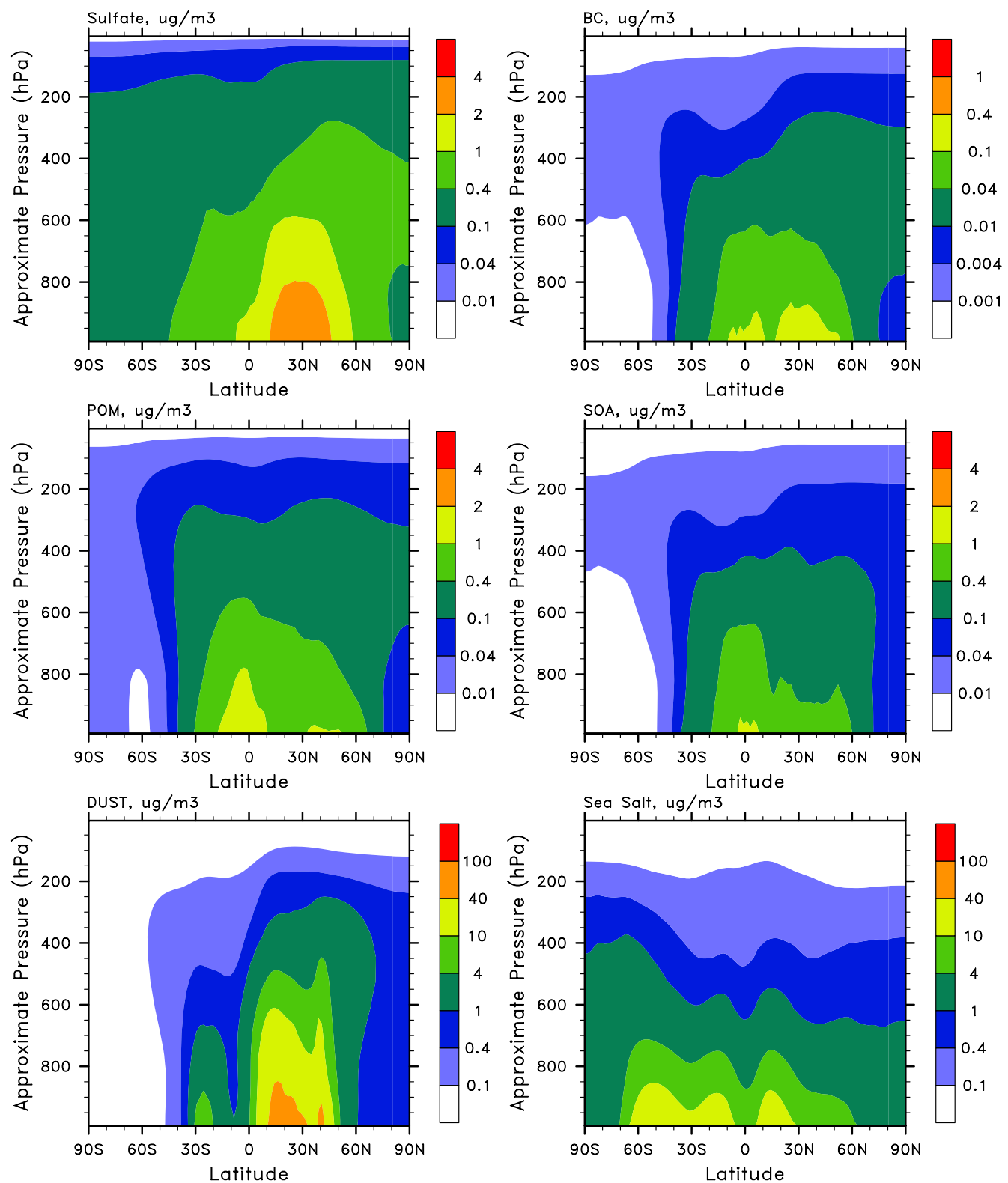

Fig. 2. Annual averaged zonal mean concentrations $\left(\mathrm{ug} \mathrm{m}^{-3}\right)$ of sulfate, BC, POM, SOA, dust and sea salt predicted by the model. The host GCM model (CAM5) used a hybrid vertical coordinate and the pressure at the $k$ th model level is given by $p(k)=A(k) p_{0}+B(k) p_{\mathrm{s}}$, where $p_{\mathrm{s}}$ is surface pressure, $p_{0}$ is a specified constant pressure $(1000 \mathrm{hPa})$, and $A$ and $B$ are coefficients. Data are plotted as a function of this hybrid vertical coordinate times 1000, and labelled "Approximate Pressure".

Figure 2 shows annual averaged zonal mean mass concentrations for sulfate, BC, POM, SOA, dust and sea salt. Sulfate zonal distribution demonstrates strong anthropogenic contributions in the $\mathrm{NH}$ and shows a strong zonal and vertical gradient. Sulfate concentrations decrease by an order of magnitude from $30^{\circ} \mathrm{N}$ to the poles. $\mathrm{BC}$ concentrations show two peaks, one located around $30^{\circ} \mathrm{N}$, due to fossil fuel emissions, and the other located in the tropics, due to biomass burning emissions. $\mathrm{BC}$ concentrations are much lower in the
Antarctic than in the Arctic region because of much less BC emissions in the $\mathrm{SH}$ middle and high latitudes. POM concentrations show two similar peaks as BC. Unlike BC, however, the peak in the tropics is stronger because the emission factor of POM from biomass burning is relatively higher than that from fossil fuel. SOA concentrations have similar spatial distributions as POM. Dust concentrations show a stronger peak in the NH subtropics and a much weaker peak in the SH subtropics. The subtropical regions are located in the descending 


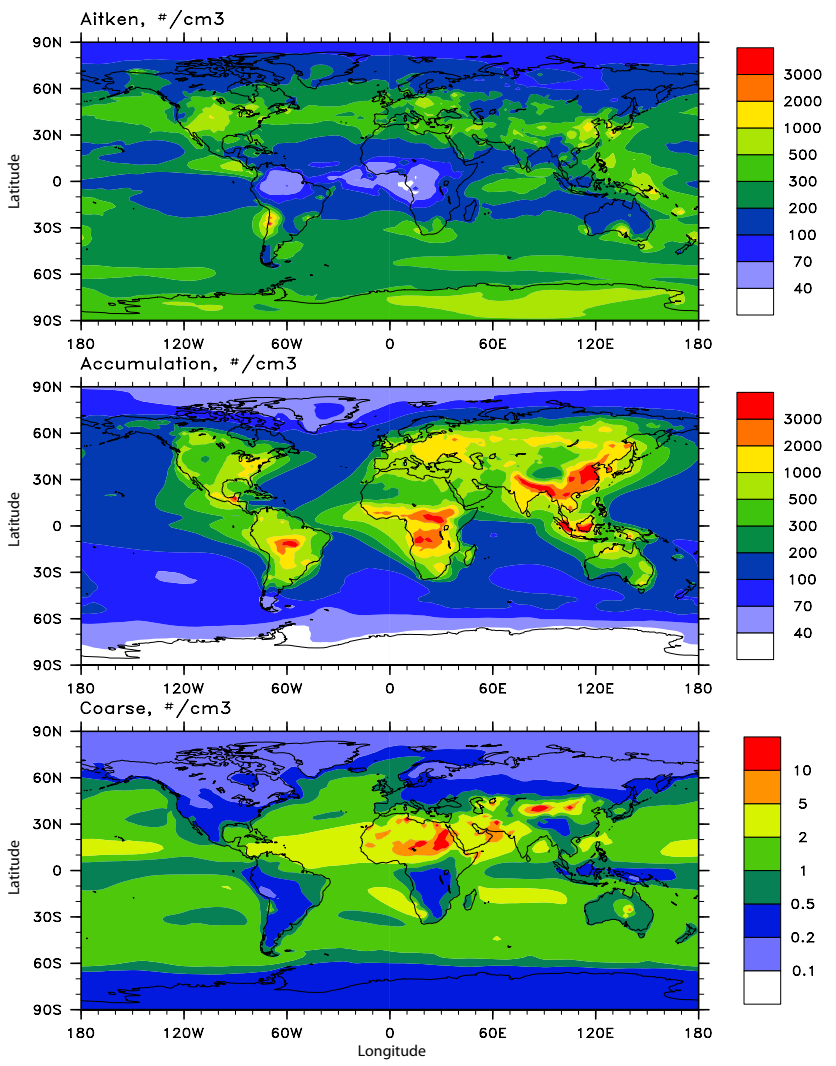

Fig. 3. Annual averaged global distributions of aerosol number concentrations (number $\mathrm{cm}^{-3}$ ) in the lowest model layer for the Aktien mode, accumulation mode, and coarse mode aerosols predicted by the model.

branch of Hadley circulation, where major deserts are located. Dust concentrations extend vertically into the upper troposphere. Simulated sea salt concentrations are stronger in the $\mathrm{SH}$ than that in the $\mathrm{NH}$, because of large open ocean areas in the $\mathrm{SH}$. The peak located in $50^{\circ} \mathrm{S}$ is caused by strong surface wind speeds and large ocean areas over that region. Two other peaks located over the subtropics are most likely caused by the less efficient wet scavenging because of less precipitation over those regions.

Figure 3 shows annual mean aerosol number concentrations in the surface layer for the Aitken, accumulation, and coarse modes. The spatial distributions of accumulation mode aerosol number concentrations are closely related to anthropogenic emissions. In the regions with strong anthropogenic emissions (e.g., East Asia, South Asia, and South America), the accumulation mode aerosol number concentrations exceed $1000 \mathrm{~cm}^{-3}$. The accumulation mode aerosol number concentrations are also high in the polluted outflow regions over oceans (e.g., $40-60^{\circ} \mathrm{N}$ over the east Pacific; tropical Atlantic, and tropical east Pacific). The accumulation mode aerosol number concentrations can be as low as $40 \mathrm{~cm}^{-3}$ in remote areas. Aerosol number concentra- tions in the Aitken mode are high over land in the regions with strong sulfur emissions in the transport and domestic sectors (e.g., the United States, Europe, and East Asia). This is not surprising since sulfur emissions in the transport and domestic sectors are the only sources of primary Aitken mode particles over land in the three-mode treatment. Aerosol number concentrations in the Aitken mode are lower over land in regions with strong biomass burning emissions. This is in part because all primary carbonaceous aerosols are emitted into the accumulation mode in the three-mode treatment, and in part because high concentrations of accumulation mode particles slow down the generation of Aitken particles from nucleation. Over oceanic regions, aerosol number concentrations in the Aitken mode are about $200-500 \mathrm{~cm}^{-3}$, which is in part from the emission of Aitken mode sea salt particles and is in part from enhanced aerosol nucleation due to low accumulation mode aerosol number concentrations. The coarse mode number concentration is highest over the source regions of dust and sea salt particles and in the downwind of dust source regions, and are generally lower than $10 \mathrm{~cm}^{-3}$.

Figure 4 shows annual zonal mean aerosol number concentrations. Simulated accumulation mode aerosol number concentrations show three peaks over the tropics, $30^{\circ} \mathrm{N}$, and $50^{\circ} \mathrm{N}$. The peak over the tropics results from biomass burning aerosols. The peak at $30^{\circ} \mathrm{N}$ is caused by pollution from South and East Asia, and the peak around $50^{\circ} \mathrm{N}$ is caused by pollution from Europe. The peak over tropics extends more to the upper levels compared with the other two peaks, and is caused by biomass burning emission which is injected at 0 $6 \mathrm{~km}$. The Aitken mode aerosol number concentrations show a prominent peak in the tropical upper troposphere, where relative humidity is high and preexisting aerosol surface area is low, both of which favor the binary homogeneous nucleation of $\mathrm{H}_{2} \mathrm{SO}_{4}$ and $\mathrm{H}_{2} \mathrm{O}$. Another peak occurs in the middle troposphere over the $\mathrm{SH}$ high latitudes, which is associated with aerosol nucleation in the austral summer (not shown). The spatial distribution of coarse mode aerosol number concentrations is similar to the spatial distributions of dust and sea salt mass concentrations (Fig. 2).

Figures 5 and 6 show the global distribution of $\mathrm{CCN}$ concentrations at $0.1 \%$ supersaturation in the surface, and zonal mean CCN concentrations, respectively. The spatial distribution of CCN concentrations is similar to that of the accumulation mode aerosol number concentrations, though $\mathrm{CCN}$ concentrations peak in around $20-30^{\circ} \mathrm{N}$ while the accumulation mode number concentrations peak in the tropical regions. The peak in the tropical regions in the accumulation mode number concentrations is caused by carbonaceous aerosol particles due to biomass burning emission, but these carbonaceous aerosol particles are less efficient to act as CCN than sulfate aerosol particles because carbonaceous aerosols are less hygroscopic. 

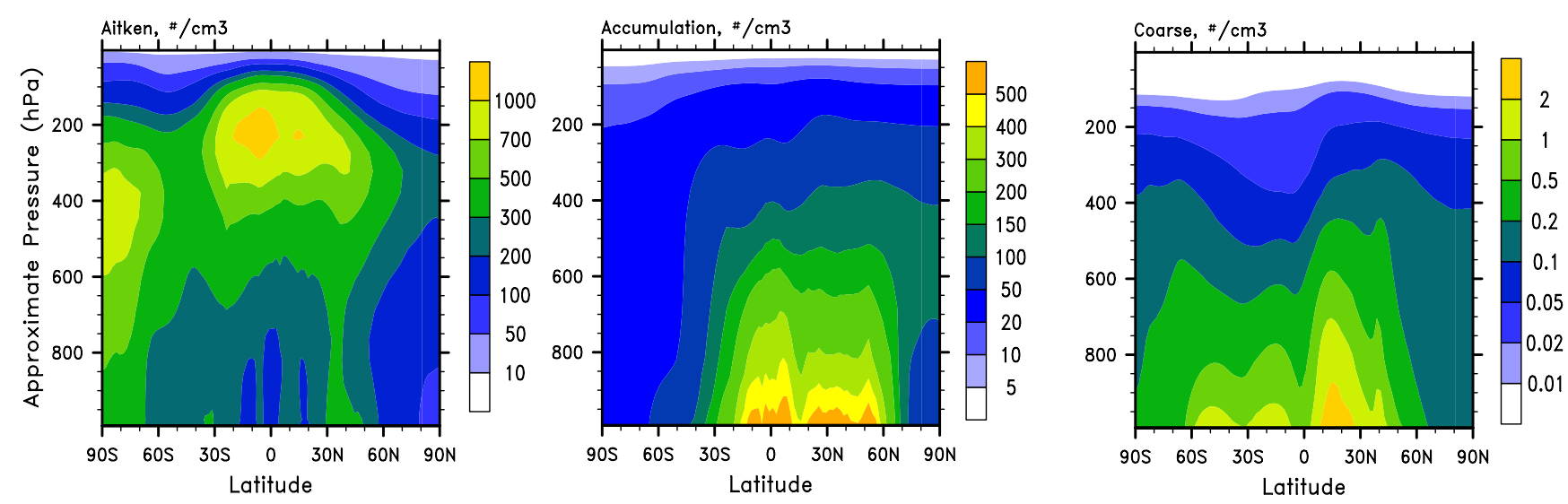

Fig. 4. Zonal mean aerosol number concentrations (number $\mathrm{cm}^{-3}$ ) for the Aikten mode, accumulation mode, and coarse mode predicted by the model.

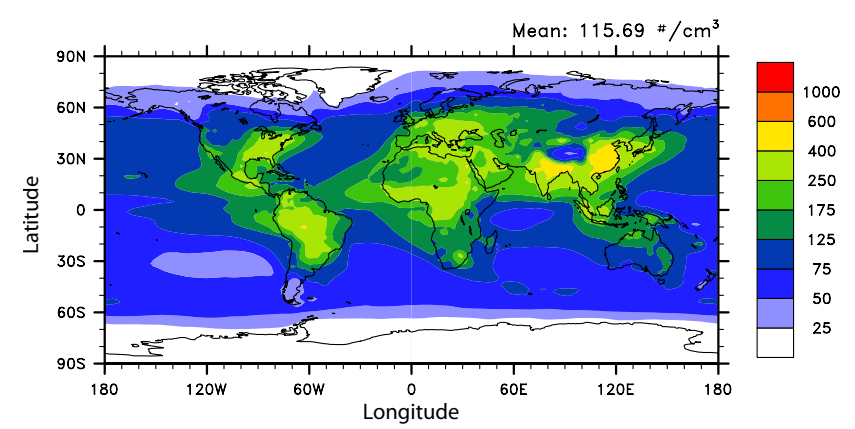

Fig. 5. Annual averaged global distributions of $\mathrm{CCN}$ concentrations (number $\mathrm{cm}^{-3}$ ) at $0.1 \%$ supersaturation in the lowest model layer.

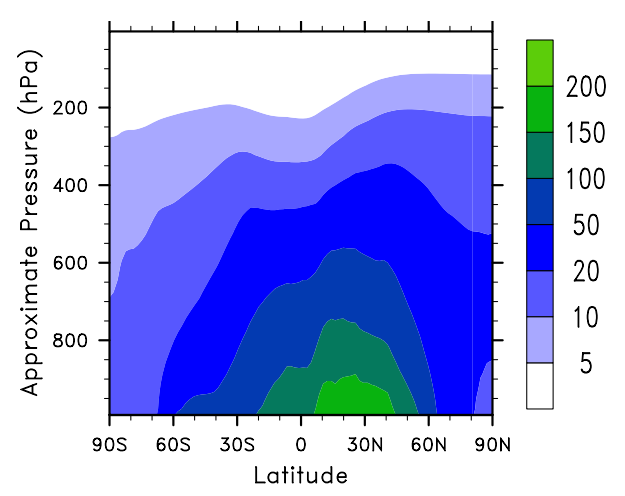

Fig. 6. Zonal mean $\mathrm{CCN}$ concentrations (number $\mathrm{cm}^{-3}$ ) at $0.1 \%$ supersaturation.

\section{Comparison with observations}

\subsection{Aerosol mass concentrations}

Figures 7 and 8 compare modeled DMS and $\mathrm{SO}_{2}$ vertical profiles with those from three field experiments (PEMTropics A, September-October, 1996; PEM-Tropics B,
March-April, 1999; TRACE-P, February-April, 2001). Vertical profile data are composites of observations binned into altitude ranges (Emmons et al., 2000). Model results are monthly mean, and averaged over the observational domain. In general, simulated DMS concentrations agree well with observations (within a factor of 2), and both the model and observations show a strong gradient from the surface to the free troposphere. The model overestimates DMS concentrations in the boundary layer near Japan, Hawaii and Guam, and underestimates DMS concentrations in the free troposphere near China and Japan. Unlike DMS, observed $\mathrm{SO}_{2}$ concentrations show a much weaker gradient from the surface to the free troposphere. At some locations, there are even elevated $\mathrm{SO}_{2}$ layers in the middle and upper troposphere (e.g., Christmas-Island, PEM-TROPICS A). Simulated $\mathrm{SO}_{2}$ also demonstrates a much weaker gradient from the surface to the free troposphere, and elevated $\mathrm{SO}_{2}$ layers are simulated over some locations. In general, simulated $\mathrm{SO}_{2}$ concentrations are in reasonable agreement with observations. However, the model overestimates $\mathrm{SO}_{2}$ concentrations near Christmas Island, PEM-Tropics A (by about a factor of 3), Easter Island (by about a factor of 3), and Guam (by about a factor of 4), especially in the upper troposphere. The overestimation in the upper troposphere is also evident in some other locations (e.g., Tahiti, PEM-TROPICS A). The overestimation in the middle and upper troposphere may indicate too strong vertical transport, and/or too weak in-cloud aqueous chemistry in the MMF model. An elevated $\mathrm{SO}_{2}$ layer is simulated in the lower troposphere (at about 3-4 km) near Hawaii, which comes from the $\mathrm{SO}_{2}$ emissions from Hawaiian volcanoes.

Figures 9 and 10 compare simulated annual mean surface $\mathrm{SO}_{2}$ and sulfate concentrations with observations from the United States Interagency Monitoring of Protected Visual Environment (IMPROVE) sites (http://vista.cira.colostate. edu/improve/), the European Monitoring and Evaluation Programme (EMEP) sites (http://www.emep.int), and the ocean 

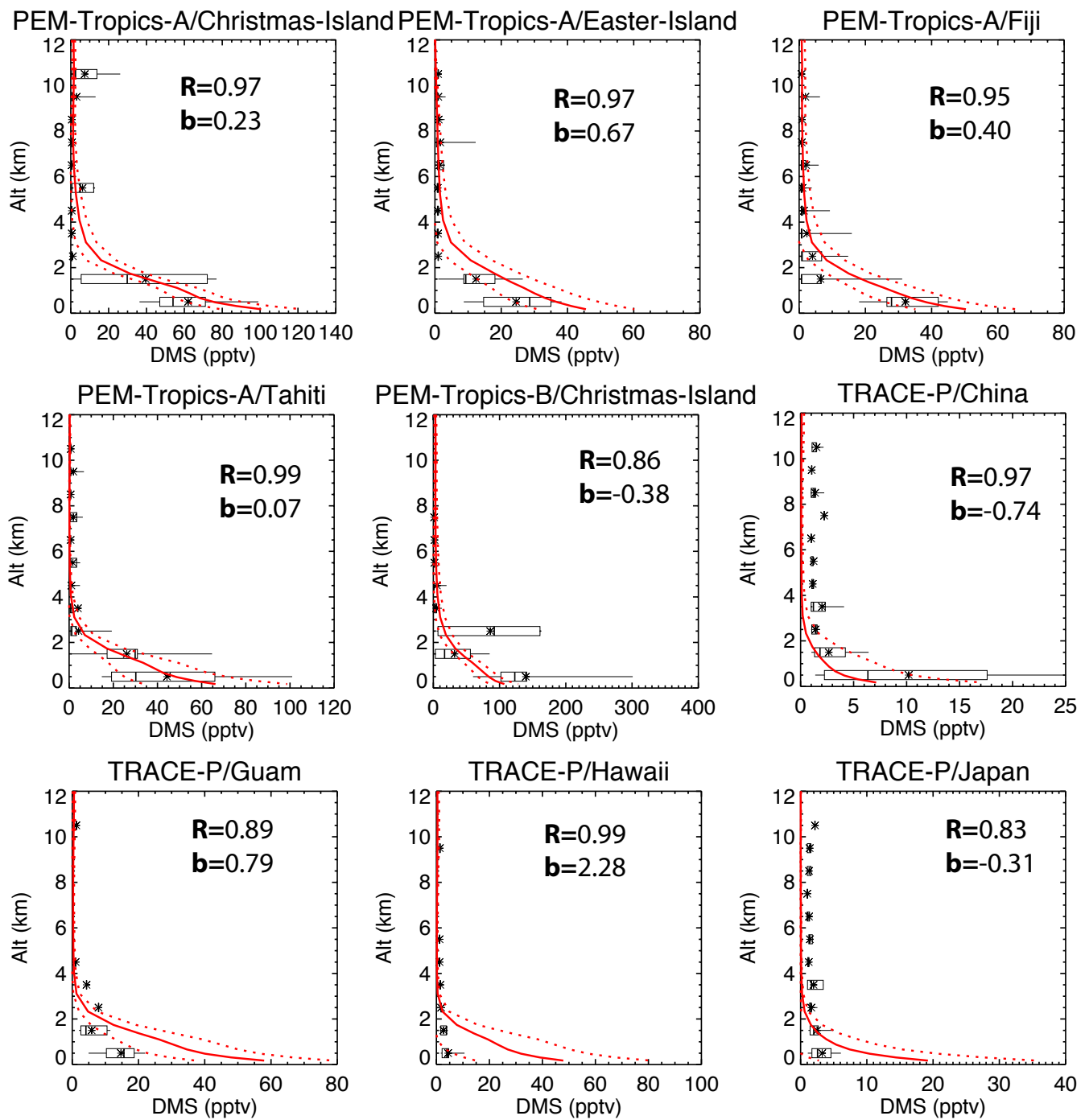

Fig. 7. DMS vertical profiles over the Pacific Ocean. Observations are from PEM-Tropics A (September-October 1996), PEM-Tropics B (March-April 1999), and TRACE-P (February-April 2001) (Emmons et al., 2000). Model results (red lines) are monthly mean, and averaged over the observational domain (solid line: mean; dash lines: \pm one standard deviation). For the observed values (in black), the whiskers show 5th and 95th percentiles, the boxes show 25th and 75th percentiles, and the star symbols and thicker vertical lines inside the boxes show mean and median. Normalized model mean bias ("b") and the correlation coefficient between the model and observations ("R") are shown in each panel. Values of $\mathrm{b}$ and $\mathrm{R}$ are calculated using observed values provided at discrete altitudes and model values interpolated from model grid to those altitudes.

network sites operated by the University of Miami (Prospero et al., 1989; Savoie et al., 1989, 1993; Arimoto et al., 1996). Simulated $\mathrm{SO}_{2}$ concentrations are in reasonable agreement with observations at a large number of European sites (within a factor of two), while simulated $\mathrm{SO}_{2}$ concentrations are overestimated at the IMPROVE sites in the United States. Sulfate concentrations are in reasonable agreement with observations. The agreement is particularly good in Europe (within a factor two) (Fig. 9). Over the United States, sulfate concentrations at most sites agree with observations within a factor of 2 , but the model overestimates sulfate concentrations for some sites, which are mostly located in the western United States (Fig. 9). Over the oceanic sites oper- ated by the University of Miami, sulfate concentrations in the MMF model are in reasonable agreement with observations (within a factor of two).

Modeled surface BC and OC/OM concentrations are compared with those observed at the IMPROVE sites, EMEP sites, and those compiled by Liousse et al. (1996), Cooke et al. (1999), and Zhang et al. (2007) in Figs. 11 and 12. In general, the model underestimated $\mathrm{BC}$ concentrations, by a factor of 2-4, especially at the EMEP sites. In the three-mode representation of aerosols in CAM5, BC particles are assumed to be internally mixed with sulfate and other aerosols particles in the accumulation mode, which may overestimate the wet removal rate of $\mathrm{BC}$ particles, although the $\mathrm{BC}$ 

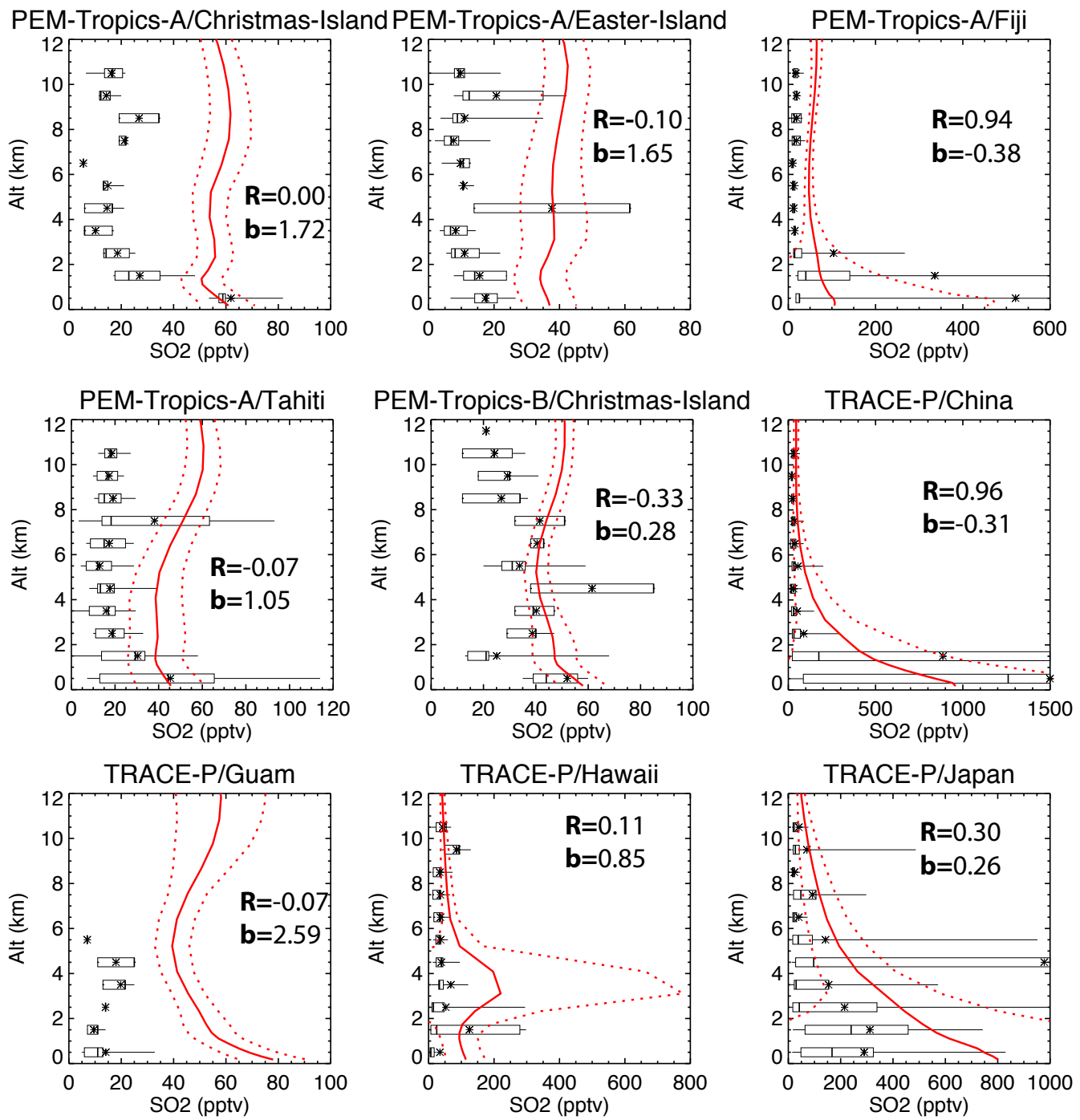

Fig. 8. The same as Fig. 7, but for $\mathrm{SO}_{2}$ vertical profiles.

lifetime is only slightly smaller than the AeroCom mean (Table 3). Simulated OC concentrations agree better with observations. At a large number of the IMPROVE sites, the model agrees with observations within a factor of two, while the model underestimates OC concentrations at the EMEP sites by a factor of 2-3, and overestimates OC concentrations in some sites compiled by Liousse et al. (1996) and Cooke et al. (1999). Simulated OM concentrations agree with observations within a factor of two at most sites compiled by Zhang et al. (2007).

Sea salt and dust concentrations are compared with those observed at the ocean network sites operated by the University of Miami in Figs. 13 and 14, respectively. Both dust and sea salt are in reasonable agreement with observations (within a factor of two at most sites). However, dust concentrations are underestimated at high latitude sites (two sites over Antarctic, and one site over Ireland), which may suggest that the wet scavenging rate of dust particles are too strong or the polarward transport is too weak. The underestimation of dust in the high latitudes is consistent with the low mass fraction in the polar regions compared with that in the AeroCom models (Table 5).

Simulated BC vertical profiles are compared with those measured in several recent aircraft campaigns at tropical and middle latitudes (Fig. 15), at high latitudes (Fig. 16) and above the remote Pacific from $67^{\circ} \mathrm{S}$ to $80^{\circ} \mathrm{N}$ in the HIAPER Pole-to-Pole Observation (HIPPO) campaign (Fig. 17) by using Single Particle Soot absorption Photometers (SP2s) (Schwarz et al., 2006). The SP2 instrument uses laserinduced incandescence to detect and size individual BC particles, which enables SP2 to detect and characterize individual $\mathrm{BC}$ particles in real-time, and make it suitable for continuous particle measurements from the surface to the lower stratosphere on board aircraft.

Measured BC concentrations show a strong gradient from the surface to the middle altitudes in the tropics (CR-AVE, 

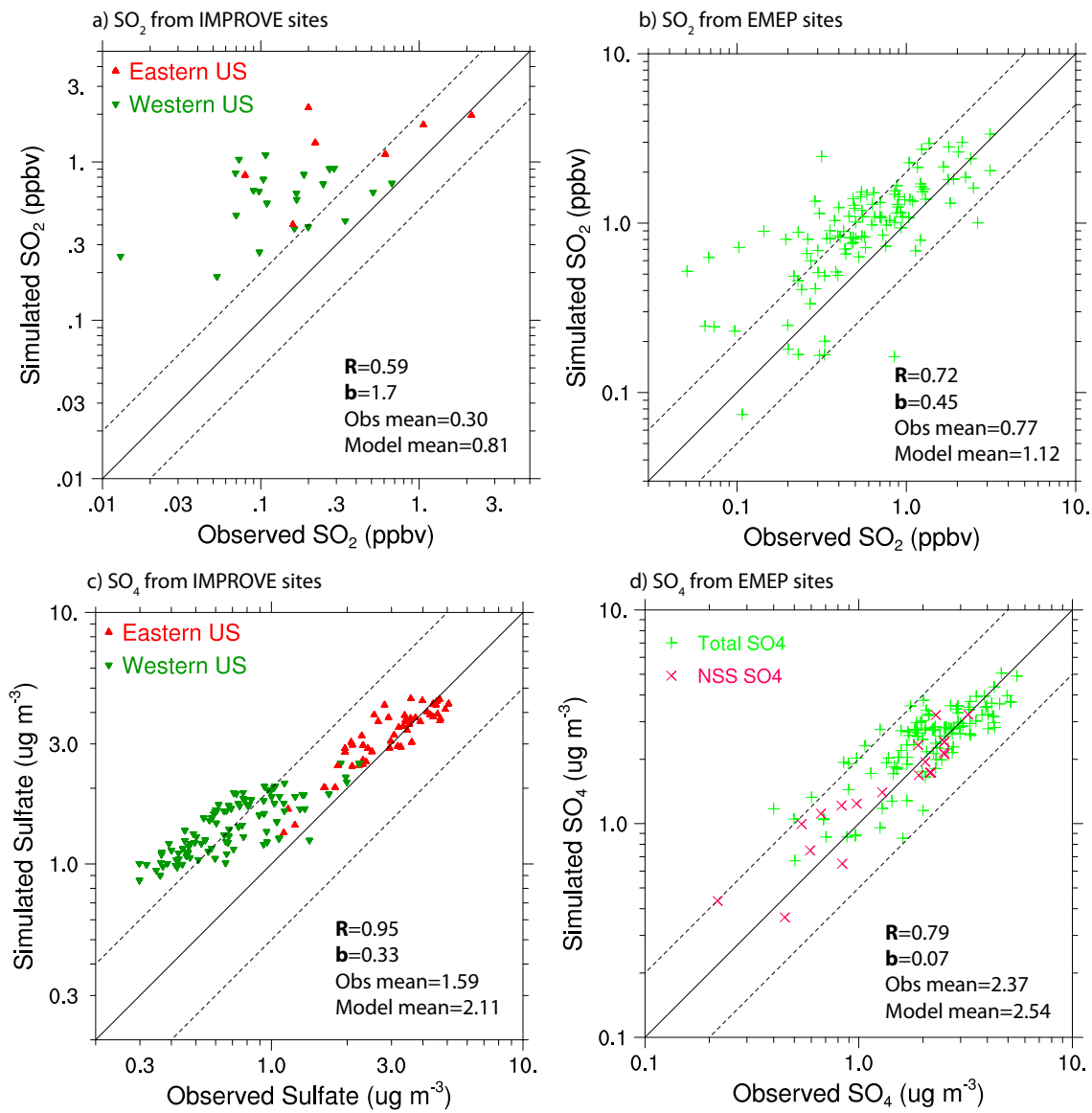

Fig. 9. Annual average simulated surface concentrations versus observations from the IMPROVE network and EMEP network: (a) $\mathrm{SO}_{2}$ concentrations at the IMPROVE sites; (b) $\mathrm{SO}_{2}$ concentrations at the EMEP sites; (c) sulfate concentrations at the IMPROVE sites; (d) sulfate concentrations at the EMEP sites. Model mean ("Model mean"), observational mean ("Obs mean"), normalized model mean bias ("b") and the correlation coefficient between model and observations ("R") are shown in each panel.

and TC4) and subtropics (AVE Houston), with BC concentrations around $100 \mathrm{ng} \mathrm{kg}^{-1}$ in the surface and $1 \mathrm{ng} \mathrm{kg}^{-1}$ at $500 \mathrm{hPa}$ (Fig. 15). The modeled BC concentrations also show a strong gradient from the surface to the middle troposphere. However, the gradient is much weaker in the MMF model, which leads to the overestimations in the middle and upper troposphere (by a factor of 10), a common problem in most AeroCom models (Fig. 9 in Koch et al., 2009). In the middle latitudes, observed BC vertical profiles show a smaller gradient between the surface and the middle troposphere than in the tropics. The model does a better job in simulating $\mathrm{BC}$ vertical profiles in the middle latitude than in the tropics, though $\mathrm{BC}$ concentrations are overestimated in the upper troposphere and underestimated in the surface.

The observed $\mathrm{BC}$ vertical profiles in the high latitudes peak in the middle troposphere in April, a feature that is not observed in June-July (Fig. 16). The MMF model underestimates $\mathrm{BC}$ concentrations in the lower and middle troposphere and overestimates BC concentrations above $200 \mathrm{hPa}$ in April. Simulated BC vertical profiles agree better with ob- servations in the summer. The underestimation at the higher latitudes (Fig. 16) and the overestimation at the lower latitudes (Fig. 15) are common problems in almost all the AeroCom models (Table 8 in Koch et al., 2009). As suggested by Koch et al. (2009), this may point to a problem in distinguishing between removal of $\mathrm{BC}$ by convective and stratiform clouds. The MMF model has a more physically-based treatment for wet scavenging from convective clouds (Sect. 2.3); however this improvement still did not solve the problem, though the MMF model did simulate aerosols in the high latitudes better than the standard CAM5 (Wang et al., 2011).

The HIPPO campaign measured $\mathrm{BC}$ vertical profiles over the remote Pacific from $67^{\circ} \mathrm{S}$ to $80^{\circ} \mathrm{N}$ during a two-week period in January 2009 (Schwarz et al., 2010). Measured $B C$ vertical profiles reveal significant dependences on latitude, with decreasing $\mathrm{BC}$ concentrations with altitude in the tropics and in the NH mid- and high latitudes, and increasing $\mathrm{BC}$ concentrations with altitude in the $\mathrm{SH}$ high latitudes (Fig. 17). The gradient in BC concentrations from the surface to the upper troposphere is the strongest over the tropics. 


\section{Relative difference of annual SO4 [ug/m3] conc with RSMAS}
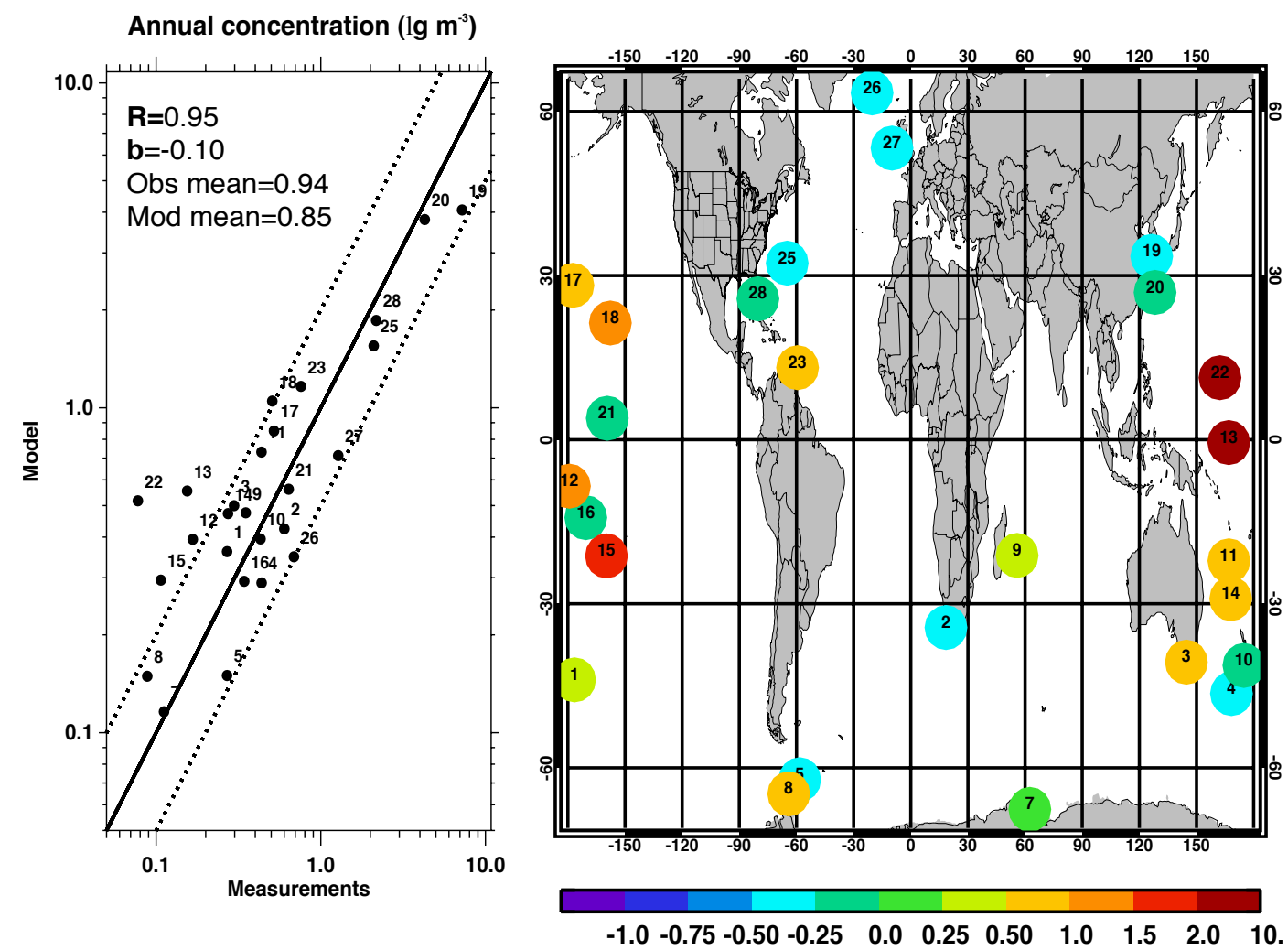

Fig. 10. Annual mean surface sulfate concentrations at the ocean network sites operated by the Rosenstiel School of Marine and Atmospheric Science (RSMAS) at the University of Miami (Arimoto et al., 1996; Prospero et al., 1989; Savoie et al., 1993, 1989). The left panel shows the scattering plot between the observations and the model. Model mean ("Mod mean"), observational mean ("Obs mean"), normalized model mean bias ("b") and the correlation coefficient between model and observations ("R") are shown. The right panel shows the global map of individual sites, and the relative difference between the model and the observations: (model-observations)/observations.

The HIPPO BC vertical profiles in the tropics and in the $\mathrm{NH}$ mid- and high latitudes are quantitatively similar to those in Figs. 15-16, though observations over Arctic in April (ARCTAS and ARCPAC in Fig. 16) show a smaller gradient in $\mathrm{BC}$ concentrations from the surface to the upper troposphere. The model produces increasing $\mathrm{BC}$ concentrations with altitude in the SH high latitudes, which agrees with the HIPPO observations, though the model overestimates BC concentrations at all levels. The model produces near constant BC concentrations in the tropics and the NH mid- and high latitudes, which leads to the overestimation of $\mathrm{BC}$ concentration in the middle and upper troposphere, and in the lower stratosphere. The MMF performs quantitatively similarly with the AeroCom models included in Schwarz et al. (2010). Schwarz et al. (2010) suggested that wet removal of BC in global aerosol models may need enhanced. We note that, however, the MMF model underestimates $\mathrm{BC}$ concentrations in the middle and upper troposphere over Arctic in April from the ARCTAS DC-8, ARCTAS P3-B, and ARCPAC campaigns (Fig. 16), though the model overestimates $\mathrm{BC}$ concentrations from the HIPPO campaign in January. This points to the need to have HIPPO-type observations in other months to fully evaluate global aerosol models.

\subsection{Aerosol number and Size distributions}

Figure 18 shows aerosol size distributions in the marine boundary layer. The observational data is from Heintzenberg et al. (2000), and were compiled and aggregated onto a $15^{\circ} \times 15^{\circ}$ grid. The model data is sampled over the same regions as those of the observations. The observational data clearly shows a bimodal distribution in the marine boundary layer: an Aitken mode with a geometric mean diameter of $20-50 \mathrm{~nm}$ and an accumulation mode with a geometric mean diameter of 100-200 $\mathrm{nm}$. The MMF model reproduces the observed bimodal distribution in most regions. Simulated Aitken mode aerosol number concentrations are generally in reasonable agreement with observations in most latitude bands. The improved simulation of the Aitken mode aerosol number concentrations compared with some previous studies (Pierce and Adams, 2006; Wang et al., 2009) 
a) BC from IMPROVE sites
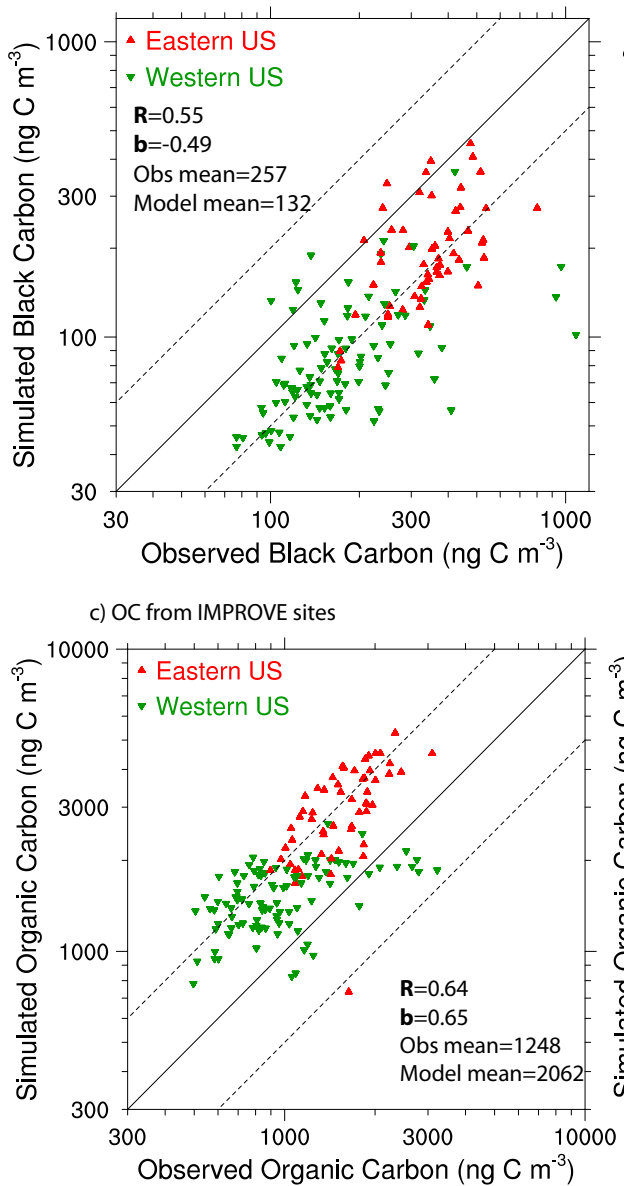

b) BC from EMEP sites
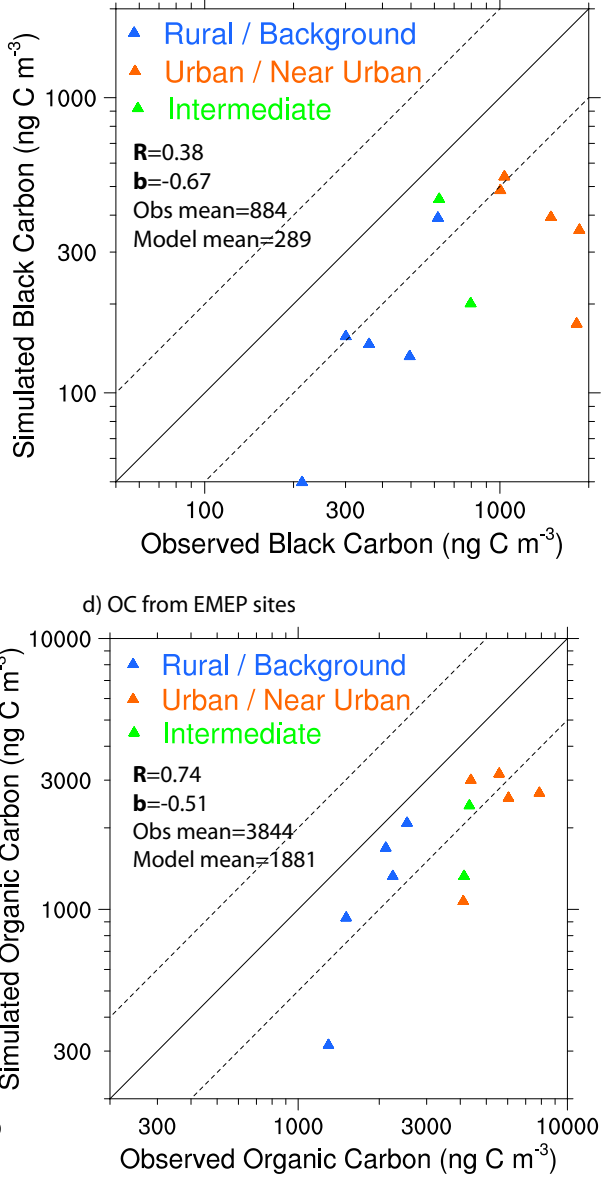

Fig. 11. Annual average simulated surface $B C$ and $O C$ concentrations versus observations from the IMPROVE network and EMEP network. (a) BC concentrations at the IMPROVE sites; (b) BC concentrations at the EMEP sites; (c) OC concentrations at the IMPROVE sites; (d) OC concentrations at the EMEP sites. An OC/OM ratio of 1.4 is used to convert simulated OM (POM+SOA) to OC. Model mean ("Model mean"), observational mean ("Obs mean"), normalized model mean bias ("b") and the correlation coefficient between model and observations ("R") are shown in each panel.

may come from the inclusion of both sea salt particles in the Aitken mode and the boundary layer nucleation mechanism in the model. However, the model underestimates the accumulation mode aerosol number concentrations, especially over the low and mid-latitude bands (e.g., by about $50 \%$ in the $30^{\circ} \mathrm{S}-45^{\circ} \mathrm{S}$ and $30^{\circ} \mathrm{S}-15^{\circ} \mathrm{S}$ latitude bands, and by about $30 \%$ in the $30^{\circ} \mathrm{N}-45^{\circ} \mathrm{N}$ latitude band). This may suggest that the model underestimates fine mode sea salt, polluted outflow from continents or the growth of Aitken mode particles. Wang et al. (2009) showed that the underestimation of fine mode sea salt particles in their model was consistent with their underestimation of accumulation mode aerosol number concentrations.

Figure 19 compares simulated aerosol size distributions in the free troposphere with observations. Unlike the marine boundary layer, observations in the free troposphere show a monomodal distribution at all sites except for the Lindenberg 4-km observations. For that case, the large accumulation mode number concentration came from one flight where the accumulation mode number concentration was $250 \mathrm{~cm}^{-3}$, while the remaining 4 flights gave an average accumulation mode number concentration of $15 \mathrm{~cm}^{-3}$ (Petzold et al., 2002). The observed monomodal size distribution in the free troposphere is believed to result from the wet removal of accumulation mode particles in the boundary layer, and the generation of Aitken particles from nucleation in the free troposphere (Raes et al., 2000). The model does simulate a prominent Aitken mode at all sites. However, the Aitken mode diameters are underestimated in the lower and middle free troposphere and the model also simulates a weak accumulation mode, which is not present in the observations (see the further discussion in Sect. 5 about this discrepancy). The accumulation mode concentrations are overestimated in the middle and upper troposphere, especially over southern 

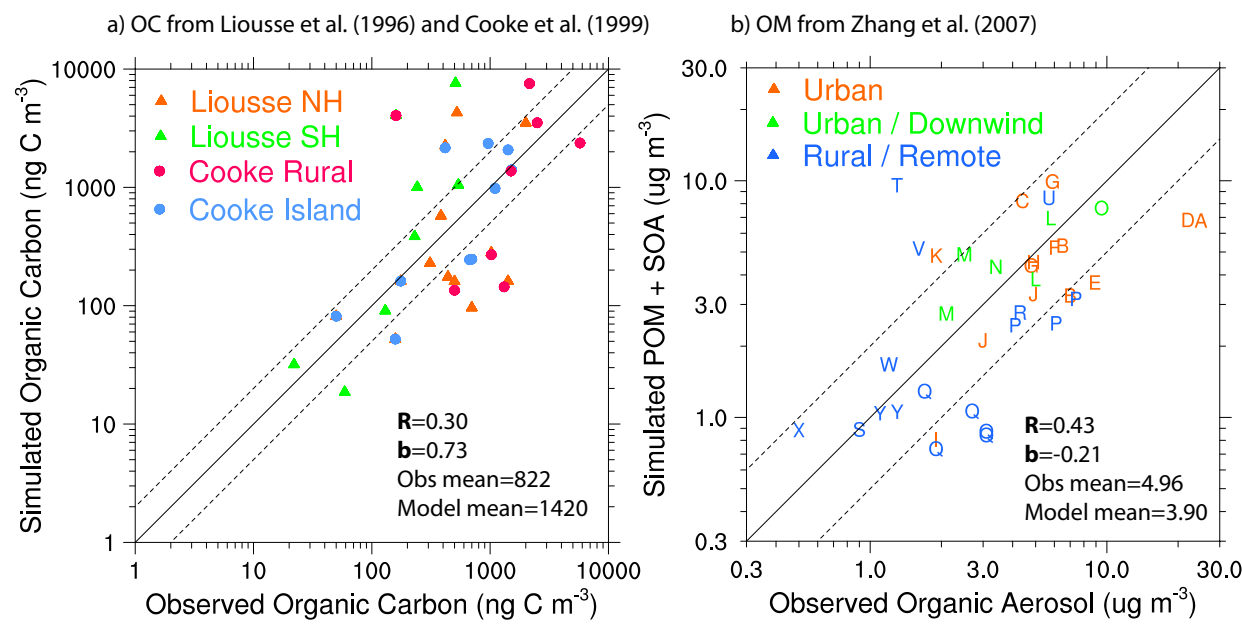

c) BC from Liousse et al. (1996) and Cooke et al. (1999)

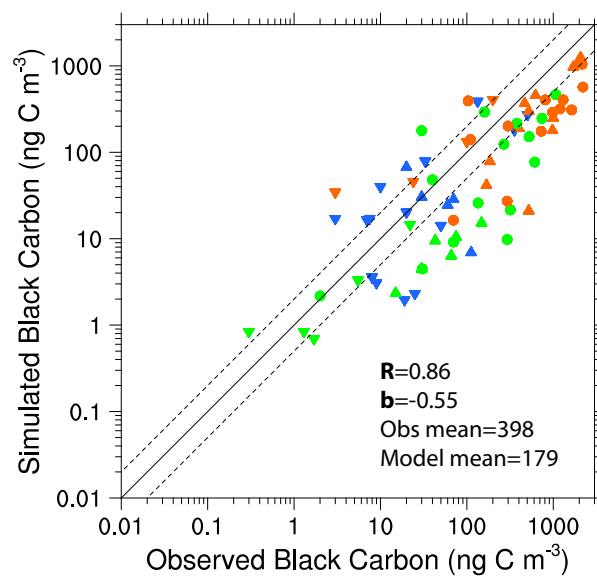

$$
\begin{aligned}
& \text { - Liousse Atlantic } \\
& \text { - Liousse Pacific } \\
& \text { - Liousse Remote NH } \\
& \text { - Cooke Remote } \\
& \text { - Cooke Rural } \\
& \text { - Liouse Rural NH } \\
& \text { Liouse Rural SH }
\end{aligned}
$$

Fig. 12. Annual average simulated BC and OC concentrations versus observations from Liousse et al. (1996), Cooke et al. (1999), and Zhang et al. (2007): (a) OC concentrations from Liousse et al. (1996) and Cooke et al. (1999); (b) OCM concentrations from Zhang et al. (2007); (c) BC concentrations from Liousse et al. (1996) and Cooke et al. (1999). An OC/OM ratio of 1.4 is used to convert simulated $\mathrm{OM}$ (POM + SOA) to OC in (a). Model mean ("Model mean"), observational mean ("Obs mean"), normalized model mean bias ("b") and the correlation coefficient between model and observations ("R") are shown in each panel.

Florida (CRYSTAL-FACE). However, it should be noted that the observations from CRYSTAL-FACE only represent a single date. Simulated Aitken mode diameters are generally underestimated.

Figure 20 shows vertical profiles of the aerosol number concentrations in the Aitken mode (diameter $>14 \mathrm{~nm}$ ), and in the accumulation mode (diameter $>100 \mathrm{~nm}$ ) from both the model and observations at Punta Arena, Chile and Prestwick, Scotland (Minikin et al., 2003). The observed Aitken mode aerosol number concentrations are around $1000 \mathrm{~cm}^{-3}$ over Scotland, and are around $500 \mathrm{~cm}^{-3}$ over southern Chile. The model simulates the Aitken mode number concentration reasonably well in the low troposphere over southern Chile, and performs better than some previous studies (Wang et al., 2009). This may come from the inclusion of ultrafine sea salt emissions and the boundary layer nucleation mechanism in the MMF. However, the model underestimates the Aitken mode number concentration over Scotland in the lower free troposphere, which may be partly explained by the fact that carbonaceous aerosols are emitted into the accumulation mode in the three-mode treatment. The model overestimates the Aitken mode particle number concentrations in the upper troposphere and stratosphere. This may suggest that nucleation in the upper troposphere is overestimated, consistent with the overestimation of $\mathrm{SO}_{2}$ concentration in the upper troposphere (Fig. 8)

Observed accumulation mode aerosol number concentrations decrease with altitude in the lower troposphere, are nearly constant with altitude in the middle troposphere, and increases slightly with altitude in the upper troposphere. The model reproduces the decreasing accumulation mode number concentrations with altitude in the lower free troposphere, 


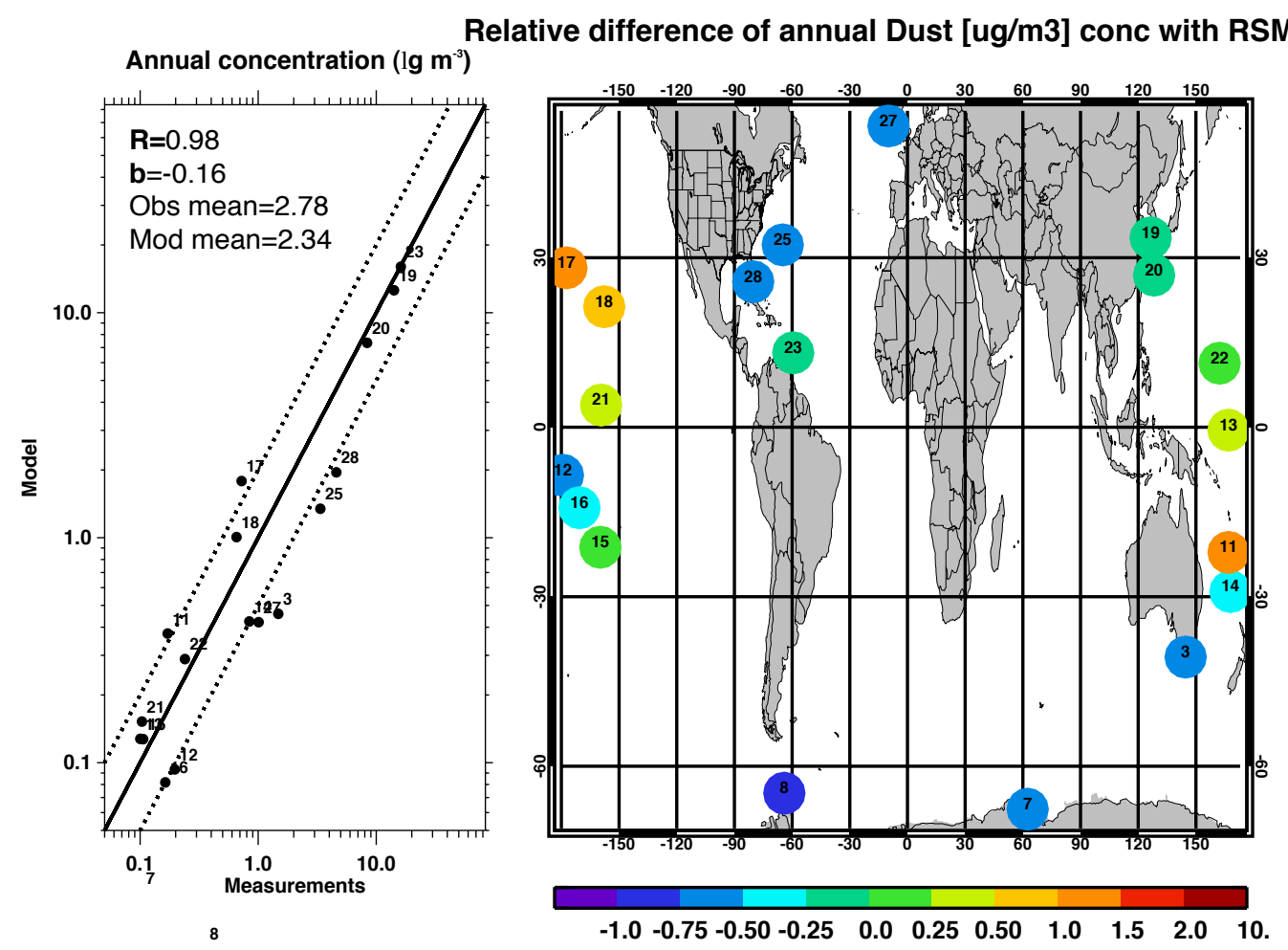

Fig. 13. The same as Fig. 10, but for dust.

Relative difference of annual SeaSalt [ug/m3] conc with RSMAS Annual concentration $\left(\mathrm{lg} \mathrm{m}^{-3}\right)$

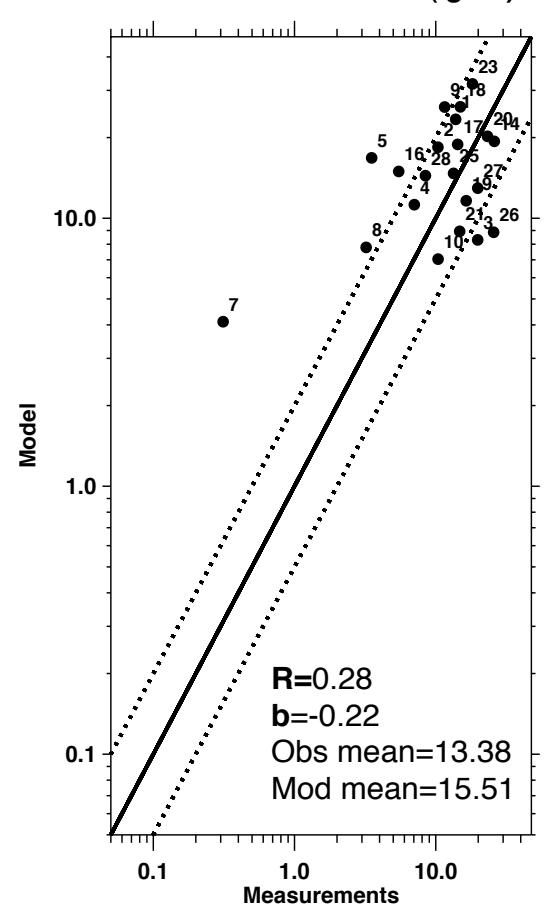

Measurements

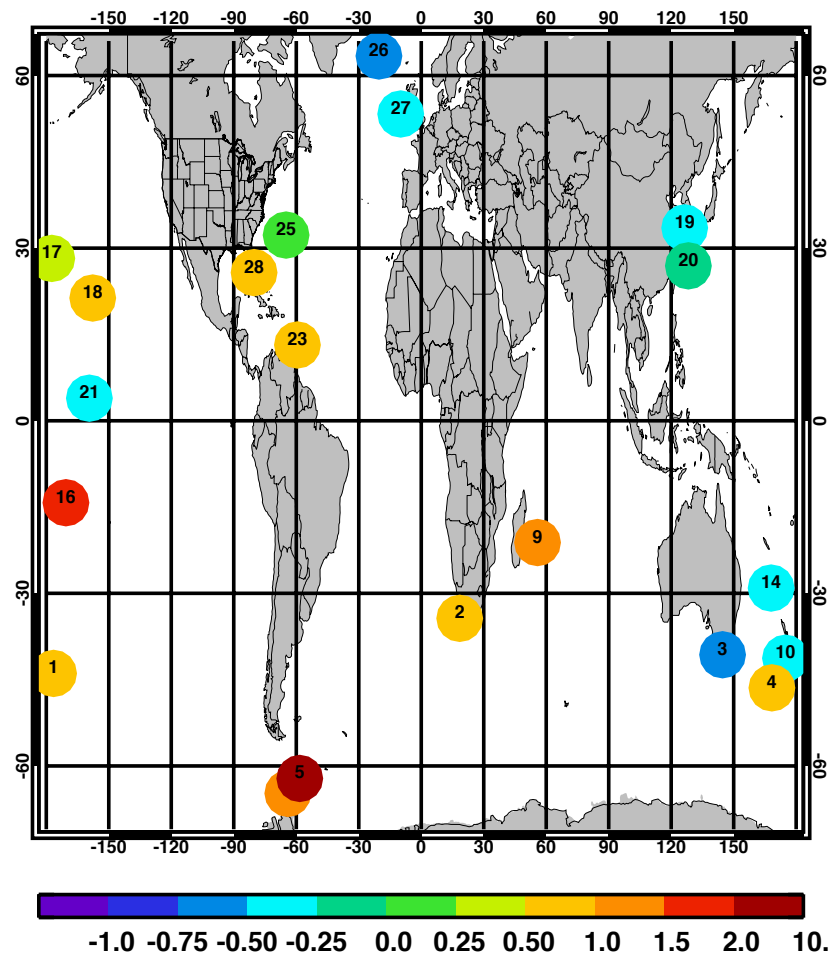

Fig. 14. The same as Fig. 10, but for sea salt. 

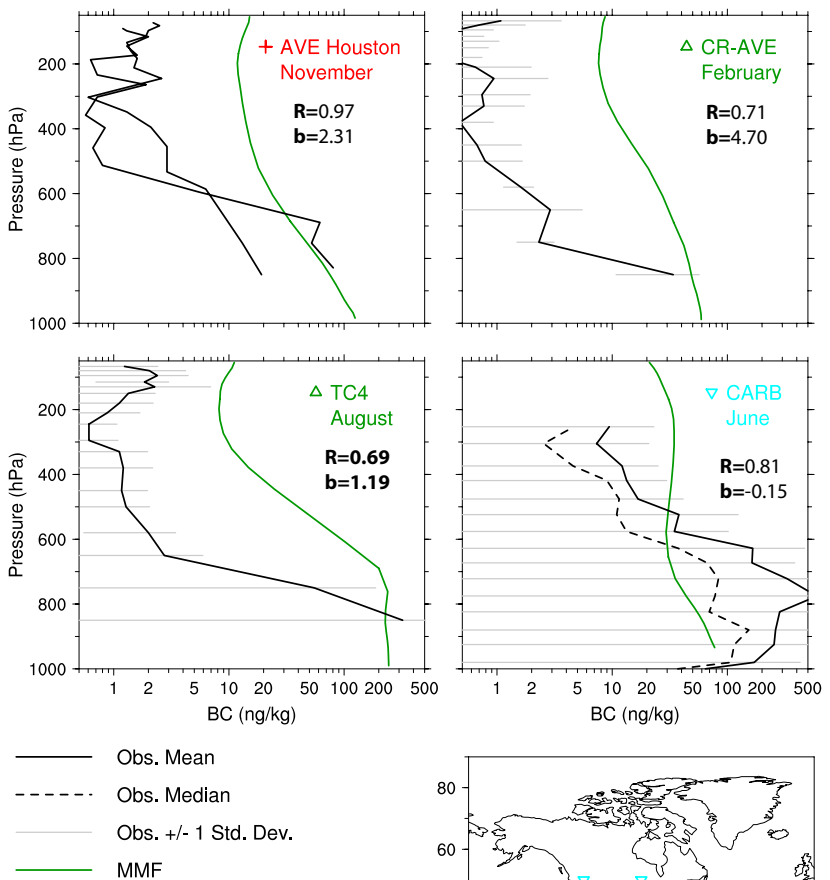
MMF

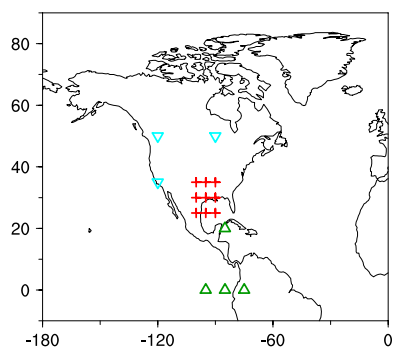

Fig. 15. BC vertical profiles in the tropics and middle latitudes over 4 different campaigns (AVE Houston: NASA Houston Aura Validation Experiment; CR-AVE: NASA Costa Rica Aura Validation Experiment; TC4: Tropical Composition, Cloud and Climate Coupling; CARB: NASA initiative in collaboration with California Air Resources Board). Monthly mean model profiles are averaged over the points in the map. Observations are average for the respective campaigns and are measured by three different groups: the NASA group (Schwarz et al., 2006) for AVE-Houston, CR-AVE, and TC4; the University of Tokyo group (Moteki and Kondo, 2007; Moteki et al., 2007) for CARB; and the University of Hawaii group (Clarke et al., 2007; Howell et al., 2006; McNaughton et al., 2009; Shinozuka et al., 2007) for CARB. The Houston campaign has two profiles measured two different days. See Table 7 in Koch et al. (2009) for flight details. Normalized model mean bias (b) and the correlation coefficient between the model and observations (R) are shown in each panel. Values of $b$ and $R$ are calculated using observed values provided at discrete altitudes and model values interpolated from model grid to those altitudes.

with a slight overestimation over southern Chile, and underestimation over Scotland. The model also simulates an increasing accumulation number concentration with altitude in the middle and upper troposphere. However, the increases with altitude are stronger in the model than that in the observations, and the model overestimates the accumulation mode number concentration in the upper troposphere by a factor of
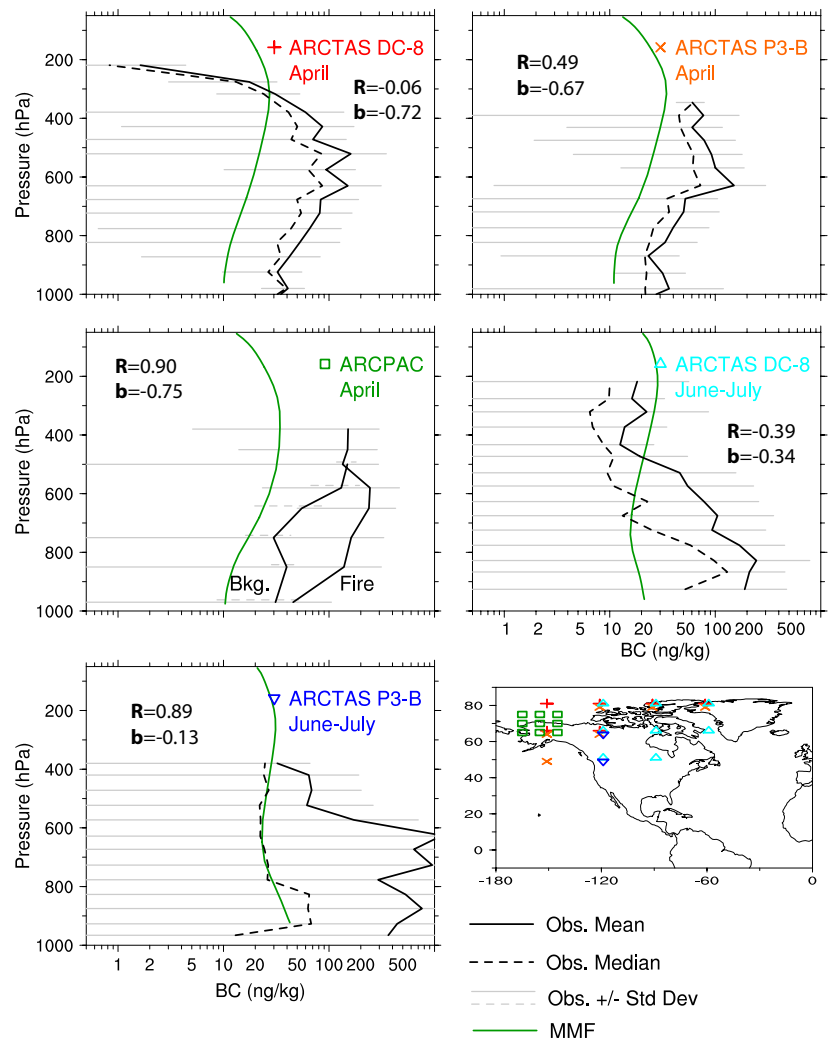

Fig. 16. The same as Fig. 15, but for BC vertical profiles in the high latitudes over two campaigns (ARCTAS: NASA Arctic Research of the Composition of the Troposphere from Aircraft and Satellite; ARCPAC: NOAA Aerosol, Radiation, and Cloud Processes affecting Arctic Climate). Observations are average for the respective campaigns, and are measured by three different groups: the NASA group for ARCPAC; the University of Tokyo group for ARCTAS; and the University of Hawaii group for ARCTAS. See Table 7 in Koch et al. (2009) for flight details.

$2-3$, which is consistent with the large aerosol mass fraction above $5 \mathrm{~km}$ in the MMF model compared with the AeroCom models.

Figure 21 compares simulated vertical profiles of $\mathrm{CCN}$ concentrations at $0.1 \%$ supersaturation with results from eight field experiments. (See Ghan et al., 2001 for the details of each experiment.) The model simulates decreasing CCN concentrations with increasing altitude over all eight locations, while the observations demonstrate a variety of vertical profiles. The elevated CCN concentrations over Tasmania during SOCEX-1 and ACE-1 may come from the continental outflow from Australia, and the monthly mean model results may not catch the continental outflow. The elevated $\mathrm{CCN}$ concentrations over the Arctic may come from poleward pollution transport in the free troposphere, and is consistent with the observed BC profiles (Fig. 14). The model did not catch this feature, although it did simulate elevated BC concentrations to some extent (Fig. 14). The observed 
Table 7. Normalized mean biases (b) and correlation coefficients (R) between the model and observations for AOD and SSA over the seven regions included in Fig. 22.

\begin{tabular}{|c|c|c|c|c|c|c|c|c|c|}
\hline & & $\begin{array}{r}\text { North } \\
\text { America }\end{array}$ & Europe & $\begin{array}{l}\text { East } \\
\text { Asia }\end{array}$ & $\begin{array}{l}\text { North } \\
\text { Africa }\end{array}$ & $\begin{array}{l}\text { South } \\
\text { Africa }\end{array}$ & $\begin{array}{r}\text { South } \\
\text { America }\end{array}$ & $\begin{array}{r}\text { South } \\
\text { Asia }\end{array}$ & Global \\
\hline \multirow{2}{*}{$\stackrel{\ominus}{\circlearrowright}$} & b & 0.10 & -0.24 & -0.35 & -0.20 & -0.30 & 0.03 & -0.47 & -0.13 \\
\hline & $\mathrm{R}$ & 0.91 & 0.37 & 0.37 & 0.37 & 0.67 & 0.51 & 0.56 & 0.74 \\
\hline \multirow{2}{*}{$\begin{array}{l}\mathbb{2} \\
\approx\end{array}$} & b & 0.00 & 0.00 & -0.04 & -0.02 & 0.02 & 0.06 & 0.02 & -0.01 \\
\hline & $\mathrm{R}$ & 0.29 & -0.16 & 0.49 & 0.53 & 0.61 & 0.20 & 0.46 & 0.22 \\
\hline
\end{tabular}

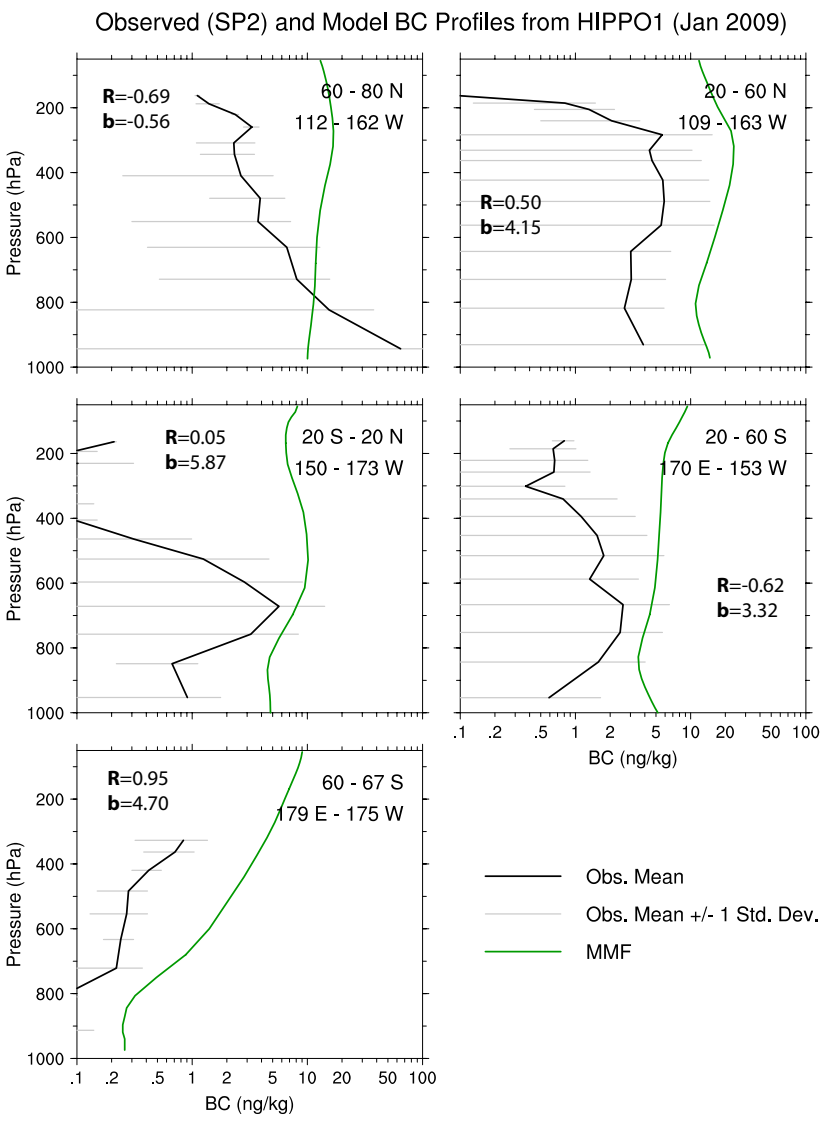

Fig. 17. The same as Fig. 15, but for BC vertical profiles above the remote Pacific from $67^{\circ} \mathrm{S}$ to $80^{\circ} \mathrm{N}$ during the HIAPER Pole-toPole Observations (HIPPO) campaign in January 2009 (Schwartz et al., 2010). The observational data was grouped into five latitude zones $\left(67-60^{\circ} \mathrm{S}, 60-20^{\circ} \mathrm{S}, 20^{\circ} \mathrm{S}-20^{\circ} \mathrm{N}, 20-60^{\circ} \mathrm{N}\right.$, and 60 $80^{\circ} \mathrm{N}$ ). Monthly mean model profiles are averaged over the observational regions defined by the latitude and longitude boundaries shown in each panel.

CCN concentrations show strong seasonal variations over Tasmania, with higher concentrations in the austral summer (SOCEX-2), and much lower concentrations in the austral winter (SOCEX-1). The model also produces this seasonal variation, but the seasonal contrast in the model is much
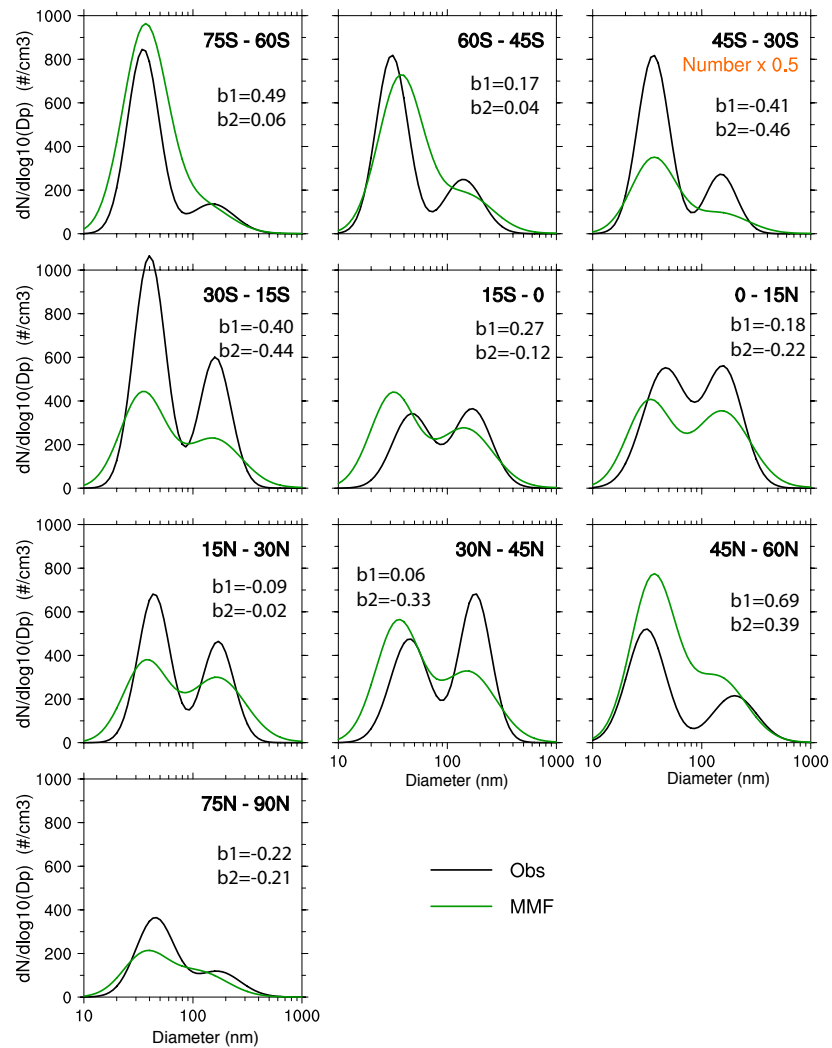

Fig. 18. Aerosol size distribution in the marine boundary layer. Observations (Obs) are from Heintzenberg et al. (2000) and were compiled and aggregated onto a $15^{\circ} \times 15^{\circ}$ grid. The model data is sampled over the same regions as those of the observations. Annualmean model data is sampled over the low latitudes $\left(30^{\circ} \mathrm{S}-30^{\circ} \mathrm{N}\right)$. Over the mid- and high latitudes, the model data are sampled in summer (December-February for the latitude bands of $75^{\circ} \mathrm{S}-45^{\circ} \mathrm{S}$, November-March for the latitude bands of $45^{\circ} \mathrm{S}-30^{\circ} \mathrm{S}$, MaySeptember for the latitude band of $30^{\circ} \mathrm{N}-45^{\circ} \mathrm{N}$, June-August for the latitude bands of $45^{\circ} \mathrm{N}-90^{\circ} \mathrm{N}$ ). For the $45^{\circ} \mathrm{S}-30^{\circ} \mathrm{S}$ latitude band, aerosol number density is scaled by 0.5 so the same y axis can be used for all latitude bands. Normalized model bias for the aerosol number concentrations with diameter larger than $10 \mathrm{~nm}$ ("b1") and diameter larger than $100 \mathrm{~nm}$ ("b2") are shown in each panel. 

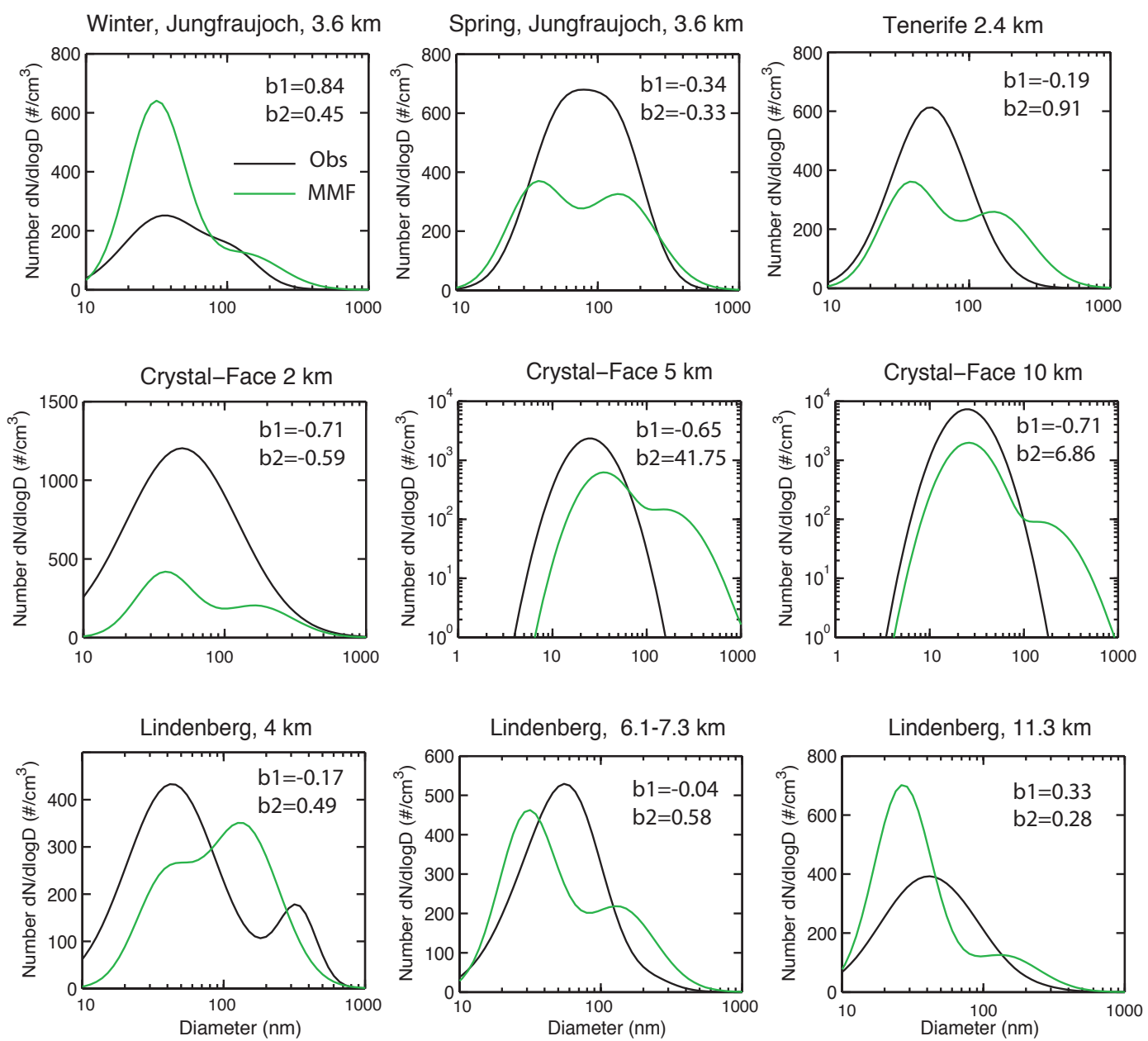

Fig. 19. Aerosol size distributions in the free troposphere. Observations (Obs) are from Putaud et al. (2003) (Jungfraujoch), Raes et al. (2000) (Tenerife); Fridland et al. (2004) (CRYSTAL-FACE, Florida, United States); and Petzold et al. (2002) (LACE8, Lindenberg, Germany). Normalized model bias for the aerosol number concentrations with diameter larger than 10 nm ("b1") and diameter larger than $100 \mathrm{~nm}$ ("b2") are shown in each panel.

weaker than that in the observations. In general, simulated $\mathrm{CCN}$ vertical profiles are within the observed variations, except over the ARM site in Oklahoma. The ARM site is located in a concentration gradient region. Given the coarse resolution used in the MMF model, the model may not be able to accurately simulate the strong gradient in CCN concentrations. The model performance is qualitatively similar to the results of Ghan et al. (2001).

\subsection{Aerosol optical properties}

Figure 22 compares modeled monthly aerosol optical depth (AOD) and single scattering albedo (SSA) with observational data from the AERONET (http://aeronet.gsfc.nasa.gov/) at sites in East and South Asia, Europe, Northern and Southern Africa, North and South America. Simulated AOD agrees with observations within a factor of 2 for most AERONET sites, and normalized mean biases for the seven regions range
(Table 7) from -0.47 to 0.10 . The model simulates AOD well in North America (with a normalized mean bias of 0.10) and South America (with a normalized mean bias of 0.03). However, it underestimates AOD in polluted industrial regions (e.g., South Asia with a normalized mean bias of 0.47). Simulated SSA is also in reasonable agreement with observations, and ranges from 0.78 to 0.98 . SSA is higher in North America than in Northern Africa and East Asia, which is caused by less absorbing aerosols (carbonaceous aerosols and/or dust aerosols) in North America. The model simulates a smaller variation in SSA than that in observations for all regions except in South Africa. For example, SSA in North America ranges from 0.89-0.96 in the model, but it ranges from 0.76 to 0.99 in the observations. The model overestimates SSA in South America with a normalized mean bias of 0.06 and underestimates SSA in East Asia with a normalized mean bias of -0.04 . 
Observed (INCA Campaigns) and Model Aerosol Number Profiles
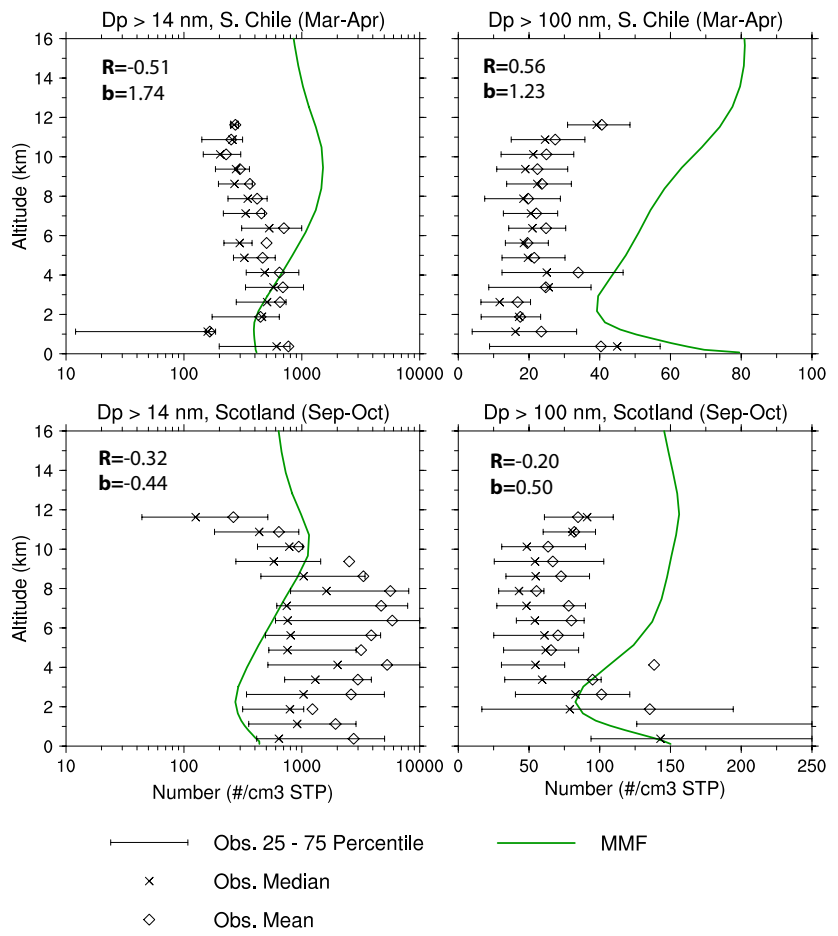

$\mathrm{Dp}>100 \mathrm{~nm}$, Scotland (Sep-Oct)

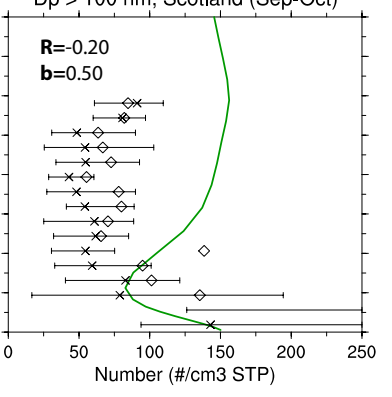

MMF

Fig. 20. Vertical profiles of the number concentration of (left) Aitken mode particles (diameter $>14 \mathrm{~nm}$ ) and (right) accumulation mode particles (diameter $>100 \mathrm{~nm}$ ) (top) over Punta Arenas, Chile, in March/April and (bottom) over Prestwick, Scotland, in September/October. Observations are from Minikin et al. (2003): median (star), 25 and 75 percentiles (left end and right end of error bars). Model results are averaged over $60-50^{\circ} \mathrm{S}, 70-85^{\circ} \mathrm{W}$ for Chile, and over $50-60^{\circ} \mathrm{N}, 10^{\circ} \mathrm{W}-5^{\circ} \mathrm{E}$ for Scotland. Normalized model mean bias (b) and the correlation coefficient between the model and observations $(\mathrm{R})$ are shown in each panel. Values of $\mathrm{b}$ and $\mathrm{R}$ are calculated using observed values provided at discrete altitudes and model values interpolated from model grid to those altitudes.

Figure 23 compares modeled annual-averaged AOD at $550 \mathrm{~nm}$ with that from a satellite AOD retrieval composite derived by Kinne et al. (2006). The satellite composite combines the strength of individual satellite retrievals (MODIS, MISR, AVHRR, TOMS, and POLDER), giving regional preferences separately over land and over ocean. Among all satellite retrievals, those with the minimum difference to the regional AERONET average are selected to contribute to the satellite composite. Simulated AOD spatial patterns are in reasonable agreement with observations, with large AOD over regions with high fossil fuel and biomass burning emissions and over the source regions of dust aerosols, and with low AOD over remote regions. However, the model underestimates AOD over the regions with strong fossil fuel and biomass burning emissions, which is consistent with the comparison with the AERONET observations (Fig. 22).

\section{Summary and discussion}

In this study, a new multi-scale aerosol-climate model (PNNL-MMF) was developed that has several major extensions to the Colorado State University multi-scale modeling framework (MMF) model, and consists of three components. The general circulation model (GCM) component is the NCAR CAM5 and includes a modal aerosol treatment that uses three log-normal modes to represent aerosol size distributions. The cloud resolving model (CRM) component is SAM, which has a two-moment microphysics scheme that predicts mass and number mixing ratios for several hydrometeor categories. The CRM is embedded in each GCM grid column to replace the GCM's conventional parameterizations of moist convection and large-scale condensation and to permit the explicit simulation of convective clouds. The third component of this multi-scale aerosolclimate model is the Explicit-Cloud-Parameterized-Pollutant (ECPP) approach, which uses cloud statistics diagnosed from the CRM component of the MMF model to drive the aerosol and gas processing by clouds (convective transport, activation/resuspension, wet scavenging, and aqueous chemistry). The ECPP approach allows explicit simulation of the effects of convective clouds on aerosols while keeping the computational cost acceptable. Simulated aerosol fields from the GCM component and the ECPP approach are used at each CRM grid for aerosol activation. Aerosol water uptake is calculated at each CRM grid cell, which accounts for the subgrid variation in relative humidity on each GCM grid. With these extensions, the PNNL-MMF model includes the treatment of aerosol and chemical processes, and allows us to study aerosol effects on climate from cumulus to global scales.

Simulated global, annual aerosol budgets from this multi-scale aerosol-climate model are within the range of results from the other models included in the AeroCom intercomparison (Textor et al., 2006). However, the mass fractions of aerosols located above $5 \mathrm{~km}$ are $44 \%, 32 \%, 33 \%$, $39 \%, 18 \%$, and $11 \%$ for sulfate, BC, POM, SOA, dust and sea salt, respectively, which are larger than those of the AeroCom models, except dust, which is similar to that of the AeroCom models. In contrast, the MMF model produces a much smaller mass fraction of aerosols in the polar regions. Differences in poleward transport or in the treatment of wet removal processes may contribute to the differences between the MMF model and the AeroCom models. Convective clouds contribute to $30-35 \%$ of the total aerosol wet removal.

We note that the mass fractions of aerosols located above $5 \mathrm{~km}$ in the standard CAM5 are smaller than those in the MMF model. The mass fractions of sulfate, BC, POM located above $5 \mathrm{~km}$ in the standard CAM5 are $30 \%, 20 \%, 20 \%$, respectively, and are close to those in the AeroCom models. The smaller mass fraction located above $5 \mathrm{~km}$ in CAM5 is consistent with its smaller contributions of convective clouds 

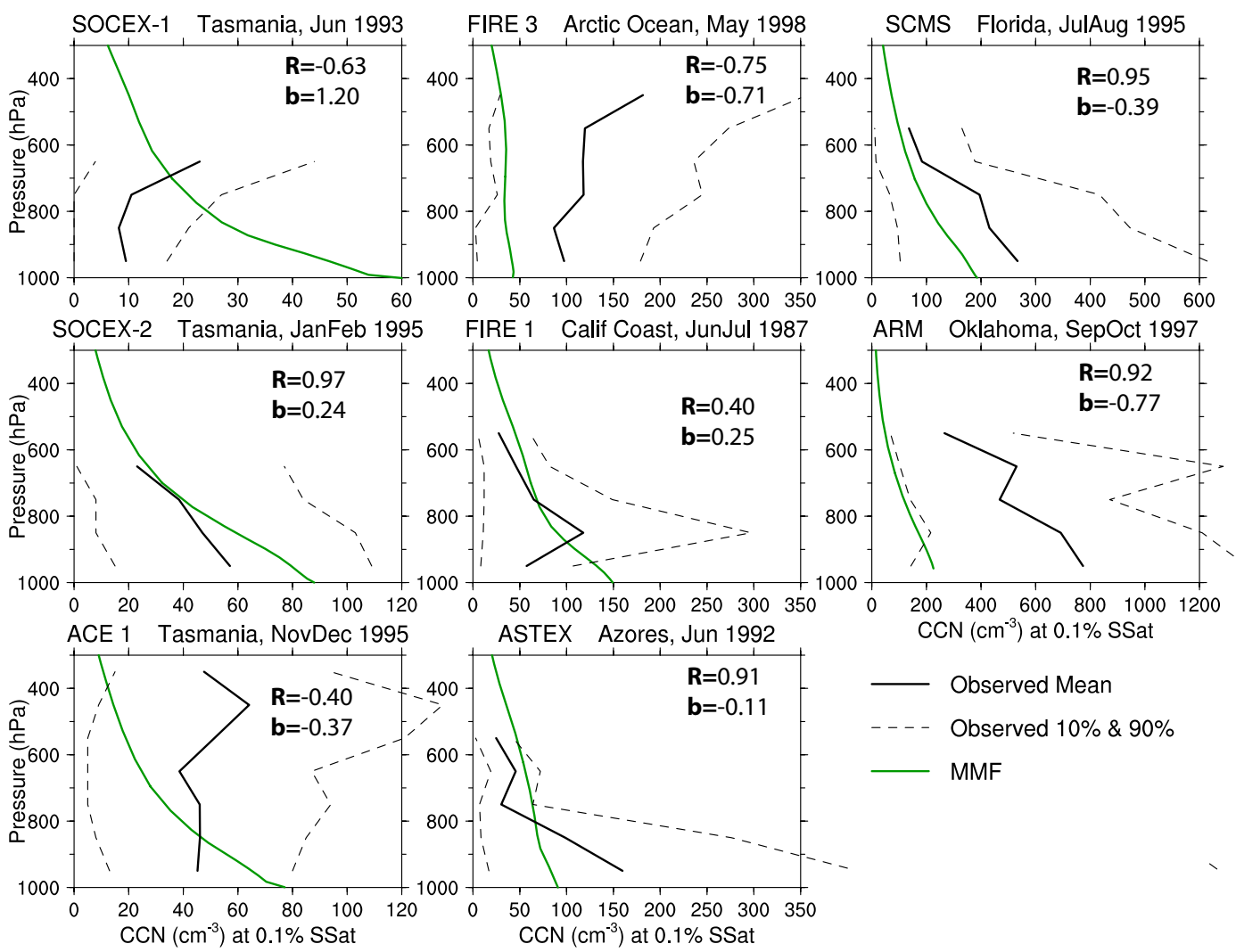

Fig. 21. Simulated vertical profiles of $\mathrm{CCN}$ concentrations at $0.1 \%$ supersaturation are compared with observations during each of eight field experiments (SOCEX-1, Tasmania, June, 1993; FIRE 3, Arctic Ocean, May, 1998; SCMS, Florida, July/August, 1995; SOCEX-2, Tasmania, January/February, 1995; FIRE-1, California Coast, June/July, 1987; ARM, Oklahoma, September/October, 1997; ACE1, Tasmanian, November/December, 1995; ASTEX, Azores, June, 1992) (ee Table 1 in Ghan et al., 2001 for more details about each experiment). Model results are from monthly data, and shown in green line. Mean (solid black), 10 percentile and 90 percentile (dash lines) are shown for observations. Normalized model mean bias (b) and the correlation coefficient between the model and observations (R) are shown in each panel. Values of $\mathrm{b}$ and $\mathrm{R}$ are calculated using observed values provided at discrete altitudes and model values interpolated from model grid to those altitudes.

a) AOD scatter

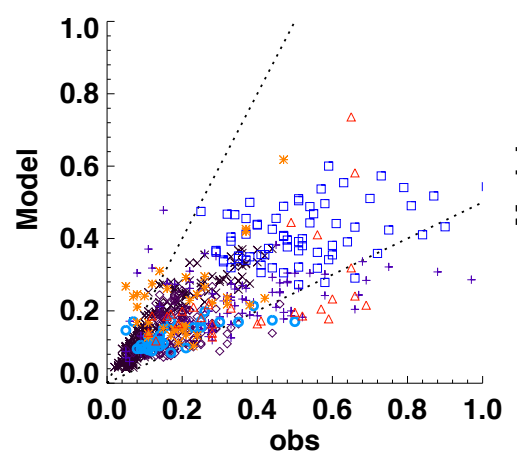

b) SSA scatter

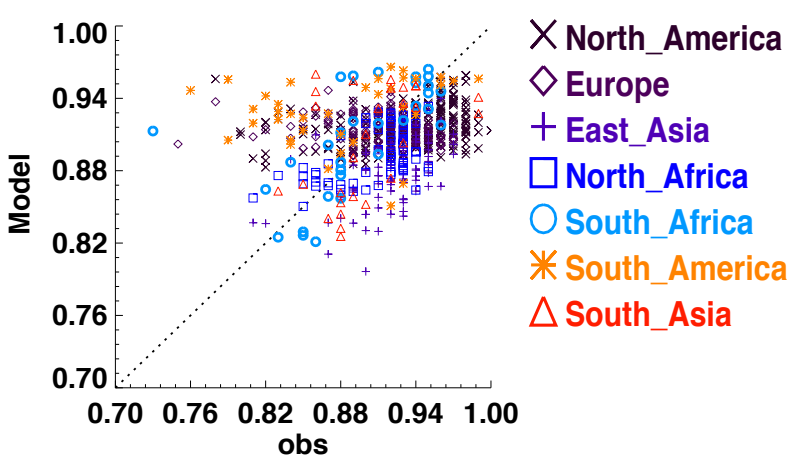

Fig. 22. Scatter plots of simulated monthly AOD and SSA in comparison with AERONET data. Results from several different regions (North America, Europe, East Asia, North Africa, South Africa, South America, and South Asia) are represented by 7 different colours and marks. The upper and lower dash lines in (a) are 2:1 and 1:2, respectively. The dash line in (b) is 1:1. See Table 7 for normalized model mean bias, and the correlation coefficients between the model and observations. 


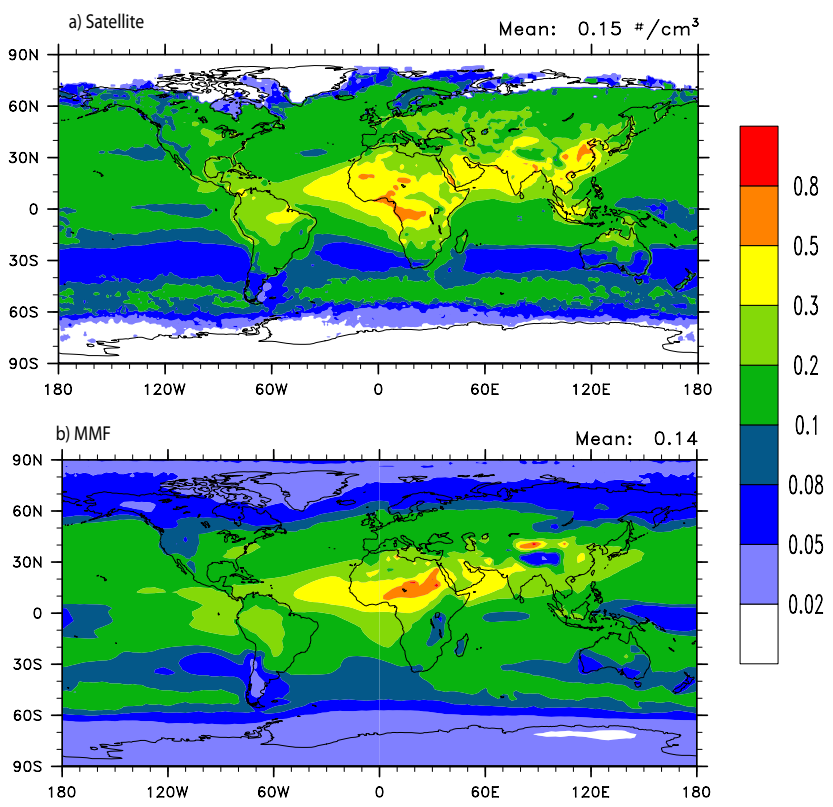

Fig. 23. Global annual-averaged AOD in the MMF model (a), and a satellite AOD retrieval composite (Kinne et al., 2006) (b).

to the total wet scavenging, which range $35-42 \%$, though it is noted that the convective clouds is diagnosed in the MMF model by using CRM cloud statistics, while they are from shallow and deep convective clouds parameterizations in CAM5. Differences in convective transport, wet scavenging in stratiform and convective clouds, and long range transport between the MMF model and CAM5 may lead to these differences. Further studies are needed to identify the causes for the differences between the CAM5 and MMF.

Simulated DMS vertical profiles agree well with observations (within a factor of 2), while the model overestimates $\mathrm{SO}_{2}$ concentrations in the upper troposphere in some locations. Simulated surface sulfate, dust and sea salt concentrations are in reasonable agreement with observations (within a factor of 2 in most cases). OC concentrations are in reasonable agreement with observations in the United States, but are underestimated in Europe by a factor of 2-4. The model underestimates surface $\mathrm{BC}$ concentrations by a factor of $2-4$, which may partly arise from the fact that $\mathrm{BC}$ is assumed internally mixed with other aerosols in the accumulation mode. The model overestimates BC concentrations in the upper troposphere over the tropics and underestimates BC concentrations in April in the Arctic regions, a common problem in other global aerosol models (Koch et al., 2009).

The model simulates a bimodal aerosol size distribution in the marine boundary layer, which is consistent with observations (Fig. 18). However, the MMF model underestimates accumulation mode number concentrations in the marine boundary layer, which may suggest that the model underestimates fine mode sea salt, pollution outflow from continents or the growth of Aitken mode particles. Simulated aerosol size distributions in the free troposphere show a prominent Aitken mode, but they also show a weak accumulation mode that is not present in the observational data (Fig. 19). The difficulties in simulating the monomodal size distributions in the lower and middle free troposphere are also true for the standard CAM5 (not shown), and the CAM-IMPACT model (Wang et al., 2009). The MMF and CAM5 also tend to simulate too much bimodality in the boundary layer over some continental regions (not shown), as do CAM-IMPACT and the ECHAM5-HAM model (Stier et al., 2005). Most modal aerosol approaches represent aerosol size distributions by using several log-normal modes with fixed standard deviations and fixed modal boundaries. The fixed modal boundaries limit their capability to simulate monomodal (or nearmonomodal) aerosol size distributions when the single mode wants to be centered near the boundary of the Aitken and accumulation modes. As condensational growth causes the Aitken mode to grow closer to this boundary, the mode merging (or remapping) algorithm transfers part of the Aitken mode into the accumulation mode, maintaining the bimodal distribution.

Simulated accumulation mode aerosol number concentrations are overestimated in the middle and upper troposphere over the mid-latitudes, while Aitken mode aerosol number concentrations are overestimated in the upper free troposphere, in comparison to the INCA campaign measurements (Fig. 20). The overestimation of accumulation mode number concentrations in the middle and upper troposphere is consistent with the large aerosol mass fraction above $5 \mathrm{~km}$ in the MMF model compared with the AeroCom models, and the overestimation of Aitken mode number concentrations is consistent with the excessive $\mathrm{SO}_{2}$ concentrations in the upper troposphere. We note that the standard CAM5 simulates less Aitken and accumulation mode aerosol number concentrations in the middle and upper free troposphere over the same locations and agrees better with observations (not shown). This can be caused by differences in simulated convective transport, wet scavenging, and cloud fields in both the MMF and CAM5.

Simulated AOD and SSA are in reasonable agreement with observations at AERONET sites (within a factor of 2). The MMF model also simulates reasonable spatial patterns of AOD compared with the satellite composite, although the model underestimates AOD over the source regions of strong fossil fuel and biomass burning emissions.

One limitation of this study is the lack of high-order turbulence schemes in the CRM, which biases the lower level clouds in the MMF model (Wang et al., 2011). Since low clouds are important components of the global climate system, the bias in low clouds may bias simulated aerosols, and further aerosol effects on climate. This will be addressed in a future study, in which we will include a high-order turbulence scheme (Golaz et al., 2002; Larson and Golaz, 2005) in the CRM component of the MMF model and explore how it will affect simulated low clouds and aerosols. 
Overall, the PNNL-MMF multi-scale aerosol climate model simulates aerosols and aerosol optical properties as well as other aerosol models. In a separate paper (Wang et al., 2011), we use this model to study aerosol indirect effects, and show that the response in liquid water path to anthropogenic aerosols in the MMF model is much smaller that that in the standard version of CAM5, which leads to a substantial smaller change in shortwave cloud forcing in MMF than in CAM5 due to anthropogenic aerosols $\left(-0.77 \mathrm{~W} \mathrm{~m}^{-2}\right.$ in MMF vs. $-1.79 \mathrm{~W} \mathrm{~m}^{-2}$ in CAM5).

Acknowledgements. This work was supported by the NASA Interdisciplinary Science Program under grant NNX07AI56G. M. K. was supported by Grant NA08OAR4310544 from the National Oceanic and Atmospheric Administration to Stony Brook University. H. M. was supported by the NOAA grant NA08OAR4310543, U.S. DOE ARM DE-FG02-08ER64574, and the NSF Science and Technology Center for Multiscale Modeling of Atmospheric Processes (CMMAP), managed by Colorado State University under cooperative agreement ATM-0425247. We are grateful to the CMMAP for providing us the CSU MMF model. We thank Manishkumar Shrivastava for his internal review and constructive comments, and Phil Rasch for helpful discussion regarding the treatment of convective transport of tracer species in GCMs. We are also grateful to Joshua Schwarz for providing the HIPPO data used in Fig. 17, and to Stefan Kinne for providing the satellite AOD retrieval composite data used in Fig. 22. The Pacific Northwest National Laboratory (PNNL) is operated for the DOE by Battelle Memorial Institute under contract DE-AC06-76RLO 1830 .

Edited by: O. Boucher

\section{References}

Abdul-Razzak, H. and Ghan, S. J.: A parameterization of aerosol activation 2. Multiple aerosol types, J. Geophys. Res., 105, 6837-6844, 2000.

Andreae, M. O., Rosenfeld, D., Artaxo, P., Costa, A. A., Frank, G. P., Longo, K. M., and Silva-Dias, M. A. F.: Smoking rain clouds over the Amazon, Science, 303, 1337-1342, 2004.

Arakawa, A. and Schubert, W. H.: Interaction of a cumulus cloud ensemble with large-scale environment, Part 1, J. Atmos. Sci., 31, 674-701, 1974.

Arimoto, R., Duce, R. A., Savoie, D. L., Prospero, J. M., Talbot, R., Cullen, J. D., Tomza, U., Lewis, N. F., and Jay, B. J.: Relationships among aerosol constituents from Asia and the North Pacific during PEM-West A, J. Geophys. Res., 101, 2011-2023, 1996.

Bechtold, P., Redelsperger, J. L., Beau, I., Blackburn, M., Brinkop, S., Grandpeix, J. Y., Grant, A., Gregory, D., Guichard, F., Hoff, C., and Ioannidou, E.: A GCSS model intercomparison for a tropical squall line observed during TOGA-COARE. II: Intercomparison of single-column models and a cloud-resolving model, Q. J. Roy. Meteor. Soc., 126, 865$888,2000$.
Chatfield, R. B. and Crutzen, P. J.: Sulfur-dioxide in remote oceanic air - cloud transport of reactive precursors, J. Geophys. Res., 89, 7111-7132, 1984.

Clarke, A., McNaughton, C., Kapustin, V., Shinozuka, Y., Howell, S., Dibb, J., Zhou, J., Anderson, B., Brekhovskikh, V., Turner, H., and Pinkerton, M.: Biomass burning and pollution aerosol over North America: Organic components and their influence on spectral optical properties and humidification response, J. Geophys. Res., 112, D12S18, doi:10.1029/2006jd007777, 2007.

Collins, W. D., Rasch, P. J., Boville, B. A., Hack, J. J., McCaa, J. R., Williamson, D. L., Briegleb, B. P., Bitz, C. M., Lin, S. J., and Zhang, M. H.: The formulation and atmospheric simulation of the Community Atmosphere Model version 3 (CAM3), J. Climate, 19, 2144-2161, 2006.

Cooke, W. F., Liousse, C., Cachier, H., and Feichter, J.: Construction of a $1^{\circ} \times 1^{\circ}$ fossil fuel emission data set for carbonaceous aerosol and implementation and radiative impact in the ECHAM4 model, J. Geophys. Res., 104, 22137-22162, 1999.

Cui, Z. Q., Carslaw, K. S., Yin, Y., and Davies, S.: A numerical study of aerosol effects on the dynamics and microphysics of a deep convective cloud in a continental environment, J. Geophys. Res., 111, D05201, doi:10.1029/2005jd005981, 2006.

Del Genio, A. D., Kovari, W., Yao, M. S., and Jonas, J.: Cumulus microphysics and climate sensitivity, J. Climate, 18, 2376-2387, 2005.

Dentener, F., Kinne, S., Bond, T., Boucher, O., Cofala, J., Generoso, S., Ginoux, P., Gong, S., Hoelzemann, J. J., Ito, A., Marelli, L., Penner, J. E., Putaud, J.-P., Textor, C., Schulz, M., van der Werf, G. R., and Wilson, J.: Emissions of primary aerosol and precursor gases in the years 2000 and 1750 prescribed data-sets for AeroCom, Atmos. Chem. Phys., 6, 43214344, doi:10.5194/acp-6-4321-2006, 2006.

Easter, R. C., Ghan, S. J., Zhang, Y., Saylor, R. D., Chapman, E. G., Laulainen, N. S., Abdul-Razzak, H., Leung, L. R., Bian, X. D., and Zaveri, R. A.: MIRAGE: model description and evaluation of aerosols and trace gases, J. Geophys. Res., 109, D20210, doi:10.1029/2004jd004571, 2004.

Ekman, A. M. L., Wang, C., Strom, J., and Krejci, R.: Explicit simulation of aerosol physics in a cloud-resolving model: aerosol transport and processing in the free troposphere, J. Atmos. Sci., 63, 682-696, 2006.

Emanuel, K. A. and Zivkovic-Rothman, M.: Development and evaluation of a convection scheme for use in climate models, J. Atmos. Sci., 56, 1766-1782, 1999.

Emmons, L. K., Hauglustaine, D. A., Muller, J. F., Carroll, M. A., Brasseur, G. P., Brunner, D., Staehelin, J., Thouret, V., and Marenco, A.: Data composites of airborne observations of tropospheric ozone and its precursors, J. Geophys. Res., 105, 2049720538, 2000.

Fridlind, A. M., Ackerman, A. S., Jensen, E. J., Heymsfield, A. J., Poellot, M. R., Stevens, D. E., Wang, D. H., Miloshevich, L. M., Baumgardner, D., Lawson, R. P., Wilson, J. C., Flagan, R. C., Seinfeld, J. H., Jonsson, H. H., VanReken, T. M., Varutbangkul, V., and Rissman, T. A.: Evidence for the predominance of midtropospheric aerosols as subtropical anvil cloud nuclei, Science, 304, 718-722, 2004.

Ghan, S., Easter, R., Hudson, J., and Breon, F. M.: Evaluation of aerosol indirect radiative forcing in MIRAGE, J. Geophys. Res., 106, 5317-5334, 2001. 
Ghan, S. J., Leung, L. R., Easter, R. C., and AbdulRazzak, K.: Prediction of cloud droplet number in a general circulation model, J. Geophys. Res., 102, 21777-21794, 1997.

Golaz, J. C., Larson, V. E., and Cotton, W. R.: A PDF-based model for boundary layer clouds. Part I: Method and model description, J. Atmos. Sci., 59, 3540-3551, 2002.

Grabowski, W. W.: Coupling cloud processes with the large-scale dynamics using the Cloud-Resolving Convection Parameterization (CRCP), J. Atmos. Sci., 58, 978-997, 2001.

Gregory, D. and Guichard, F.: Aspects of the parametrization of organized convection: contrasting cloud-resolving model and single-column model realizations, Q. J. Roy. Meteorol. Soc., 128, 625-646, 2002.

Gustafson, W. I., Berg, L. K., Easter, R. C., and Ghan, S. J.: The Explicit-Cloud Parameterized-Pollutant hybrid approach for aerosol-cloud interactions in multiscale modeling framework models: tracer transport results, Environ. Res. Lett., 3, 025005 , doi:10.1088/1748-9326/3/2/025005, 2008.

Heintzenberg, J., Covert, D. C., and Van Dingenen, R.: Size distribution and chemical composition of marine aerosols: a compilation and review, Tellus B, 52, 1104-1122, 2000.

Holtslag, A. A. M. and Boville, B. A.: Local versus nonlocal boundary-layer diffusion in a global climate model, J. Climate, 6, 1825-1842, 1993.

Horowitz, L. W., Walters, S., Mauzerall, D. L., Emmons, L. K., Rasch, P. J., Granier, C., Tie, X. X., Lamarque, J. F., Schultz, M. G., Tyndall, G. S., Orlando, J. J., and Brasseur, G. P.: A global simulation of tropospheric ozone and related tracers: description and evaluation of MOZART, version 2, J. Geophys. Res., 108, 4784, doi:10.1029/2002jd002853, 2003.

Howell, S. G., Clarke, A. D., Shinozuka, Y., Kapustin, V., McNaughton, C. S., Huebert, B. J., Doherty, S. J., and Anderson, T. L.: Influence of relative humidity upon pollution and dust during ACE-Asia: Size distributions and implications for optical properties, J. Geophys. Res., 111, D06205, doi:10.1029/2004jd005759, 2006.

Iacono, M. J., Delamere, J. S., Mlawer, E. J., and Clough, S. A.: Evaluation of upper tropospheric water vapor in the NCAR Community Climate Model (CCM3) using modeled and observed HIRS radiances, J. Geophys. Res., 108, 4037, doi:10.1029/2002jd002539, 2003.

Iacono, M. J., Delamere, J. S., Mlawer, E. J., Shephard, M. W., Clough, S. A., and Collins, W. D.: Radiative forcing by long-lived greenhouse gases: calculations with the AER radiative transfer models, J. Geophys. Res., 113, D13103, doi:10.1029/2008jd009944, 2008.

IPCC: Climate Change 2007: The Physical Science Basis, in: Contribution of Working Group I to the Fourth Assessment Report of the Intergovernmental Panel on Climate Change, edited by: Solomon, S., Qin, D., Manning, M., Chen, Z., Marquis, M., Averyt, K. B., Tignor, M., and Miller, H. L., Cambridge University Press, Cambridge, UK and New York, NY, USA, 996 pp., 2007.

Iversen, T. and Seland, O.: A scheme for process-tagged $\mathrm{SO}_{4}$ and BC aerosols in NCAR CCM3: validation and sensitivity to cloud processes, J. Geophys. Res., 107, 4751, doi:10.1029/2001jd000885, 2002.

Jacob, D. J., Prather, M. J., Rasch, P. J., Shia, R. L., Balkanski, Y. J., Beagley, S. R., Bergmann, D. J., Blackshear, W. T., Brown, M., Chiba, M., Chipperfield, M. P., deGrandpre, J.,
Dignon, J. E., Feichter, J., Genthon, C., Grose, W. L., Kasibhatla, P. S., Kohler, I., Kritz, M. A., Law, K., Penner, J. E., Ramonet, M., Reeves, C. E., Rotman, D. A., Stockwell, D. Z., VanVelthoven, P. F. J., Verver, G., Wild, O., Yang, H., and Zimmermann, P.: Evaluation and intercomparison of global atmospheric transport models using Rn-222 and other short-lived tracers, J. Geophys. Res., 102, 5953-5970, 1997.

Jensen, J. B. and Charlson, R. J.: On the efficiency of nucleation scavenging, Tellus B, 36, 367-375, 1984.

Kerminen, V. M. and Kulmala, M.: Analytical formulae connecting the "real" and the "apparent" nucleation rate and the nuclei number concentration for atmospheric nucleation events, J. Aerosol Sci., 33, 609-622, 2002.

Khairoutdinov, M., Randall, D., and DeMott, C.: Simulations of the atmospheric general circulation using a cloud-resolving model as a superparameterization of physical processes, J. Atmos. Sci., 62, 2136-2154, 2005.

Khairoutdinov, M., DeMott, C., and Randall, D.: Evaluation of the simulated interannual and subseasonal variability in an AMIPStyle simulation using the CSU multiscale modeling framework, J. Climate, 21, 413-431, doi:10.1175/2007jcli1630.1, 2008.

Khairoutdinov, M. F. and Randall, D. A.: A cloud resolving model as a cloud parameterization in the NCAR community climate system model: preliminary results, Geophys. Res. Lett., 28, 3617-3620, 2001.

Khairoutdinov, M. F. and Randall, D. A.: Cloud resolving modeling of the ARM summer 1997 IOP: model formulation, results, uncertainties, and sensitivities, J. Atmos. Sci., 60, 607-625, 2003.

Kinne, S., Schulz, M., Textor, C., Guibert, S., Balkanski, Y., Bauer, S. E., Berntsen, T., Berglen, T. F., Boucher, O., Chin, M., Collins, W., Dentener, F., Diehl, T., Easter, R., Feichter, J., Fillmore, D., Ghan, S., Ginoux, P., Gong, S., Grini, A., Hendricks, J., Herzog, M., Horowitz, L., Isaksen, I., Iversen, T., Kirkevåg, A., Kloster, S., Koch, D., Kristjansson, J. E., Krol, M., Lauer, A., Lamarque, J. F., Lesins, G., Liu, X., Lohmann, U., Montanaro, V., Myhre, G., Penner, J., Pitari, G., Reddy, S., Seland, O., Stier, P., Takemura, T., and Tie, X.: An AeroCom initial assessment - optical properties in aerosol component modules of global models, Atmos. Chem. Phys., 6, 1815-1834, doi:10.5194/acp-6-1815-2006, 2006.

Koch, D., Schulz, M., Kinne, S., McNaughton, C., Spackman, J. R., Balkanski, Y., Bauer, S., Berntsen, T., Bond, T. C., Boucher, O., Chin, M., Clarke, A., De Luca, N., Dentener, F., Diehl, T., Dubovik, O., Easter, R., Fahey, D. W., Feichter, J., Fillmore, D., Freitag, S., Ghan, S., Ginoux, P., Gong, S., Horowitz, L., Iversen, T., Kirkevåg, A., Klimont, Z., Kondo, Y., Krol, M., Liu, X., Miller, R., Montanaro, V., Moteki, N., Myhre, G., Penner, J. E., Perlwitz, J., Pitari, G., Reddy, S., Sahu, L., Sakamoto, H., Schuster, G., Schwarz, J. P., Seland, Ø., Stier, P., Takegawa, N., Takemura, T., Textor, C., van Aardenne, J. A., and Zhao, Y.: Evaluation of black carbon estimations in global aerosol models, Atmos. Chem. Phys., 9, 9001-9026, doi:10.5194/acp-9-9001-2009, 2009.

Koren, I., Kaufman, Y. J., Remer, L. A., and Martins, J. V.: Measurement of the effect of Amazon smoke on inhibition of cloud formation, Science, 303, 1342-1345, 2004.

Koren, I., Kaufman, Y. J., Rosenfeld, D., Remer, L. A., and Rudich, Y.: Aerosol invigoration and restructuring of Atlantic convective clouds, Geophys. Res. Lett., 32, L14828, 
doi:10.1029/2005g1023187, 2005.

Lamarque, J.-F., Bond, T. C., Eyring, V., Granier, C., Heil, A., Klimont, Z., Lee, D., Liousse, C., Mieville, A., Owen, B., Schultz, M. G., Shindell, D., Smith, S. J., Stehfest, E., Van Aardenne, J., Cooper, O. R., Kainuma, M., Mahowald, N., McConnell, J. R., Naik, V., Riahi, K., and van Vuuren, D. P.: Historical (1850-2000) gridded anthropogenic and biomass burning emissions of reactive gases and aerosols: methodology and application, Atmos. Chem. Phys., 10, 7017-7039, doi:10.5194/acp10-7017-2010, 2010.

Larson, V. E. and Golaz, J. C.: Using probability density functions to derive consistent closure relationships among higherorder moments, Mon. Weather Rev., 133, 1023-1042, 2005.

Liousse, C., Penner, J. E., Chuang, C., Walton, J. J., Eddleman, H., and Cachier, H.: A global three-dimensional model study of carbonaceous aerosols, J. Geophys. Res., 101, 19411-19432, 1996.

Liu, X. H., Penner, J. E., and Herzog, M.: Global modeling of aerosol dynamics: model description, evaluation, and interactions between sulfate and nonsulfate aerosols, J. Geophys. Res., 110, D18206, doi:10.1029/2004JD005674, 2005.

Liu, X. H., Easter, R. C., Ghan, S. J., Zaveri, R., Rasch, P., Shi, X., Lamarque, J.-F., Gettelman, A., Morrison, H., Vitt, F., Conley, A., Park, S., Neale, R., Hannay, C., Ekman, A., Hess, P., Mahowald, N., Collins, W., Iacon, M., Bretherton, C., and Flanner, M.: Toward a Minimal Representation of Aerosol Direct and Indirect Effects, J. Climate, to be submitted, 2011.

Lohmann, U.: Global anthropogenic aerosol effects on convective clouds in ECHAM5-HAM, Atmos. Chem. Phys., 8, 2115-2131, doi:10.5194/acp-8-2115-2008, 2008.

Mahowald, N. M., Rasch, P. J., and Prinn, R. G.: Cumulus parameterizations in chemical transport models, J. Geophys. Res., 100, 26173-26189, 1995.

Mahowald, N. M., Muhs, D. R., Levis, S., Rasch, P. J., Yoshioka, M., Zender, C. S., and Luo, C.: Change in atmospheric mineral aerosols in response to climate: last glacial period, preindustrial, modern, and doubled carbon dioxide climates, J. Geophys. Res., 111, D10202, doi:10.1029/2005jd006653, 2006a.

Mahowald, N. M., Yoshioka, M., Collins, W. D., Conley, A. J., Fillmore, D. W., and Coleman, D. B.: Climate response and radiative forcing from mineral aerosols during the last glacial maximum, pre-industrial, current and doubled-carbon dioxide climates, Geophys. Res. Lett., 33, L20705, doi:10.1029/2006g1026126, 2006b.

Mann, G. W., Carslaw, K. S., Spracklen, D. V., Ridley, D. A., Manktelow, P. T., Chipperfield, M. P., Pickering, S. J., and Johnson, C. E.: Description and evaluation of GLOMAP-mode: a modal global aerosol microphysics model for the UKCA composition-climate model, Geosci. Model Dev., 3, 519-551, doi:10.5194/gmd-3-519-2010, 2010.

Martensson, E. M., Nilsson, E. D., de Leeuw, G., Cohen, L. H., and Hansson, H. C.: Laboratory simulations and parameterization of the primary marine aerosol production, J. Geophys. Res., 108, 4297, doi:10.1029/2002jd002263, 2003.

McNaughton, C. S., Clarke, A. D., Kapustin, V., Shinozuka, Y., Howell, S. G., Anderson, B. E., Winstead, E., Dibb, J., Scheuer, E., Cohen, R. C., Wooldridge, P., Perring, A., Huey, L. G., Kim, S., Jimenez, J. L., Dunlea, E. J., DeCarlo, P. F., Wennberg, P. O., Crounse, J. D., Weinheimer, A. J., and Flocke, F.: Observations of heterogeneous reactions between Asian pollution and mineral dust over the Eastern North Pacific during INTEX-B, Atmos. Chem. Phys., 9, 8283-8308, doi:10.5194/acp-9-8283-2009, 2009.

Menon, S. and Rotstayn, L.: The radiative influence of aerosol effects on liquid-phase cumulus and stratiform clouds based on sensitivity studies with two climate models, Clim. Dynam., 27, 345-356, doi:10.1007/S00382-006-0139-3, 2006.

Minikin, A., Petzold, A., Strom, J., Krejci, R., Seifert, M., van Velthoven, P., Schlager, H., and Schumann, U.: Aircraft observations of the upper tropospheric fine particle aerosol in the Northern and Southern Hemispheres at midlatitudes, Geophys. Res. Lett., 30, 1503, doi:10.1029/2002g1016458, 2003.

Mlawer, E. J., Taubman, S. J., Brown, P. D., Iacono, M. J., and Clough, S. A.: Radiative transfer for inhomogeneous atmospheres: RRTM, a validated correlated-k model for the longwave, J. Geophys. Res., 102, 16663-16682, 1997.

Morrison, H., Curry, J. A., and Khvorostyanov, V. I.: A new doublemoment microphysics parameterization for application in cloud and climate models. Part I: Description, J. Atmos. Sci., 62, 16651677, 2005.

Morrison, H., Thompson, G., and Tatarskii, V.: Impact of cloud microphysics on the development of trailing stratiform precipitation in a simulated squall line: comparison of one- and two-moment schemes, Mon. Weather Rev., 137, 991-1007, doi:10.1175/2008mwr2556.1, 2009.

Moteki, N. and Kondo, Y.: Effects of mixing state on black carbon measurements by laser-induced incandescence, Aerosol Sci. Tech., 41, 398-417, doi:10.1080/02786820701199728, 2007.

Moteki, N., Kondo, Y., Miyazaki, Y., Takegawa, N., Komazaki, Y., Kurata, G., Shirai, T., Blake, D. R., Miyakawa, T., and Koike, M.: Evolution of mixing state of black carbon particles: Aircraft measurements over the western Pacific in March 2004, Geophys. Res. Lett., 34, L11803, doi:10.1029/2006g1028943, 2007.

Nober, F. J., Graf, H. F., and Rosenfeld, D.: Sensitivity of the global circulation to the suppression of precipitation by anthropogenic aerosols, Global Planet. Change, 37, 57-80, doi:0.1016/S09218181(02)00191-1, 2003.

Ovtchinnikov, M. and Ghan, S. J.: Parallel simulations of aerosol influence on clouds using cloud-resolving and single-column models, J. Geophys. Res., 110, D15S10, doi:10.1029/2004jd005088, 2005.

Ovtchinnikov, M., Ackerman, T., Marchand, R., and Khairoutdinov, M.: Evaluation of the multiscale modeling framework using data from the atmospheric radiation measurement program, J. Climate, 19, 1716-1729, 2006.

Petzold, A., Fiebig, M., Flentje, H., Keil, A., Leiterer, U., Schroder, F., Stifter, A., Wendisch, M., and Wendling, P.: Vertical variability of aerosol properties observed at a continental site during the Lindenberg Aerosol Characterization Experiment (LACE 98), J. Geophys. Res., 107, 8128, doi:10.1029/2001jd001043, 2002.

Pierce, J. R. and Adams, P. J.: Global evaluation of CCN formation by direct emission of sea salt and growth of ultrafine sea salt, J. Geophys. Res., 111, D06203, doi:10.1029/2005JD006186, 2006.

Pritchard, M. S. and Somerville, R. C. J.: Empirical orthogonal function analysis of the diurnal cycle of precipitation in a multi-scale climate model, Geophys. Res. Lett., 36, L05812, doi:10.1029/2008GL036964, 2009a. 
Pritchard, M. S. and Somerville, R. C. J.: Assessing the diurnal cycle of precipitation in a multiscale climate model, J. Adv. Model. Earth Syst., 1, 12, 16 pp., 2009b.

Prospero, J. M., Uematsu, M., and Savoie, D. L.: Mineral aerosol transport to the Pacific Ocean, in: Chemical Oceanography, edited by: Ridley, J. P., Chester, R., and Duce, R. A., Elsevier, New York, 188-218, 1989.

Putaud, J., van Dingenen, R., Baltensperger, U., Bruggemann, E., Charron, A., Facchini, M., Decesari, S., Fuzzi, S., Gehrig, R., H. H.-C., Harrison, R. M., Jones, A. M., Laj, P., Lorbeer, G., Maenhaut, W., Mihalopoulos, N., Müller, K., Palmgren, F., Querol, X., Rodriguez, S., Schneider, J., Spindler, G., ten Brink, H., Tunved, P., Torseth, K., Wehner, B., Weingartner, E., Wiedensohler, A., Wahlin, P., and Raes, F.: A european aerosol phenomenology, European Comission Joint Research Center, Ispra, ItalyEUR 20411 EN, 55 pp., 2003.

Raes, F., Van Dingenen, R., Vignati, E., Wilson, J., Putaud, J. P., Seinfeld, J. H., and Adams, P.: Formation and cycling of aerosols in the global troposphere, Atmos. Environ., 34, 4215-4240, 2000.

Rasch, P. J., Feichter, J., Law, K., Mahowald, N., Penner, J., Benkovitz, C., Genthon, C., Giannakopoulos, C., Kasibhatla, P., Koch, D., Levy, H., Maki, T., Prather, M., Roberts, D. L., Roelofs, G. J., Stevenson, D., Stockwell, Z., Taguchi, S., Kritz, M., Chipperfield, M., Baldocchi, D., McMurry, P., Barrie, L., Balkansi, Y., Chatfield, R., Kjellstrom, E., Lawrence, M., Lee, H. N., Lelieveld, J., Noone, K. J., Seinfeld, J., Stenchikov, G., Schwartz, S., Walcek, C., and Williamson, D.: A comparison of scavenging and deposition processes in global models: results from the WCRP Cambridge Workshop of 1995, Tellus B, 52, 1025-1056, 2000.

Rosenfeld, D., Lohmann, U., Raga, G. B., O’Dowd, C. D., Kulmala, M., Fuzzi, S., Reissell, A., and Andreae, M. O.: Flood or drought: how do aerosols affect precipitation?, Science, 321, 1309-1313, doi:10.1126/Science.1160606, 2008.

Savoie, D. I., Prospero, J. M., Larsen, R. J., Huang, F., Izaguirre, M. A., Huang, T., Snowdon, T. H., Custals, L., and Sanderson, C. G.: Nitrogen and sulfur species in Antarctic aerosols at Mawson, Palmer Station, and Marsh (King George Island), J. Atmos. Chem., 17, 95-122, 1993.

Savoie, D. L., Prospero, J. M., and Saltzman, E. S.: Nitrate, nonseasalt sulfate and methanesulfonate over the Pacific Ocean, in: Chemical Oceanography, edited by: Ridley, J. P., Chester, R., and Duce, R. A., Elsevier, New York, 219-250, 1989.

Schwarz, J. P., Gao, R. S., Fahey, D. W., Thomson, D. S., Watts, L. A., Wilson, J. C., Reeves, J. M., Darbeheshti, M., Baumgardner, D. G., Kok, G. L., Chung, S. H., Schulz, M., Hendricks, J., Lauer, A., Karcher, B., Slowik, J. G., Rosenlof, K. H., Thompson, T. L., Langford, A. O., Loewenstein, M., and Aikin, K. C.: Single-particle measurements of midlatitude black carbon and light-scattering aerosols from the boundary layer to the lower stratosphere, J. Geophys. Res., 111, D16207, doi:10.1029/2006jd007076, 2006.

Schwarz, J. P., Spackman, J. R., Gao, R. S., Watts, L. A., Stier, P., Schulz, M., Davis, S. M., Wofsy, S. C., and Fahey, D. W.: Global-scale black carbon profiles observed in the remote atmosphere and compared to models, Geophys. Res. Lett., 37, L18812, doi:10.1029/2010g1044372, 2010.

Shinozuka, Y., Clarke, A. D., Howell, S. G., Kapustin, V. N., McNaughton, C. S., Zhou, J. C., and Anderson, B. E.: Air- craft profiles of aerosol microphysics and optical properties over North America: Aerosol optical depth and its association with PM2.5 and water uptake, J. Geophys. Res., 112, D12S20, doi:10.1029/2006jd007918, 2007.

Sihto, S.-L., Kulmala, M., Kerminen, V.-M., Dal Maso, M., Petäjä, T., Riipinen, I., Korhonen, H., Arnold, F., Janson, R., Boy, M., Laaksonen, A., and Lehtinen, K. E. J.: Atmospheric sulphuric acid and aerosol formation: implications from atmospheric measurements for nucleation and early growth mechanisms, Atmos. Chem. Phys., 6, 4079-4091, doi:10.5194/acp-6-4079-2006, 2006.

Stier, P., Feichter, J., Kinne, S., Kloster, S., Vignati, E., Wilson, J., Ganzeveld, L., Tegen, I., Werner, M., Balkanski, Y., Schulz, M., Boucher, O., Minikin, A., and Petzold, A.: The aerosolclimate model ECHAM5-HAM, Atmos. Chem. Phys., 5, 11251156, doi:10.5194/acp-5-1125-2005, 2005.

Suzuki, K., Nakajima, T., Satoh, M., Tomita, H., Takemura, T., Nakajima, T. Y., and Stephens, G. L.: Global cloud-systemresolving simulation of aerosol effect on warm clouds, Geophys. Res. Lett., 35, L19817, doi:10.1029/2008g1035449, 2008.

Tao, W. K., Chern, J. D., Atlas, R., Randall, D., Khairoutdinov, M., Li, J. L., Waliser, D. E., Hou, A., Lin, X., Peters-Lidard, C., Lau, W., Jiang, J., and Simpson, J.: A multiscale modeling system developments, applications, and critical issues, B. Am. Meteorol. Soc., 90, 515, doi:10.1175/2008bams2542.1, 2009.

Textor, C., Schulz, M., Guibert, S., Kinne, S., Balkanski, Y., Bauer, S., Berntsen, T., Berglen, T., Boucher, O., Chin, M., Dentener, F., Diehl, T., Easter, R., Feichter, H., Fillmore, D., Ghan, S., Ginoux, P., Gong, S., Grini, A., Hendricks, J., Horowitz, L., Huang, P., Isaksen, I., Iversen, I., Kloster, S., Koch, D., Kirkevåg, A., Kristjansson, J. E., Krol, M., Lauer, A., Lamarque, J. F., Liu, X., Montanaro, V., Myhre, G., Penner, J., Pitari, G., Reddy, S., Seland, Ø., Stier, P., Takemura, T., and Tie, X.: Analysis and quantification of the diversities of aerosol life cycles within AeroCom, Atmos. Chem. Phys., 6, 1777-1813, doi:10.5194/acp-6-1777-2006, 2006.

Vehkamaki, H., Kulmala, M., Napari, I., Lehtinen, K. E. J., Timmreck, C., Noppel, M., and Laaksonen, A.: An improved parameterization for sulfuric acid-water nucleation rates for tropospheric and stratospheric conditions, J. Geophys. Res., 107, 4622, doi:10.1029/2002JD002184, 2002.

Wang, C.: A modeling study of the response of tropical deep convection to the increase of cloud condensation nuclei concentration: 1. Dynamics and microphysics, J. Geophys. Res., 110, D21211, doi:10.1029/2004jd005720, 2005.

Wang, M. and Penner, J. E.: Aerosol indirect forcing in a global model with particle nucleation, Atmos. Chem. Phys., 9, 239-260, doi:10.5194/acp-9-239-2009, 2009.

Wang, C. and Prinn, R. G.: On the roles of deep convective clouds in tropospheric chemistry, J. Geophys. Res., 105, 22269-22297, 2000.

Wang, M., Ghan, S., Ovchinnikov, M., Liu, X., Easter, R., Kassianov, E., Qian, Y., and Morrison, H.: Aerosol indirect effects in a multi-scale aerosol-climate model PNNL-MMF, Atmos. Chem. Phys. Discuss., 11, 3399-3459, doi:10.5194/acpd11-3399-2011, 2011.

Wang, M. H., Penner, J. E., and Liu, X. H.: Coupled IMPACT aerosol and NCAR CAM3 model: evaluation of predicted aerosol number and size distribution, J. Geophys. Res., 114, 
D06302, doi:10.1029/2008jd010459, 2009.

Xie, S. C., Xu, K. M., Cederwall, R. T., Bechtold, P., Del Genio, A. D., Klein, S. A., Cripe, D. G., Ghan, S. J., Gregory, D., Iacobellis, S. F., Krueger, S. K., Lohmann, U., Petch, J. C., Randall, D. A., Rotstayn, L. D., Somerville, R. C. J., Sud, Y. C., Von Salzen, K., Walker, G. K., Wolf, A., Yio, J. J., Zhang, G. J., and Zhang, M. G.: Intercomparison and evaluation of cumulus parametrizations under summertime midlatitude continental conditions, Q. J. Roy. Meteor. Soc., 128, 1095-1135, 2002.

$\mathrm{Xu}$, K. M.: Partitioning Mass, Heat, and Moisture Budgets of Explicitly Simulated Cumulus Ensembles into Convective and Stratiform Components, J. Atmos. Sci., 52, 551-573, 1995.

Xu, K. M., Cederwall, R. T., Donner, L. J., Grabowski, W. W., Guichard, F., Johnson, D. E., Khairoutdinov, M., Krueger, S. K., Petch, J. C., Randall, D. A., Seman, C. J., Tao, W. K., Wang, D. H., Xie, S. C., Yio, J. J., and Zhang, M. H.: An intercomparison of cloud-resolving models with the atmospheric radiation measurement summer 1997 intensive observation period data, Q. J. Roy. Meteor. Soc., 128, 593-624, 2002.
Yoshioka, M., Mahowald, N. M., Conley, A. J., Collins, W. D., Fillmore, D. W., Zender, C. S., and Coleman, D. B.: Impact of desert dust radiative forcing on Sahel precipitation: relative importance of dust compared to sea surface temperature variations, vegetation changes, and greenhouse gas warming, J. Climate, 20, 14451467, doi:10.1175/Jcli4056.1, 2007.

Zhang, J. H., Lohmann, U., and Stier, P.: A microphysical parameterization for convective clouds in the ECHAM5 climate model: single-column model results evaluated at the Oklahoma Atmospheric Radiation Measurement Program site, J. Geophys. Res., 110, D15S07, doi:10.1029/2004jd005128, 2005.

Zhang, Q., Jimenez, J. L., Canagaratna, M. R., Allan, J. D., Coe, H., Ulbrich, I., Alfarra, M. R., Takami, A., Middlebrook, A. M., Sun, Y. L., Dzepina, K., Dunlea, E., Docherty, K., DeCarlo, P. F., Salcedo, D., Onasch, T., Jayne, J. T., Miyoshi, T., Shimono, A., Hatakeyama, S., Takegawa, N., Kondo, Y., Schneider, J., Drewnick, F., Borrmann, S., Weimer, S., Demerjian, K., Williams, P., Bower, K., Bahreini, R., Cottrell, L., Griffin, R. J., Rautiainen, J., Sun, J. Y., Zhang, Y. M., and Worsnop, D. R.: Ubiquity and dominance of oxygenated species in organic aerosols in anthropogenically-influenced Northern Hemisphere midlatitudes, Geophys. Res. Lett., 34, L13801, doi:10.1029/2007g1029979, 2007. 